Naila de Oliveira Elias Barbosa

\title{
Influência do crescimento intra-uterino restrito e da asfixia perinatal sobre os níveis séricos de magnésio em recém-nascidos de termo na primeira semana de vida
}

\author{
Dissertação apresentada à Faculdade de \\ Medicina da Universidade de São Paulo para a \\ obtenção do título de Mestre em Ciências. \\ Área de Concentração: Pediatria \\ Orientadora: Prof ${ }^{a} \cdot{ }^{\mathrm{a}}{ }^{\mathrm{a}}$ Cléa Rodrigues Leone
}

São Paulo

2003 


\section{DEDICATÓRIA}

A meu marido, Maurício, pelo amor, apoio e por sempre me fazer ver o lado bom da vida.

A meus filhos, Maurício e Ana Luísa, por fazerem tudo valer a pena.

A meu pai (in memorian), Antônio, que embora ausente, sempre iluminou o meu caminho.

A minha mãe, Norma, pelo carinho, dedicação e formação recebida.

Ao meu sogro, Marcelo (in memorian), pelos firmes princípios que guiaram a sua vida.

A minha sogra, Yonne, por sua presença, na minha ausência .

Ao meu irmão, Marcelo, por me ensinar que a vida pode ser trilhada de maneiras diferentes, mas com igual sucesso. 


\section{AGRADECIMENTOS ESPECIAIS}

À Prof: Dr $r^{a}$ Cléa Rodrigues Leone, pela confiança, orientação e por dividir comigo um pouco de sua imensa sabedoria.

$\grave{A}$ todas as mães que entenderam e consentiram em participar deste estudo e confiaram a mim o seu bem mais precioso.

À todos os recém-nascidos que mesmo sem entender, contribuíram para o crescimento da Neonatologia. 


\section{AGRADECIMENTOS}

Ao Prof. Dr. Flávio Adolfo Costa Vaz, pelo estímulo e incentivo.

Ao Prof. Dr. Yassushiko Okay, pelo estímulo e incentivo.

À Dra. Sandra Veiga da Silveira, pela eterna amizade.

Ao Dr. Renato T. Yamada, pela amizade, dedicação e imensa colaboração na coleta de dados.

À Dra. Silvana Darcie, pela amizade, carinho e pela revisão do inglês.

Às Dras. Monique Catache, Ana Carolina Novo e Roberta Berardi, pela amizade e companheirismo.

Ao Dr. Oscar Tadashi Matsuoka e Dra. Marta Mataloun, por compartilharem comigo as mesmas angústias e emoções.

À Dra. Alice Deustch e Dra.Lilian Sadeck pelo carinho e ensinamentos de todos esses anos.

À Dra. Valdenise Martins Laurindo Tuma Calil, Dr.Ary Lopes Cardoso e Dra. Sônia Regina Testa da Silva Ramos pelas importantes sugestões no Exame de Qualificação.

Ao Prof.Dr.Cláudio Leone, pelo apoio e orientação de toda a análise estatística. 
À Dra.Thelma Suely Okay, responsável pelo Laboratório do Instituto da Criança, pelas ricas sugestões no exame de qualificação e coordenação para realização das dosagens laboratoriais

Aos colegas do Berçário Anexo à Maternidade, pela colaboração na coleta dos exames, apoio e amizade.

À Edi Toma, enfermeira-chefe e, aos demais membros da equipe de Enfermagem do Berçário Anexo à Maternidade do HC-FMUSP, pelo carinho e colaboração em várias etapas desta pesquisa.

À bibliotecária Mariza Kazue Umetsu Yoshkawa, pelo apoio e auxílio no levantamento e revisão bibliográfica.

Às biólogas Karina H.Kawasato, Regina M.Yamagata e Patrícia Nagaoka, pelas determinações laboratoriais.

À Maria Aparecida Albuquerque, por providenciar o adequado encaminhamento do material coletado.

À FAPESP, pelo auxílio financeiro.

À SARSTEDT, pela doação das seringas de gasometria. 


\section{SUMÁRIO}

Lista de abreviaturas …........................................................................... $\mathrm{x}$

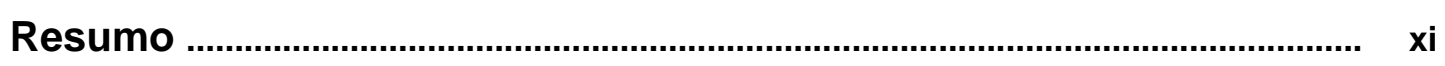

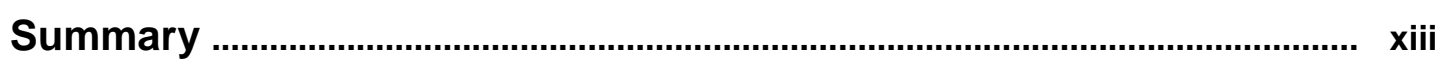

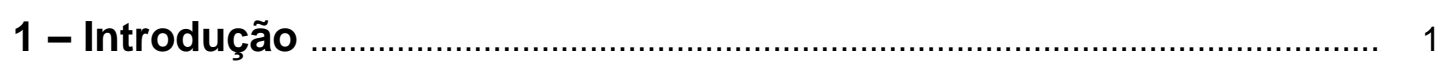

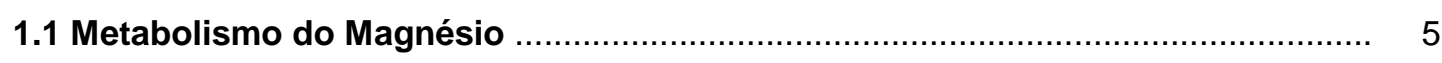

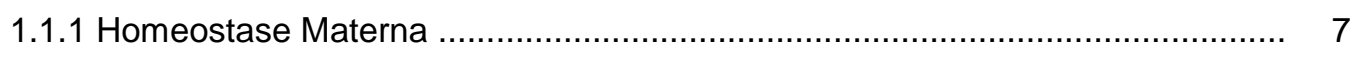

1.1.2 Transporte Placentário ..................................................................... 8

1.1.3 Homeostase Fetal ........................................................................ 10

1.1.4 Homeostase Neonatal ................................................................. 11

1.1.4.1 Absorção Intestinal ..................................................................... 13

1.1.4.2 Excreção Renal .................................................................... 15

1.1.4.3 Modulação Hormonal.................................................................... 17

1.1.4.3.1 Hormônio da paratireóide ..................................................... 18

1.1.4.3.2 Vitamina D..................................................................... 20

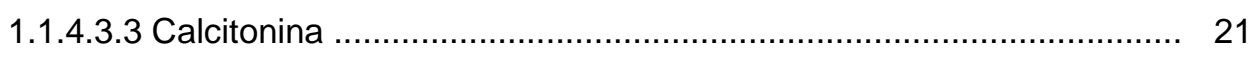

1.1.4.3.4 Hormônios Esteróides e Aldosterona …......................................... 21

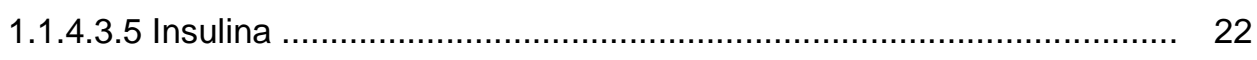

1.1.4.3.6 Glucagon e Hormônio Antidiurético ……...................................... 22

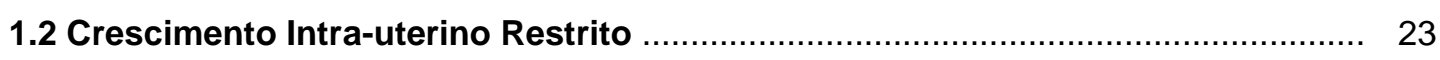

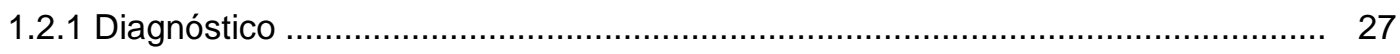

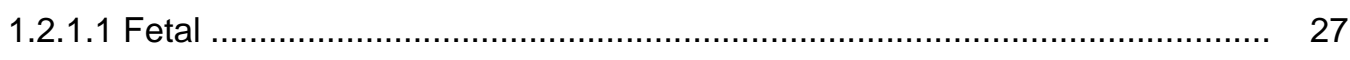

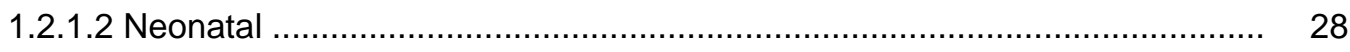

1.2.2 Repercussões sobre o Feto e Recém-nascido ........................................... $\quad 30$

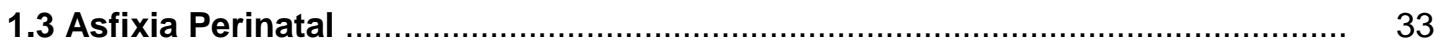

1.3.1 Repercussões sobre o Sistema Nervoso Central ......................................... 36 


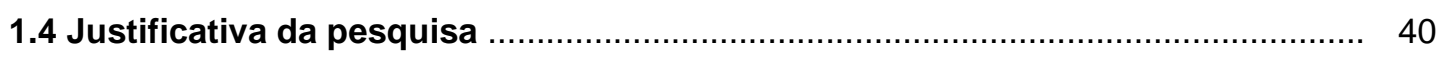

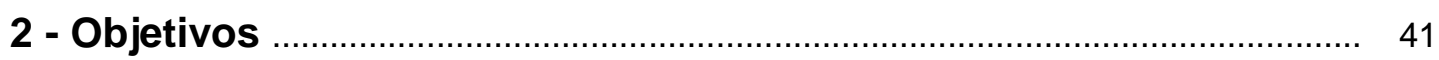

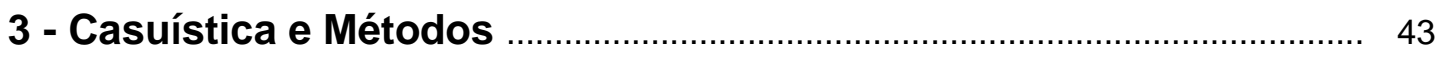

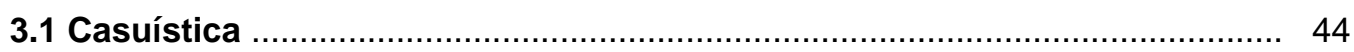

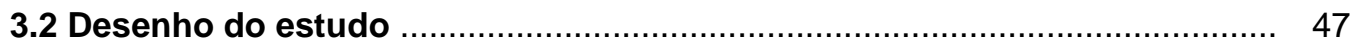

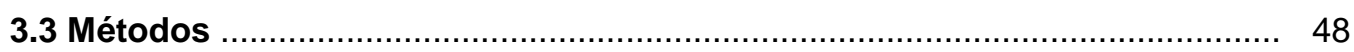

3.3.1 Informações sobre a gestação .......................................................... 48

3.3.2 Informações sobre a evolução pós-natal .............................................. 48

3.3.3 Medidas antropométricas ............................................................... 48

3.3.4 Avaliação laboratorial ................................................................... 50

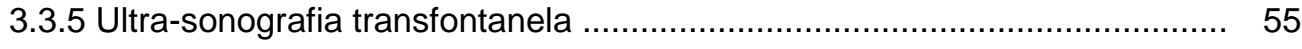

3.3.6 Avaliação Neurológica ...................................................................... 55

3.3.7 Análise Estatística ................................................................... 56

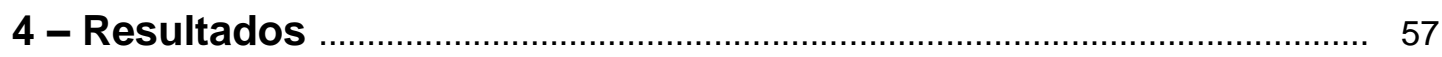

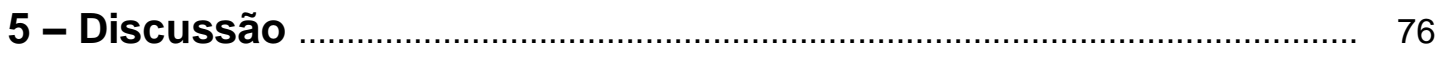

5.1 Discussão da casuística e métodos ……….......................................... 77

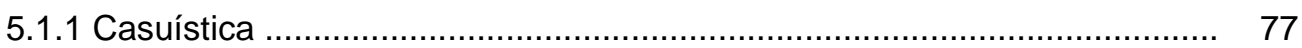

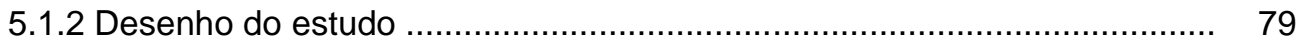

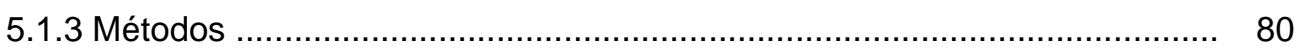

5.1.3.1 Avaliação da presença de CIUR ................................................. 80

5.1.3.2 Avaliação da presença de asfixia .................................................. 82

5.1.3.3 Avaliação laboratorial ................................................................ 83

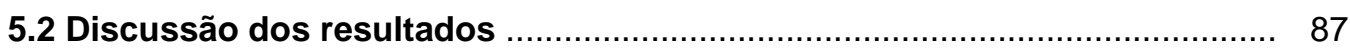

5.2.1 Características da população estudada ……......................................... 87

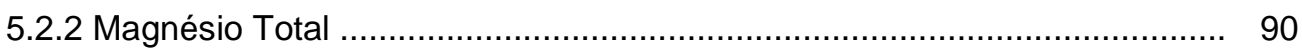

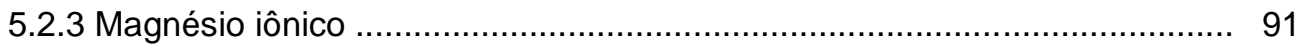

5.2.4 Relação entre Mgi e outros indicadores ................................................. 93 


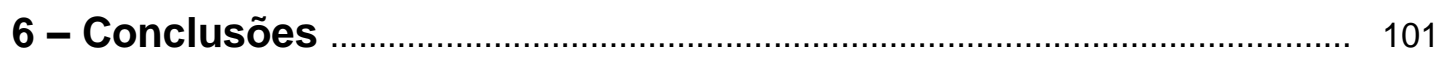

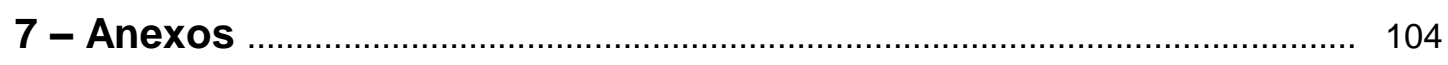

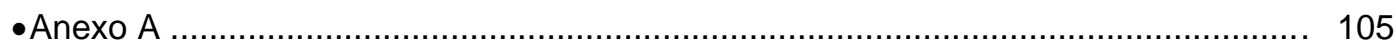

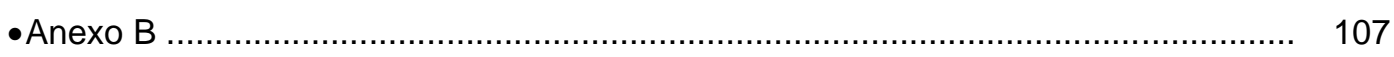

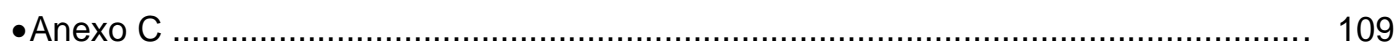

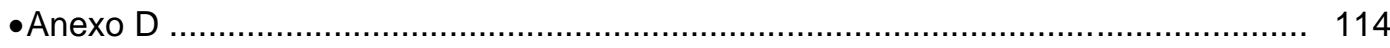

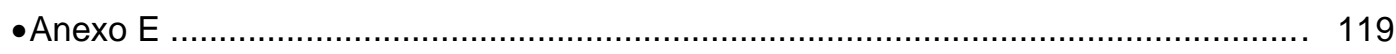

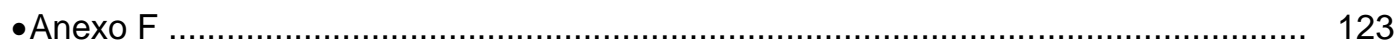

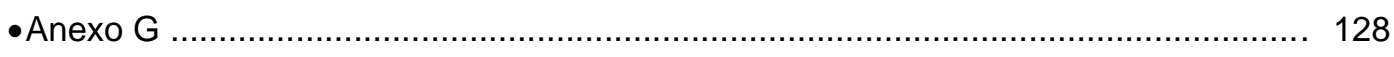

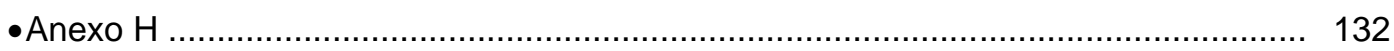

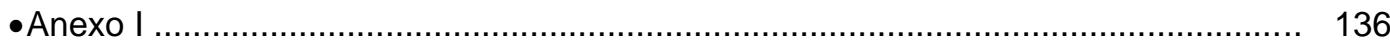

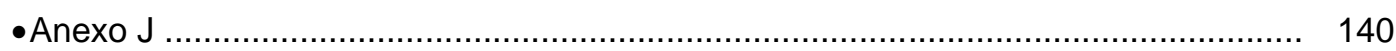

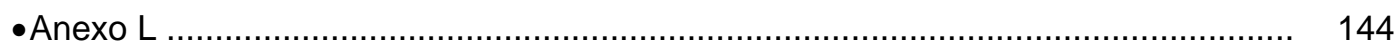

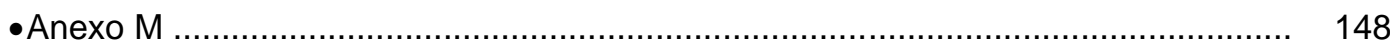

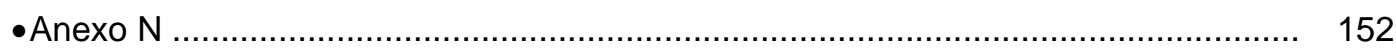

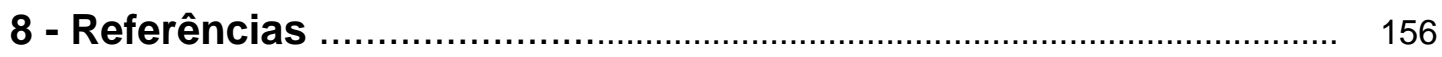




\section{LISTA DE ABREVIATURAS}

$\begin{array}{ll}\text { AIG } & \text { Adequado para a idade gestacional } \\ \text { ATP } & \text { Adenosina trifosfato } \\ \text { BAM } & \text { Berçário Anexo à Maternidade } \\ \text { Cai } & \text { Cálcio iônico } \\ \text { Cr } & \text { Creatinina } \\ \text { CIUR } & \text { Crescimento intra-uterino restrito } \\ \text { EIH } & \text { Encefalopatia Hipóxico-isquêmica } \\ \text { FMUSP } & \text { Faculdade de Medicina da Universidade de São Paulo } \\ \text { HC } & \text { Hospital das Clínicas } \\ \text { IG } & \text { Idade Gestacional } \\ \text { Mg } & \text { Magnésio } \\ \text { Mgi } & \text { Magnésio iônico } \\ \text { MgT } & \text { Magnésio Total } \\ \text { NMDA } & \text { N-metil-D-aspartato } \\ \text { O2 } & \text { Rexigênio } \\ \text { P } & \text { Fósforo } \\ \text { PIG } & \text { Pequeno para a idade gestacional } \\ \text { PTH } & \text { Paratormônio } \\ \text { RN } & \text { RNT }\end{array}$




\section{RESUMO}

BARBOSA,NOE. Influência do crescimento intra-uterino restrito e da asfixia perinatal sobre os níveis séricos de Magnésio em recém-nascidos de termo na primeira semana de vida. [dissertação] São Paulo: Faculdade de Medicina, Universidade de São Paulo; 2003.

O Magnésio é o segundo cátion intracelular mais comum e desempenha importante papel na modulação de funções de transporte e receptores, atividades enzimáticas, metabolismo energético, síntese de proteínas e ácidos nucleicos e proteção de membranas biológicas. Apesar de sua importância, o conhecimento de sua homeostase não é completo, principalmente por dificuldade de acesso a seus estoques intracelulares e da ausência de métodos laboratoriais confiáveis para medida da fração iônica. O desenvolvimento recente de um eletrodo ín-seletivo permitiu a determinação das concentrações de $\mathrm{Mg}$ iônico(Mgi), em pequenas amostras de sangue, o que possibilitou a realização de estudos para determinação desta fração no período neonatal. A presença de alguns distúrbios, como o Crescimento Intra-uterino Restrito(CIUR) e a Asfixia Perinatal, poderiam potencialmente levar a desvios da homeostase do $\mathrm{Mg}$, ainda não totalmente esclarecidos. O objetivo deste estudo foi descrever, em Recém-nascidos de termo(RNT) sem CIUR, os níveis de Mgi e total (MgT) em sangue de cordão umbilical, $3^{\circ}$ e $7^{\circ}$ dias de vida e comparar os valores obtidos entre os RNT, com e sem CIUR e asfixia perinatal. Realizou-se um estudo prospectivo, no qual foram incluídos 95 RNT, divididos em dois grupos de estudo: Grupo I sem CIUR(50 RN - 52,6\%) e Grupo II - com CIUR(45 RN - 47,4\%). A presença de CIUR foi determinada por um peso de nascimento abaixo do percentil 10 para a curva de Ramos(1983), associado a uma relação $P / P_{50}<$ 0,85 . Cada um desses grupos foi subdividido em 2 subgrupos : Grupo la - 30 RN (31,6\%), sem ClUR e sem asfixia perinatal; Grupo lb - $20 \mathrm{RN}(21,0 \%)$, sem CIUR e com asfixia perinatal; Grupo Ila - 40 RN(42,1\%), com CIUR e 
sem asfixia perinatal; Grupo llb - $5 \mathrm{RN}(5,3 \%)$, com CIUR e asfixia perinatal. A presença de asfixia perinatal foi indicada por um Apgar de $5^{\circ}$ minuto $\leq 6$ associada a presença de um dos seguintes critérios: $\mathrm{pH}$ de sangue de cordão umbilical $<7,2$, disfunção de um ou mais órgãos, sequelas neurológicas no período neonatal imediato. Foram realizadas determinações de Mgi, Cálcio iônico(Cai), Uréia(U), pH, MgT, Fósforo(P) e Creatinina(Cr), em sangue de cordão umbilical, no $3^{\circ}$ e no $7^{\circ}$ dias de vida. Verificou-se que nos RNT sem ClUR(Grupo la), as concentrações médias de MgT, ao nascimento, foram menores do que as de RN com CIUR e elevaram-se, de forma significante, até o $7^{\circ}$ dia de vida, enquanto as de Mgi mantiveram-se. As concentrações de Mgi neste grupo, foram significativamente menores do que as de RN com CIUR(Grupo lla) durante a $1^{\text {a }}$ semana de vida e do que as de RN com asfixia perinatal(Grupo lb) no $3^{\circ}$ e $7^{\circ}$ dias de vida. Concluiu-se que, em RNT sem CIUR, há um aumento dos níveis de MgT durante a $1^{\text {a }}$ semana de vida, sem alteração das concentrações de Mgi. A presença de CIUR, bem como a asfixia perinatal, podem influenciar as concentrações neonatais de $\mathrm{Mg}$, através de seus efeitos de modulação da homeostase deste íon, durante os períodos fetal e neonatal. 


\section{SUMMARY}

BARBOSA, NOE. Influence of intrauterine growth restriction and perinatal asphyxia on serum magnesium levels in term neonates in the first week of life. [dissertação] São Paulo: Faculdade de Medicina, Universidade de São Paulo; 2003.

Magnesium is the second most abundant intracellular cation and plays an important role in regulation of transporting and receptors functions, enzymatic activities, energy metabolism, protein and nucleic acid synthesis and biologic membranes protection. In spite of this, the knowledge of its homeostasis is still limited, mainly due to inacessibility of its intracellular stores and the absence of a reliable methodology to measuring the ionized fraction. The recent development of an ion-selective electrode has allowed not only the determination of ionized magnesium(iMg) concentrations in a small blood sample volume, but also an increasing number of researches as to this fraction in neonatal period. The presence of some disorders,i.e. like Intrauterine Growth Restriction (IUGR) and Perinatal Asphyxia, could lead to an unclear imbalance of magnesium homeostasis, in a way not yet clear. The aim of this study was to describe, in term newborns without IUGR, iMg and Total $\mathrm{Mg}$ (TMg) concentrations in umbilical cord blood, third and seventh days of life and to compare the results among term newborns with and without IUGR and perinatal asphyxia. Ninety-five term newborn infants were enrolled in a prospective study and were divided into two study groups: Group I : without IUGR(50RN - 52.6\%) and Group II - with IUGR(45RN 47.4\%). Intrauterine growth restriction was defined as a birth weight below the $10^{\text {th }}$ percentil for Ramos Curve(1983) besides to a birth weight ratio $<0,85$. Each one of these groups were divided in two subgroups: Group la :30 RN (31,6\%), without IUGR or perinatal asphyxia; Group Ib : 20 RN (21,0\%), without IUGR, with perinatal asphyxia ; Group Ila : 40 RN (42,1\%), with IUGR, without perinatal asphyxia; Group Illb: $5 \mathrm{RN}(5,3 \%)$, with perinatal asphyxia and IUGR. Perinatal asphyxia was defined as a 5 minutes Apgar 
score $\leq 6$ besides to one of the following: umbilical cord blood $\mathrm{pH}<7,2$, disfunction of one or more organs, neonatal neurologic manifestations. iMg, $\mathrm{TMg}$, ionized calcium, urea, $\mathrm{pH}$, phosphorus and creatinine concentrations were determined in umbilical cord blood, third and seventh days of life. We observed that in term newborns without IUGR (Group la), TMg concentrations increased significantly during the first week of life, while iMg concentrations remained unchanged. iMg levels in this group, were significantly lower than in the group with IUGR (Group Ila) from birth to $7^{\text {th }}$ day of life and than in the group without IUGR, with perinatal asphyxia (Group lb) in the third and seventh days of life. We concluded that in term newborns without IUGR, TMg levels increased during the first week of life, while iMg levels remained unchanged. The presence of IUGR, as well as, perinatal asphyxia, may influence neonatal levels of magnesium, through their effect on the modulation of this ion homeostasis, during fetal and neonatal periods. 
1 - INTRODUÇÃO 
A importância do Magnésio $(\mathrm{Mg})$ e sua relação com a origem da vida foi demonstrada, desde a determinação da composição da crosta terrestre e do oceano primitivo, ricos em $\mathrm{Mg}$, à formação da clorofila, que contém $\mathrm{Mg}$ no centro da molécula e, finalmente, à sua incorporação nas células animais que possuem adenosina trifosfato (ATP), que depende do Mg (Fawcett et al.,1999). A formação da molécula de clorofila fez com que a fotossíntese e, consequentemente, um ambiente rico em oxigênio fosse possível. O Mg na molécula de clorofila é essencial para o processo de captura de fótons do sol e sua conversão em ATP (Reinhart ,1988).

É o $4^{\circ}$ mineral mais abundante no organismo. Tem várias funções metabólicas : é cofator em mais de 325 sistemas enzimáticos, ativando várias enzimas envolvidas no metabolismo do fósforo, fosforilação oxidativa mitocondrial e síntese e degradação nucleicas. Também é parte integrante e ativador de ATP e adenil-ciclase (Marcus et al.,1997; Duran et al.,1998).

$\mathrm{O} \mathrm{Mg}$ tem recebido menor atenção ao longo do tempo, tendo sido inclusive apontado na literatura, durante vários anos, como o "ín esquecido", mesmo após o reconhecimento de sua importância no metabolismo, quando comparado a outros íons (James,1999). A ausência de estudos clínicos e experimentais controlados, a aparente falta de correlação entre os níveis séricos e teciduais de $\mathrm{Mg}$ e a subsequente dificuldade de 
interpretação desses valores, contribuíram para essa falta de interesse em relação às determinações séricas de rotina desse íon (Mclean,1994; Altura; Altura,1995).

No período perinatal, o reconhecimento de que podem ocorrer convulsões secundárias à hipomagnesemia e depressão respiratória neonatal devido à hipermagnesemia, após administração de sulfato de $\mathrm{Mg}$ à mãe, fez crescer o interesse sobre este íon (Bajpai et al.,1966; Verive et al., 2000).

Entretanto, é possível que distúrbios, como o Crescimento Intra-uterino Restrito (CIUR) e a Asfixia perinatal, possam causar alterações da homeostase do $\mathrm{Mg}$, ainda não bem definidas.

O CIUR é caracterizado por um crescimento fetal insuficiente e está associado a um maior risco de morbidade e mortalidade perinatal. A morbidade neonatal associada ao CIUR, inclui: a asfixia perinatal, síndrome de aspiração meconial, hemorragia pulmonar, síndrome de hiperviscosidade e distúrbios metabólicos (Pollack; Divon,1992; Cetin et al.,1996).

Inúmeros fatores podem causar restrição do crescimento, desde maternos e placentários, até fetais. Independentemente da etiologia, a falha no crescimento será devida a um dos seguintes mecanismos: inadequado suprimento materno de nutrientes, dificuldade de transferência desses pela placenta e incapacidade do feto de utilizá-los (Pollack; Divon,1992; Gluckman; Harding,1997).

A asfixia perinatal grave pode levar a vários distúrbios metabólicos no período neonatal, mas os relatos referentes à homeostasia do Mg são 
discordantes. A presença de níveis séricos diminuídos de $\mathrm{Mg}$ foi demonstrada por alguns autores em RN com Encefalopatia hipóxicoisquêmica $(E I H)$, gerada principalmente por um aumento dos níveis séricos de fósforo $(P)$, proveniente da quebra de glicogênio e proteína tecidual, na presença de inadequada excreção renal de $\mathrm{P}$. Este aumento do $\mathrm{P}$ sérico poderia induzir a um aumento da atividade da calcitonina e a um hipoparatireoidismo funcional, o que causaria uma diminuição do Mg sérico (Tsang et al.,1974; Mimouni et al.,1986).

De forma inversa, alguns estudos relatam uma associação da asfixia perinatal a um aumento das concentrações séricas de $\mathrm{Mg}$, relacionada principalmente à diminuição do ATP e à lesão renal, com diminuição da excreção urinária de $\mathrm{Mg}$, já que o rim seria o principal regulador da concentração sérica desse íon (Donovan et al.,1980; Williams; Smith,1995; Ilves et al.,2000). A acidose gerada pela hipoxia, também poderia levar a um desvio do $\mathrm{Mg}$, do intra para o extracelular, com aumento das concentrações séricas desse íon (Engel ; Elin,1970; Classen et al.,1971).

Embora o Mg seja predominantemente um cátion intracelular, dificuldades técnicas na determinação de seu conteúdo celular em diferentes tecidos, fez com que sua dosagem plasmática fosse a utilizada como parâmetro clínico. Todos os métodos para estimativa do conteúdo corpóreo de $M g$ no organismo são custosos e não estão disponíveis para uso de rotina (Fiser et al.,1998). Vários estudos mostraram correlação entre o Mg plasmático e suas concentrações intracelulares, como a presente em eritrócitos ou células musculares (Schuck et al.,1998) . 
A concentração sérica de Magnésio Total $(\mathrm{MgT})$, que inclui a ligada a proteínas, a complexos e a iônica, foi a primeira forma e a mais facilmente medida de $\mathrm{Mg}$ e é a rotineiramente usada na prática clínica para se acessar o Mg circulante (Munoz et al.,2000; Sasaki et al.,2000). A forma iônica (Mgi), entretanto, é a fisiologicamente ativa e possui uma faixa estreita de normalidade quando comparada ao $\mathrm{MgT}$, o que também fornece uma medida mais precisa de sua importância clínica (Marcus et al.,1997).

Uma vez que o Mgi está em equilíbrio com o compartimento intracelular, sua determinação sérica tem grande valor clínico na avaliação de distúrbios do metabolismo do Mg (Hristova et al.,1999).

\subsection{Metabolismo do $\mathrm{Mg}$}

O Mg é o $4^{\circ}$ cátion mais comum no organismo e $02^{\circ}$ intracelular (Marcus et al, 1997). O corpo humano adulto contém 21-28g ou 2000 mEq de $\mathrm{Mg}$, enquanto o recém-nascido de termo (RNT), com peso de $3500 \mathrm{~g}$, contém aproximadamente 0,75g de Mg (Wacker; Parisi,1968; Forfar,1976).

Menos de $1 \%$ do $\mathrm{Mg}$ corpóreo total é encontrado no espaço extracelular. Distribui-se principalmente nos ossos (65\%), sob a forma cristalina, e no compartimento intracelular dos músculos e tecidos moles (34\%). Somente uma pequena parte do Mg ósseo é trocado livremente com o presente no extracelular (Paunier,1992; Cashman; Flynn,1999).

O Mg plasmático apresenta-se sob três formas: ligado a proteínas (25\% a albumina e $8 \%$ a globulinas), a complexos, como citrato e fosfato (12\%) e 
ionizado (55\%). Aproximadamente $70 \%$ do $\mathrm{MgT}$ é ultrafiltrável e livremente filtrado no glomérulo (Tsang,1972b; Munoz et al.,2000). Já a fração ionizada do $\mathrm{Mg}$ é a fisiologicamente importante e é controlada dentro de limites estreitos pelo rim (Foley; Zaritsky,1998; Massry;Seelig,1977; Wicks,1999).

Em contraste às baixas concentrações de Cálcio (Ca) intracelular, a concentração de íons de $\mathrm{Mg}$ livre é de $5 \times 10^{-4} \mathrm{M}$ no citosol, e esta concentração é mantida estável. Esta estabilidade é reflexo dos muitos papéis críticos que $\mathrm{o} \mathrm{Mg}$ desempenha no metabolismo celular, principalmente como cofator de várias reações enzimáticas e na regulação da excitabilidade neuromuscular (Murphy,2000).

A presença do $M g$ é essencial para as reações intracelulares que envolvem o ATP, na transferência, estoque e utilização de energia. Uma vez que o ATP é necessário para utilização de glicose, gordura, proteína, ácidos nucleicos e síntese de coenzimas, contração muscular, transferência de grupo metil, ativação de sulfato e acetato, pode-se inferir que o efeito do $\mathrm{Mg}$ se estende a todas essas funções (Wacker; Parisi,1968; Altura; Altura,1995).

Ao causar uma alteração conformacional ou por promover agregação de vários complexos enzimáticos, o Mg ativa mais de 300 enzimas. O Mgi livre participa da regulação do metabolismo intermediário, ao ativar enzimas, como hexoquinase, piruvato-desidrogenase, enolase e creatinofosfoquinase. Regula sete enzimas glicolíticas, quatro no ciclo tricarboxílico e 12 fotossintéticas (Altura; Altura,1995; Wicks, 1999).

Dentro do núcleo, promove a estabilização do duplo filamento do ácido desoxiribonucleico (DNA) e mantém a estrutura altamente organizada da 
cromatina. Ao regular a síntese de ácido ribonucleico (RNA) e a ligação do RNA-mensageiro aos ribossomos, os íons Mg são ativos no controle do crescimento celular, replicação e estrutura de membrana (Altura; Altura,1995).

$\mathrm{Na}$ membrana celular, regula a permeabilidade, fluxo de eletrólitos, ligação de hormônios e agonistas aos receptores de superfície celulares, e adesão célula a célula (Altura; Altura,1995). É essencial para quase todas as reações hormonais que ocorrem no organismo (Dacey,2001).

\subsubsection{Homeostase Materna}

Durante a gestação, o crescimento de tecidos maternos (útero, músculo, tecido mamário e sangue), além da placenta e do feto, altera a homeostase materna de Mg. A absorção gastrointestinal de Mg está aumentada, assim como a reabsorção renal, causada por um aumento da taxa de filtração glomerular, devido ao aumento da carga ultrafiltrada (Husain; Sibley,1993).

No entanto, as concentrações de MgT e Mgi ao final da gestação, são menores do que na mulher não grávida (Forfar,1976; Handwerker et al.,1995), correspondendo a aproximadamente $80 \%$ do $\mathrm{Mg}$ de adultos saudáveis (Krachler et al.,1999). Durante a gestação, há uma redução progressiva do Mg sérico, alcançando um nadir no $3^{\circ}$ trimestre da gestação, antes de elevarse no período pós-parto. Esta diminuição progressiva ocorre pelo aumento do volume plasmático e, talvez, a própria gestação normal possa criar algum tipo de estresse no balanço de Mg (Husain; Sibley,1993; Handwerker et al. ,1995). 
Vários estudos demonstraram haver, também, um aumento da secreção de paratormônio (PTH), que parece ser mais importante ao final da gestação, o que representa um ajuste materno esperado ao aumento do volume extracelular e à perda de $\mathrm{Ca}$ e $\mathrm{Mg}$ via transferência placentária (Forfar,1976; Pitkin,1985). Teoricamente, também seria esperado um aumento na secreção de calcitonina, para proteção do esqueleto materno da ação do PTH. Os estudos em humanos, no entanto, são controversos, não se observando alterações nas concentrações de calcitonina em alguns destes ou elevação não significante em outros, ou mesmo uma elevação progressiva (Pitkin,1985; Wieland et al.,1980).

Não se observou influência da gestação sobre a $25(\mathrm{OH}) \mathrm{D}$, enquanto a forma biologicamente ativa, a $1,25(\mathrm{OH})_{2} \mathrm{D}$, tem seus níveis aumentados durante a mesma. O principal mecanismo fisiológico que promove a hidroxilação da $25(\mathrm{OH}) \mathrm{D}$ é o $\mathrm{PTH}$, podendo se explicar o aumento da $1,25(\mathrm{OH})_{2} \mathrm{D}$ através deste possível hiperparatireoidismo fisiológico da gestação (Pitkin,1985; Venkataraman; Tsang,1995).

\subsubsection{Transporte Placentário}

Pouco se sabe sobre os mecanismos precisos de transporte de $\mathrm{Mg}$ através da placenta (Perveen et al.,2002). O transporte ativo parece desempenhar papel predominante na transferência de $\mathrm{Mg}$ através da placenta (Nandakumaran et al.,2002). 
Vários estudos experimentais demonstraram que, fetos de mães submetidas a graves privações de Mg, são capazes de manter níveis séricos de $\mathrm{Mg}$ iguais ou maiores do que os maternos, durante o período de privação (Handwerker et al.,1995). Estudo realizado em placentas de ratas perfundidas com $\mathrm{Mg}$, demonstra que esta concentra ativamente o $\mathrm{Mg} \mathrm{e}$ mantém um gradiente para o feto, através de um mecanismo de transporte ativo, contra um gradiente de concentração (Shaw et al.,1990).

Outros autores referem, no entanto, que todos os mecanismos de transferência placentária de cátions divalentes em humanos não estão completamente elucidados. Elementos com baixo peso atômico, como o Mg parecem atravessar a placenta inteira por difusão (Perveen et al.,2002).

A regulação deste transporte e o que leva ao aumento exponencial da retenção de $\mathrm{Mg}$ no último trimestre da gestação, ainda não estão claros (Husain; Sibley,1993).

Em contraste ao Ca e Mg, os hormônios PTH e Calcitonina parecem não atravessar a placenta (Pitkin,1985). Entretanto, uma disfunção da paratireóide materna pode afetar adversamente a função da paratireóide fetal, através de variações na concentração de Ca. O hiperparatireoidismo materno resulta em hipercalcemia materna, que leva à hipercalcemia fetal e supressão das paratireóides no RN. Por outro lado, o hipoparatireoidismo materno não tratado, leva à hipocalcemia materna e fetal e, secundariamente, ao hiperparatireoidismo fetal e neonatal (Tsang et al.,1973a). 
Em relação à passagem de vitamina $D$, os estudos são controversos. Alguns, realizados em ovelhas, mostram algum grau de transferência de $25(\mathrm{OH}) \mathrm{D}$ e $1,25(\mathrm{OH})_{2} \mathrm{D}$, assim como outros em humanos. Entretanto, a comparação dos valores de vitamina $D$ em cordão umbilical e maternos ao nascimento, tornam duvidosa a existência de transporte transplacentário de $1,25(\mathrm{OH})_{2} \mathrm{D}$ in vivo (Pitkin,1985).

\subsubsection{Homeostase Fetal}

Durante a gestação, quantidades crescentes de Mg são transportados da mãe para o feto (Tsang et al.,1972a). As concentrações plasmáticas de Mg total e ultrafiltrável no feto excedem às da mãe (Tsang et al',1973b), sendo que, no último trimestre, o feto humano incorpora $\pm 2-3 \mathrm{mg} / \mathrm{kg} / \mathrm{dia}$ de Mg (Venkataraman; Tsang,1995).

O papel do PTH na homeostase de Ca e Mg intra-útero não está clara. Foi demonstrado que o PTH não atravessa a placenta e, assim, o PTH presente na circulação fetal seria de origem fetal. As glândulas paratireóides iniciam a secreção deste hormônio com 12 semanas de gestação e parecem ser ativas na regulação do Ca fetal. Há poucos estudos em relação à resposta da glândula paratireóide fetal às baixas concentrações séricas de Mg, mas a paratireóide fetal parece ser menos efetiva em proteger o feto contra situações de hipomagnesemia do que em hipocalcemias (Loughead et al.,1991). 
Em relação à calcitonina, observou-se que a tireóide fetal contem calcitonina, identificada imunologicamente durante a maior parte da vida intra-uterina. A medida desta em cordão umbilical excede os níveis maternos em vários estudos (Pitkin,1985).

Os níveis de $1,25(\mathrm{OH})_{2} \mathrm{D}$ também foram mais elevados no sangue de artéria do que de veia umbilical, sugerindo que o feto participa na síntese desta vitamina (Wieland et al.,1980).

Presumindo-se que o feto responda endocrinologicamente de uma maneira similar ao adulto, a hipercalcemia e hipermagnesemia fetal, promoveriam uma supressão da secreção de PTH e/ou estimulariam a liberação de calcitonina, principalmente ao final da gestação (Tsang et al.,1973b; Pitkin,1985).

A concentração de Mg no líquido amniótico ao final do $1^{\circ}$ trimestre é 2 vezes maior do que ao termo. Por outro lado, o nível de Mg no líquido amniótico é menor do que no soro materno durante toda a gestação (Anastasiadis et al.,1981).

\subsubsection{Homeostase Neonatal}

Após o nascimento, há uma abrupta interrupção do transporte placentário de $\mathrm{Ca}$ e $\mathrm{Mg}$, com uma diminuição em suas concentrações séricas (Loughead et al.,1991). A secreção de PTH está diminuída nas primeiras 48 horas de vida, provavelmente induzida pelos elevados níveis de Ca plasmático no feto (David; Anast,1974), aumentando progressivamente a 
seguir, acarretando um crescimento secundário dos níveis de $\mathrm{Ca}$ (Pitkin,1985; Mimouni; Tsang,1994). Da mesma forma, as concentrações de $1,25(\mathrm{OH})_{2} \mathrm{D}$ se elevam no período pós-natal (Venkataraman; Tsang,1995).

Medidas das concentrações séricas de calcitonina, PTH, Ca e Mg, realizadas em recém-nascidos de baixo peso(RNBP), nas primeiras 12 horas de vida, evidenciaram um aumento da calcitonina a partir de 2 a 5 horas de vida, sendo a magnitude deste inversamente proporcional à idade gestacional. É possível que esta elevação possa contribuir para a diminuição precoce que ocorre no Ca sérico e indiretamente para o aumento do PTH nas 1 as horas de vida. No entanto, não se observou alteração dos níveis de Mg (David et al.,1981).

Já em RNT, detectou-se um aumento da calcitonina de 2 a 3 vezes com 48 horas de vida e redução a partir de 7 dias de vida, mas ainda com concentrações acima daquelas de cordão umbilical (Hillman et al.,1977). Este aumento parece ser fisiológico, protegendo o esqueleto da excessiva reabsorção óssea (Shaul et al.,1987).

Além das alterações hormonais que ocorrem no período perinatal e que influenciam direta e indiretamente a homeostase do $\mathrm{Mg}$, a disponibilidade celular do $\mathrm{Mg}$ é regulada dentro de limites estreitos, principalmente pelos rins e, em menor intensidade, pelo trato gastrointestinal e osso. 


\subsubsection{Absorção Intestinal}

O Mg é absorvido principalmente no intestino delgado distal. A absorção ocorre primariamente por difusão passiva paracelular e arraste por solvente, sendo também referido por alguns autores, o transporte ativo (Duran et al.,1998; Saris et al.,2000).

A difusão passiva é dirigida pelo gradiente eletroquímico ao longo do epitélio. O movimento de água ao longo do epitélio intestinal tem a capacidade de transportar solutos na mesma direção, sendo este transporte denominado de arraste por solvente. Usando técnica de perfusão in vivo em ratos, Behar(1974) observou uma relação positiva entre a absorção de água e de $\mathrm{Mg}$, não excluindo, entretanto, a presença de outros mecanismos de transporte de $\mathrm{Mg}$ no intestino.

As evidências reforçando o transporte ativo, derivam principalmente de observações indiretas de que a velocidade de absorção do $\mathrm{Mg}$ não permanece constante ou linear, com o aumento da concentração deste. Tais observações sugerem, mas não estabelecem, a existência de um mecanismo de transporte saturado, mediado celularmente, para o $\mathrm{Mg}$ no intestino delgado. É possível que altas concentrações deste reduzam a permeabilidade das "tight junctions", causando uma diminuição da velocidade de absorção difusional do $\mathrm{Mg}$, resultando na participação de um mecanismo saturável (Duran et al.,1998). 
Quantidades significativas de $\mathrm{Mg}$ são secretadas ao longo do tubo gastrointestinal, sendo quase todo $\mathrm{Mg}$ secretado, reabsorvido (Namgung; Tsang, 1998).

Estudos utilizando radioisótopos indicam que a absorção é influenciada pela carga apresentada : quanto menor a carga, maior será a absorção (Reinhart,1988; Mclean,1994). Em adultos, a absorção intestinal varia de 34 a $62 \%$ da ingestão total, enquanto em RNT e recém-nascidos pré-termo (RNPT), é maior, variando entre 60 e 86\% (Namgung; Tsang,1998).

Sementes inteiras, grãos e vegetais de folhas verdes, legumes e nozes constituem as fontes dietéticas mais ricas em Mg (Rude,2001), embora o processamento da comida diminua muito esse conteúdo (Saris et al.,2000).

Fitato, fibras, álcool e um excesso de $\mathrm{Ca}$ ou fosfato diminuem a absorção intestinal de Mg, provavelmente pela redução de sua concentração no lúmen (Saris et al.,2000).

Há outros fatores que podem afetar a absorção intestinal de Mg, como os polímeros de glicose, que intensificam a absorção jejunal de $\mathrm{Mg}$, provavelmente devido a um consequente aumento da absorção de água, ocasionando maior absorção de Mg através de arraste por solvente (Bei et al.,1986).

A ingestão diária de Mg para adultos é de 300 a 350 mg/dia(Weisinger et al.,1998) e, para crianças, de 4 a 5 mg/kg (Geven et al.,1993).

Dados epidemiológicos têm mostrado um declínio na ingestão diária, nos Estados Unidos, de aproximadamente 500 mg/dia no início do século, para 175-225 mg/dia nos dias atuais (Altura,1994). 
O leite humano contém aproximadamente 20 a $40 \mathrm{mg} / \mathrm{l}$ de $\mathrm{Mg}$, mantendo-se essa concentração estável, independentemente de fatores constitucionais ou ambientais, dieta ou ação de agentes que alterem seu metabolismo (Dorea,2000). O RN necessita reter 0,85 mEq/dia de Mg para satisfazer suas necessidades de crescimento, e esta está contida em cerca de $350 \mathrm{ml}$ de leite humano (Harris; Wilkinson,1971; Paunier,1992). Segundo Saris et al.,2000, o Mg do leite humano é bem absorvido e fornece adequada quantidade deste para a criança em crescimento.

\subsubsection{Excreção renal}

O rim é o principal regulador da concentração sérica e do conteúdo corpóreo total de Mg (Reinhart,1988). O principal regulador da reabsorção de Mg é sua própria concentração plasmática. Assim, na hipomagnesemia, a excreção urinária reduz-se a valores de aproximadamente zero, enquanto na hipermagnesemia verifica-se uma redução na reabsorção de $\mathrm{Mg}$ e um aumento em sua excreção urinária (Weisinger; Bellorin-Font,1998).

Vários fatores podem diminuir a reabsorção tubular de $\mathrm{Mg}$, como: expansão de volume do extracelular, vasodilatação renal, diurese osmótica, hipercalcemia, ingestão de álcool e oferta elevada de sódio (Massry; Seelig,1977). Várias drogas, como: diuréticos de alça, gentamicina, anfotericina $B$, digoxina, pentamidina e ciclosporina também causam perda de Mg na urina, através de inibição de sua reabsorção (Mclean,1994; Saris et al.,2000). 
A excreção renal de $\mathrm{Mg}$ é baixa no período neonatal imediato, aumentando para 0,61 $\pm 0,42 \mathrm{mg} / \mathrm{kg} / \mathrm{dia}$ com 1 semana de vida em $\mathrm{RN}$ alimentados ao seio materno e, finalmente, alcançando o valor de $2,8 \pm 1,1$ $\mathrm{mg} / \mathrm{kg} / \mathrm{dia}$, que se mantém no $1 \underline{0}$ ano de vida. O aumento observado na excreção urinária nas $1 \underline{\text { as }}$ semanas de vida em relação aos 1 osmeses de vida, está provavelmente relacionado à elevação da taxa de filtração glomerular com a idade e à ingestão diária de Mg (Namgung; Tsang,1998).

No adulto, aproximadamente $75 \%$ do Mg plasmático é filtrado através da membrana glomerular mas, somente $15 \%$ deste é reabsorvido nos túbulos proximais, sendo a maioria (50-60\%) na porção espessa da alça ascendente de Henle. Apesar do túbulo distal ser responsável pela reabsorção de somente $10 \%$ do $\mathrm{Mg}$ filtrado, constitui o principal local de regulação do $\mathrm{Mg}$. Muitos fatores, hormonais e não hormonais, influenciam sua reabsorção na alça de Henle e no túbulo distal. Em condições normais, somente 3-5\% do Mg filtrado é excretado na urina (Massry; Seelig,1977; Elin,1987; Mclean,1994; Quamme,1997).

Alguns estudos demonstram que a regulação do $\mathrm{Mg}$ no $\mathrm{RN}$ pode ser diferente daquela do adulto, sendo observado que, em ratos $\mathrm{RN}$, sua reabsorção ocorre predominantemente no túbulo proximal e não na alça de Henle, semelhante ao $\mathrm{Na}$ e ao $\mathrm{Ca}$. Esta maior absorção no néfron imaturo em relação ao do adulto pode ser devida à falta de maturação da via paracelular, que permitiria que grandes quantidades de $\mathrm{Mg}$ fossem movimentadas junto com o $\mathrm{Na}, \mathrm{Ca}$ e água. Assim, poder-se-ia prever que, em animais jovens, o controle da reabsorção de $\mathrm{Mg}$ seja influenciado, mais 
por fatores que agem no túbulo proximal, do que na alça ou túbulo distal (Quamme,1997).

A reabsorção tubular de $\mathrm{Mg}$ no túbulo proximal e na porção espessa ascendente da alça de Henle ocorre através de transporte paracelular, passivo, dirigido por um gradiente eletroquímico ao longo do epitélio tubular e, no túbulo distal, por transporte transcelular ativo (Wong; Goodenough,1999; Yu,2001; Vetter; Lohse,2002).

A reabsorção varia em função da carga filtrada, sendo caracterizada por um sistema $\mathrm{T}_{\mathrm{m}}$-limitado. Com o aumento do $\mathrm{Mg}$ filtrado no glomérulo, a reabsorção de Mg aumenta até um máximo; a partir deste ponto, qualquer alteração na carga filtrada, leva a um aumento proporcional na excreção urinária (Saris et al.,2000).

\subsubsection{Modulação hormonal}

O conhecimento do controle hormonal da homeostase do Mg ainda está incompleto, devido a uma aparente falta de controle hormonal específico, similar ao que existe para o Ca. Os principais hormônios reguladores das concentrações de $\mathrm{Ca}$, fosfato e $\mathrm{Mg}$ são o $\mathrm{PTH}$, vitamina $\mathrm{D}$ e calcitonina. Suas ações são similares para Ca e Mg, embora suas relações não sejam tão bem definidas, como as relativas ao Ca. Alterações agudas na concentração sérica de Mg têm efeitos similares sobre a secreção de PTH às alterações agudas no $\mathrm{Ca}$, embora o $\mathrm{Mg}$ seja um estímulo menos potente do que este último (Saris et al ',2000). 
Outros hormônios, como: insulina, glucagon, hormônio antidiurético, aldosterona e hormônios sexuais têm sido relatados como reguladores da homeostase do Mg. Parece não haver, entretanto, um simples hormônio que controle a homeostase do $\mathrm{Mg}$, ocorrendo na verdade, uma ação conjunta destes (Quamme,1997).

\subsection{Hormônio da Paratireóide}

O PTH é um polipeptídeo com peso molecular de 9500 daltons, sintetizado e secretado pelas glândulas paratireóides, sendo secretado em resposta a reduções na concentração de Ca iônico no líquido extracelular. Eleva a concentração de $\mathrm{Ca}$, por ação direta no aumento da reabsorção óssea e da reabsorção renal e, indiretamente, por intensificação da síntese renal de 1,25(OH) 2 D, através da ativação da 25(OH)D- $\alpha$-1-hidroxilase na célula tubular proximal (Venkataraman; Tsang,1995). Também causa inibição da reabsorção de fosfato e bicarbonato no túbulo proximal (Vetter; Lohse,2002).

Os níveis de Mg também podem influenciar a secreção de PTH, através de um "feed-back" negativo, no qual a hipomagnesemia aguda estimula a secreção de PTH (Venkataraman; Tsang,1995). Este estimula a reabsorção de Mg na alça de Henle e no túbulo distal, através da ativação da adenilciclase e produção de Adenosina monofosfato cíclico (AMPc). Há relatos de que o PTH também aumente a reabsorção óssea de $\mathrm{Mg}$ e sua absorção no intestino delgado (Vetter; Lohse,2002). 
A hipomagnesemia crônica, no entanto, pode suprimir a secreção de PTH e abolir sua ação em órgãos alvo (Venkataraman; Tsang,1995). Este bloqueio pode levar a hipocalcemia grave em pacientes com hipomagnesemia crônica (Vetter, Lohse,2002).

Estudos "in vitro" mostraram que a liberação de PTH das glândulas paratireóides bovinas se elevou até que ocorresse uma diminuição média da concentração de $\mathrm{Mg}$ em nível de $0,72 \mathrm{mg} / 100 \mathrm{ml}$ e que, abaixo dessa concentração, a secreção de PTH diminuiu (Anast et al.,1972).

A etiologia da supressão do PTH na presença de hipomagnesemia crônica não está suficientemente esclarecida. Foi sugerido que alterações da enzima adenil-ciclase Ca-sensível Mg-dependente, envolvida na secreção do hormônio, possam ter um papel importante (Shaul et al.,1987; Loughead et al.,1991; Mclean,1994) ou pela existência de resistência dos órgãos-alvo ao PTH (Cruikshank et al.,1979; Paunier,1992; Loughead et al.,1991; Vetter; Lohse,2002).

Mais recentemente, alguns autores referem que a secreção de PTH pela paratireóide é controlada pelo nível sérico de $\mathrm{Ca}$, via uma proteína $\mathrm{G}$ específica ligada ao receptor na superfície celular, o receptor sensível ao $\mathrm{Ca}$ extracelular(CaR). A estimulação do $\mathrm{CaR}$ por cátions extracelulares, inibe a liberação de PTH e, talvez o bloqueio paradoxal da secreção do PTH seja mediado por desinibição das subunidades-G-[alfa], o que mimetizaria ativação do $\mathrm{CaR}$, com consequente supressão da liberação de PTH(Vetter; Lohse,2002). As subunidades-G(alfa) são responsáveis pela ligação do $\mathrm{CaR}$ 
a seus efetores e haveria aumento desta taxa de ligação, em vigência de hipomagnesemia crônica (Vetter; Lohse,2002).

\subsection{Vitamina D}

A Vitamina $D$ é obtida a partir de duas fontes: síntese da vitamina $D_{3}$ (colecalciferol) na pele sob exposição aos raios ultravioleta e absorção a partir da dieta no duodeno e jejuno, da vitamina $D_{2}$ (ergocalciferol). É transportada ao fígado, onde é convertida em $25(\mathrm{OH}) \mathrm{D}$ e, subsequentemente ao rim, onde é transformada no metabólito ativo $1,25(\mathrm{OH})_{2} \mathrm{D}$. Os principais fatores que regulam a síntese de $1,25(\mathrm{OH})_{2} \mathrm{D}$ são $0 \mathrm{PTH}$, a hipocalcemia e hipofosfatemia. Seus principais sítios de ação são: o intestino, onde aumenta a absorção de Ca e P; o osso, no qual mobiliza Ca e P; os rins, aumentando a reabsorção de Ca e P (Venkataraman; Tsang,1995).

A vitamina $D$ parece aumentar a absorção intestinal de Mg através de mecanismos individuais de transporte ativo. Contudo, este fenômeno parece não ter papel importante na homeostase do $\mathrm{Mg}$, já que poderia promover também uma elevação de sua excreção urinária (Saris et al.,2000; Duran et al.,1998).

O Mg é cofator essencial para a reação de 25-hidroxilação na formação hepática da $25(\mathrm{OH}) \mathrm{D}$, e a deficiência de $\mathrm{Mg}$ é associada a uma diminuição das concentrações séricas de $1,25(\mathrm{OH})_{2} \mathrm{D}$ em adultos, provavelmente pelo seu papel nas células tubulares renais como cofator para a $25(\mathrm{OH})_{2} \mathrm{D}-\alpha 1-$ hidroxilase (Namgung; Tsang,1998). 


\subsection{Calcitonina}

É um peptídeo com 32 aminoácidos, que é secretado primariamente pelas células parafoliculares ou C da glândula tireóide. Seu efeito biológico principal é de inibir a atividade dos osteoclastos. A secreção de calcitonina varia de acordo com as alterações agudas da concentração sérica de Ca: aumenta quando a concentração sérica de Ca se eleva e se reduz, quando esta diminui (Venkataraman; Tsang,1995).

Pouco se sabe sobre os efeitos da calcitonina sobre o Mg. Aumentos nas concentrações séricas de Mg resultam em elevação da secreção de calcitonina (Venkataraman; Tsang,1995). Estudos "in vitro" mostraram que, um aumento de $100 \%$ na concentração do $\mathrm{Mg}$, leva a uma descarga de calcitonina das células parafoliculares da tireóide, comparável a um aumento de $20 \%$ das concentrações séricas de Ca (Namgung; Tsang,1998).

Por outro lado, parece estimular a reabsorção renal de $\mathrm{Mg}$ no rato. Em humanos, a calcitonina diminui a reabsorção tubular de Mg (Namgung; Tsang,1998).

\subsection{Hormônios Esteróides e Aldosterona}

Embora não hajam estudos diretos do efeito dos mineralocorticóides no transporte de Mg no túbulo proximal, parece haver um aumento na absorção 
de Mg. A aldosterona potencializa a formação de AMPc estimulada pelo PTH no túbulo distal e aumenta a captação de Mg (Vetter; Lohse,2002).

O hiperaldosteronismo crônico, no entanto, leva à expansão do volume extracelular e diminuição da absorção de sal no túbulo proximal. Isto está associado a um aumento da excreção urinária de Mg (Kobayashi; Igarashi,1968; Mclean,1994; Quamme,1997).

\subsection{Insulina}

Vários estudos demonstraram que, em pacientes com diabetes mellitus, a frequência de hipomagnesemia é maior do que a esperada, e está correlacionada ao grau de gravidade da hipoglicemia. Resultados obtidos "in vitro" com plaquetas humanas, indicam que a insulina pode aumentar a captação celular de $\mathrm{Mg}$ de uma maneira dose, tempo e receptor dependentes. Em humanos, o hormônio pode agir na alça de Henle e no túbulo distal, diminuindo a excreção de Mg (Quamme,1997; Vetter; Lohse,2002).

\subsection{Glucagon e Hormônio antidiurético (ADH)}

Em adultos saudáveis, não se observou diminuição do Mgi ou MgT circulante após injeção de glucagon (Mimouni et al.,1990), enquanto no rato, o glucagon pode aumentar a reabsorção de $\mathrm{Mg}$ na alça de Henle e nos túbulos distais. As ações do glucagon e ADH foram aditivas e são mediadas 
pela adenil-ciclase e AMPc. Podem estimular a captação de Mg nas células tubulares distais de uma maneira concentração-dependente, ação inibida por bloqueadores de canais de $\mathrm{Ca}$ e bloqueada pela proteína quinase $\mathrm{A}$, indicando um papel do AMPc (Quamme,1997; Saris et al.,2000).

\subsection{Crescimento Intra-uterino Restrito (CIUR)}

O CIUR pode ser definido como uma diminuição patológica na taxa de crescimento fetal. Isto resulta em um feto que não alcança seu inerente potencial de crescimento, colocando-o em risco para aumento da morbidade e mortalidade perinatal (Pollack; Divon,1992).

Duas expressões, "retardo" e "restrição", têm sido utilizadas para definir este fenômeno. Entretanto, na literatura atual tem se utilizado mais o termo "restrição", já que este define melhor uma condição que é uma limitação, mais que um atraso no crescimento (Larsen,2001).

A mortalidade perinatal entre $\mathrm{RN}$ com CIUR é 5 a 20 vezes maior do que em RN AIG. Morte intra-uterina decorrente da hipoxia fetal crônica, asfixia perinatal e suas consequências, como a encefalopatia hipóxicoisquêmica, a persistência do padrão fetal e a miocardiopatia, além das anomalias congênitas associadas, são os principais fatores associados à alta taxa de mortalidade entre esses fetos (Kliegman,1997). Além disto, a incidência de problemas de desenvolvimento neurológico está 
significantemente aumentada, nos casos de CIUR acompanhados de microcefalia (Georgieff,1998).

Em muitos estudos recentes, os autores tendem a usar como sinônimos os termos pequeno para a idade gestacional (PIG) e CIUR. Battaglia e Lubchenco (1967) descreveram três categorias de peso ao nascimento, denominadas: PIG (pequenos para a idade gestacional) com peso ao nascimento abaixo do percentil 10 para a idade gestacional ; AIG (adequados para a idade gestacional) com peso ao nascimento entre os percentis 10 e 50; GIG (grandes para a idade gestacional) acima do percentil 90. No grupo abaixo do percentil 10, há RN com restrição de crescimento, entretanto, esta classificação ignora o inerente potencial de crescimento, havendo aproximadamente $10 \%$ de $\mathrm{RN}$ pequenos e bem nutridos, classificados como PIG. Por outro lado, RN originalmente destinados a terem pesos muito maiores ao nascimento, podem ser classificados como AIG ou mesmo GIG, apesar de menores que o esperado (Beattie; Johnson,1994; Goldenberg; Cliver,1997).

Assim, o termo crescimento intra-uterino restrito deve ser reservado aos fetos, onde há evidências definitivas de falta de crescimento ou nos casos onde houve perda de peso intra-útero (Altman; Hytten,1989).

Além disso, se os $\mathrm{RN}$ forem classificados apenas pela adequação do peso de nascimento à idade gestacional, muitos destes, com diagnóstico de PIG, serão nutricionalmente normais e não terão aumento dos riscos perinatais, não tendo, portanto, crescimento intra-uterino restrito. Alguns autores recomendam a classificação neonatal baseada no estado nutricional 
e não no peso ao nascimento, para predizer a ocorrência de morbidade perinatal (Patterson; Pouliot,1987).

As causas de CIUR podem ser divididas em: causas fetais (por exemplo, as infecções congênitas e anormalidades genéticas), causas placentárias (insuficiência placentária e anormalidades de placentação) e maternas (alterações cardiovasculares, doença hipertensiva específica da gestação e desnutrição materna, por exemplo) (James,1990; Pollack; Divon, 1992).

O crescimento e desenvolvimento do feto intra-útero reflete um balanço entre $\mathrm{O}$ feto, a placenta e a mãe. $\mathrm{O}$ feto depende de um adequado suprimento materno de nutrientes e de oxigênio, e da capacidade da árvore vascular materna de fornecê-lo à unidade feto-placentária. Qualquer alteração na homeostase materna, poderá ter efeitos adversos no crescimento e desenvolvimento fetais (James,1990; Pollack; Divon,1992).

A fisiopatologia do CIUR não está completamente entendida. A interação entre a insulina fetal, o fator de crescimento insulina-símile (IGF) e o metabolismo da glicose, têm papel chave no crescimento fetal, principalmente no 3 o trimestre da gestação (Nieto-Diaz et al.,1996; Gluckman et al.,1996).

Estudos em animais demonstraram o papel central do sistema IGF, agindo através do receptor IGF-I, na regulação do crescimento fetal. Foi observada uma correlação entre os níveis sanguíneos de IGF-I em cordão umbilical e o tamanho ao nascimento. O principal estímulo para liberação de IGF-I, principalmente ao final da gestação, é a disponibilidade de glicose via 
placentária. Este efeito da glicose é mediado via aumento da secreção de insulina. Assim, o fator dominante que regula o crescimento fetal durante o final da gestação, parece ser a disponibilidade de glicose, que altera a liberação de insulina pelo feto, modificando a secreção de IGF-I (Gluckman et al.,1996) .

Crianças com desnutrição proteico-calórica mostram níveis aumentados de Hormônio de Crescimento $(\mathrm{GH})$ e de IGF-I, talvez associados à diminuição da insulina circulante ou menor disponibilidade de substratos (Nieto-Diaz et al.,1996).

A liberação de IGF-I ao final da gestação também é controlada pelo $\mathrm{GH}$, que tem um pequeno papel sobre o crescimento fetal. Os receptores de $\mathrm{GH}$ estão presentes nos tecidos fetais, mas com menor expressão do que na vida pós-natal. O eixo somatotrófico fetal, entretanto, é sensível à regulação normal: a menor nutrição intra-útero leva à elevação dos níveis plasmáticos de $\mathrm{GH}$ e, assim, em $\mathrm{RN}$ com CIUR, os níveis de $\mathrm{GH}$ tendem a estar elevados (Gluckman et al.,1996). Durante períodos de menor disponibilidade de glicose ao feto, esta maior produção de GH poderia estimular a lipólise e aumentar a circulação de ácidos graxos livres (Nieto-Diaz et al.,1996).

Em estudo caso-controle de $31 \mathrm{RN}$ com CIUR, foram observados menores níveis de insulina e IGF-I em cordão umbilical, devidos provavelmente à menor disponibilidade de substratos para o feto, por alterações metabólicas ou insuficiência placentária, mais do que por diminuição da transferência placentária em uma mãe malnutrida. Isto pôde ser comprovado pelos menores níveis de glicose, triglicerídeos, colesterol e 
albumina em fetos com CIUR, quando comparados a RNT sem CIUR, sem diferenças entre os grupos nos indicadores maternos nutricionais, como triglicérides e colesterol. Os níveis de GH em cordão umbilical e líquido amniótico foram maiores nos $\mathrm{RN}$ com CIUR e mostraram relação negativa significante com o peso de nascimento; quanto menor o peso, maiores os níveis de GH (Nieto-Diaz et al.,1996).

Evidências recentes demonstraram que IGF-I é um potente indutor do desenvolvimento de oligodendrócitos no cérebro, que é responsável pela síntese de mielina. Poderia se fazer a hipótese de que os baixos níveis de IGF-I em RN com CIUR estejam relacionados a distúrbios do desenvolvimento intelectual desses RN (Nieto-Diaz et al.,1996).

\subsubsection{Diagnóstico}

\subsubsection{Fetal}

O acompanhamento pré-natal adequado é de extrema importância para a detecção de alterações do crescimento fetal. A presença de fatores de risco, a avaliação do ganho de peso materno, a medida da altura uterina e a ultra-sonografia são parâmetros importantes para diagnóstico da presença de CIUR (Chiswick,1985; Bittar et al.,2002).

É importante destacar que, para um acompanhamento ultra-sonográfico adequado, é necessário primeiramente a determinação exata da idade gestacional. $\mathrm{O}$ exame realizado entre a $7 \underline{a}$ e $12^{\underline{a}}$ semanas permite 0 
conhecimento da idade gestacional com margem de erro de 3 a 4 dias, permitindo a valorização das medidas uterinas e dos exames ultrasonográficos subsequentes (Takeda; Iwashita,1997; Bittar et al.,2002).

Várias estruturas fetais são medidas para diagnóstico intra-uterino do CIUR através da ultra-sonografia (Goldenberg; Cliver,1997). A estimativa do peso fetal no entanto, permanece como um importante parâmetro para definição de um crescimento fetal limitado (Ott,2002). É possível que, utilizando-se várias medidas possa se obter um padrão de velocidade de crescimento intra-uterino e, assim, um desvio negativo em relação ao normal, possa sugerir o diagnóstico de CIUR (Larsen,2001).

A medida do volume de líquido amniótico tem grande valor no diagnóstico do CIUR. Na presença de oligoâmnio, o CIUR esteve presente em 96\% dos casos (Takeda; Iwashita,1997; Bittar et al.,2002).

Apesar da ajuda da ultra-sonografia no diagnóstico do CIUR, sua confirmação somente poderá ocorrer após o nascimento (Bittar et al.,2002).

\subsubsection{Neonatal}

\section{- Exame Clínico}

O exame físico de RN com suspeita de CIUR, deve incluir a procura de sintomas de hipoglicemia, anomalias associadas e efeitos da hipoxia intrauterina crônica sobre os sistemas renal, cardiovascular, pulmonar e cerebral (Beattie; Johnson,1994). 
Frequentemente, encontra-se nesses $\mathrm{RN}$ a cabeça relativamente grande em relação ao restante do corpo, a fontanela bregmática grande, diminuição de tecido celular subcutâneo, pele fina, abdome escavado, descamação em mãos e pés, que aparentam ser grandes em relação ao restante do corpo. São crianças ativas e vigorosas, a menos que estejam deprimidas por asfixia, acidose ou hipoglicemia prévios (Beattie; Johnson, 1994).

\section{- Antropometria}

A avaliação do estado nutricional é geralmente baseada no peso, estatura, circunferência do braço e espessura da prega cutânea e suas relações, como perímetro braquial/cefálico, índice ponderal, índice de massa corpórea e outros (Beattie; Johnson,1994).

A presença de CIUR também pode ser estabelecida com base na taxa de crescimento fetal, definida como a razão entre o peso encontrado e o peso estimado do percentil 50 para determinada idade gestacional $\left(P / P_{50}\right)$. Os RN são classificados como sem CIUR se a razão estiver entre 0,90 a 1,10, CIUR leve entre 0,80 a <0,85, CIUR moderado entre 0,75 e <0,80 e CIUR grave se $<0,75$. Fornece importante informação em relação a porcentagem de peso abaixo do esperado para a média (Kramer et al.,1989). 
Todas essas variáveis são intrinsecamente dependentes da idade gestacional, que deve ser conhecida antes da aplicação do valor de referência apropriado (Beattie; Johnson,1994).

\subsubsection{Repercussões sobre o feto e o RN}

O estado metabólico de fetos com CIUR é bem definido, seja experimentalmente, principalmente em ovelhas, seja em humanos, como consequência de medidas realizadas por cordocentese. Estes fetos geralmente apresentam acidose metabólica, secundária ao aumento de produção de lactato e inadequada transferência de glicose pela placenta, o que também pode levar à hipoglicemia. Ao final da gestação, em condições de extrema insuficiência placentária, o feto se torna catabólico, a gliconeogênese fetal é induzida, e glicose e aminoácidos são fornecidos do feto para a placenta, para manter a função placentária. O feto geralmente apresenta hipercapnia, devido a falha placentária no clareamento do dióxido de carbono, geralmente acompanhado de hipoxemia, resultante de inadequada oferta de oxigênio (Hawdon; Platt,1993; Gluckman et al.,1996).

Esses achados confirmam o conceito de que as reservas fetais podem estar reduzidas antes do parto e que a hipoxia e acidose ao nascimento podem não ser necessariamente o resultado de eventos intra-parto (Soothhill et al.,1987). 
A hipoglicemia é um distúrbio metabólico frequente nesses $\mathrm{RN}$, sendo a principal causa, a diminuição dos depósitos hepáticos de glicogênio, além da redução da capacidade de gliconeogênese (Kliegman,1997).

Estudos em humanos mediram as concentrações de nutrientes nos vasos umbilicais de fetos com CIUR logo após o parto, observando menores concentrações de aminoácidos, principalmente os essenciais, como: valina, leucina $\mathrm{e}$ isoleucina em $\mathrm{RN}$ pequenos para a idade gestacional(PIG) em relação a RN AIG (Cetin et al.,1988).

Foi observada uma redução do conteúdo mineral ósseo em RN PIG em relação a RN AIG, proporcional à redução do tamanho corpóreo. Diminuição das concentrações séricas de osteocalcina, proteína óssea específica sintetizada pelos osteoblastos, que reflete a atividade osteoblástica com alta sensibilidade, também foram encontradas nesses RN. As concentrações de 1,25 $(\mathrm{OH})_{2}$ D foram menores em RN PIG em relação aos AIG. Foi sugerido que a redução do fluxo placentário pudesse levar a uma diminuição da produção placentária de $1,25(\mathrm{OH})_{2} \mathrm{D}$, além de redução da massa renal fetal. O menor conteúdo ósseo e a diminuição da osteocalcina, que reflete a formação óssea, poderia ser consequente à menor ação da vitamina $D$, possivelmente decorrente de sua ação no transporte de Ca através da placenta (Namgung et al.,1993).

Em relação ao metabolismo do $\mathrm{Ca}$ e $\mathrm{Mg}$, os estudos são ainda discordantes. A redução do suprimento sanguíneo placentário, observado frequentemente no CIUR, poderia causar uma diminuição do transporte 
placentário de $\mathrm{Mg}$, e consequente redução de suas concentrações séricas (Tsang, 1972b).

Por outro lado, a menor massa renal existente nesses $\mathrm{RN}$, está associada à menor produção de $1,25(\mathrm{OH})_{2} \mathrm{D}$ e à "resistência" ao $\mathrm{PTH}$, com aumento das concentrações séricas deste hormônio, o que poderia agravar a desmineralização óssea e levar a uma elevação da concentração plasmática de Mg (Namgung et al.,1993).

A hipoxemia intra e extra-uterinas a que estes $\mathrm{RN}$ estão mais frequentemente expostos, também poderia gerar um aumento das concentrações séricas de Mg (Soothhill et al.,1997).

Estudos epidemiológicos mostraram que RN com CIUR, por desnutrição intra-uterina, estão predispostos a várias doenças na vida adulta, como: diabetes mellitus não insulino-dependente, hipertensão, hiperlipidemia e doenças cardiovasculares. Para explicar essa associação, o conceito de reprogramação foi introduzido: a desnutrição intra-uterina induziria a uma adaptação fetal, destinada a minimizar o gasto energético para 0 crescimento e favorecer a sobrevivência e desenvolvimento de órgãos vitais, como o cérebro. Quando a exposição a um suprimento insuficiente de nutrientes ocorresse durante períodos críticos da vida fetal, o desenvolvimento e função do sistema endócrino ficaria permanentemente afetado (Henriksen;Clausen,2002; Cianfarani et al.,2002). 


\subsection{Asfixia perinatal}

A asfixia perinatal aguda é a maior causa de morte e lesão cerebral em RN. Muitos morrem no período neonatal e 20 a $30 \%$ dos sobreviventes têm deficiências neurológicas a longo prazo (Engidawork et al.,2001). A origem e o momento da lesão cerebral nem sempre são bem estabelecidos (Rivkin,1997; Du Plessis; Johston,2002).

Entre RNT, aproximadamente $1 / 1000$ morrem ou sofrem danos neurológicos consequentes a essa condição (Levene et al.,1995).

Existem alguns parâmetros que podem ser utilizados como referência para que seja determinado o risco de ocorrência de asfixia perinatal grave. No entanto, até o momento, ainda não foi estabelecido o referencial ideal para indicação deste distúrbio.

- $\mathbf{p H}$

A acidose metabólica decorre da elevação dos níveis séricos de lactato, consequente à glicólise anaeróbia em resposta à hipoxia. Não há um consenso sobre o valor de corte para se considerar a presença de acidemia fetal, variando, segundo alguns autores, de 7,0 a 7,15. Outros, definem 0 valor do $\mathrm{pH}$ inferior a 7,2 em sangue de cordão umbilical ou vasos de couro cabeludo fetal, na ausência de acidose materna, como anormal e indicativo de asfixia perinatal (Anslow,1998; Nordstrom; Arulkumaran,1998). 
Embora a sensibilidade da medida do $\mathrm{pH}$ para predizer o prognóstico neonatal seja baixa, esta aumenta quando associada a um escore de Apgar de $5^{\circ}$ minuto entre 0 a 3 (Casey et al.,2001).

\section{- Índice de Apgar}

Desde sua apresentação em 1953, foi considerado como o ponto principal para definição da asfixia perinatal. Entretanto, um escore de Apgar baixo de 1ㅇ minuto não se correlacionou com o prognóstico futuro. $\mathrm{O}$ de $5^{\circ}$ minuto e, principalmente, a alteração do escore entre 1 e 5 minutos, constitui um índice útil da eficácia da ressuscitação. Um valor de 0 a 3 com 5 minutos está associado a um risco aumentado de paralisia cerebral em RNT, embora esse aumento esteja entre 0,3 e 1\%. Já um escore de Apgar de 7 a 10 no 5o minuto é considerado normal, não estando associado a um risco aumentado de posterior disfunção neurológica (AAP,1996; Casey et al.,2001).

Além disso, apenas $20 \%$ dos RN com notas inferiores a 7 , no 5o minuto, têm $\mathrm{pH}<7,1$ no sangue da artéria umbilical e, por outro lado, dentre aqueles com acidemia em sangue de artéria umbilical no momento do parto, somente 14\% tem nota de Apgar no 5ㅇ minuto $\leq 7$ (Martin-Ancel et al.,1995; Nordstrom; Arulkumaran,1998; AAP,1996).

A correlação do Índice de Apgar com o prognóstico neurológico aumenta quando o escore permanece 0 a 3 com 10, 15 e 20 minutos (AAP, 1996). 
O Índice de Apgar não pode estabelecer sozinho, a hipoxia como a causa da paralisia cerebral. Um RNT com Apgar de 0 a 3 com 5 minutos, com melhora do índice para 4 ou mais com 10 minutos, tem $99 \%$ de chance de não ter paralisia cerebral aos 7 anos de idade. Por outro lado, $75 \%$ das crianças com paralisia cerebral tem escore de Apgar normal ao nascimento (AAP, 1996).

\section{- Disfunção de múltiplos órgãos}

A asfixia perinatal é frequentemente seguida pela disfunção de um ou mais órgãos, tendo se observado envolvimento de pelo menos um órgão em $82 \%$ dos RN com asfixia perinatal grave. O Sistema Nervoso Central foi o órgão mais frequentemente envolvido, seguido dos rins, pulmão, miocárdio e trato gastrointestinal (Martin-Ancel et al.,1995).

A deficiência tecidual de oxigênio $\left(\mathrm{O}_{2}\right)$ parece ser a causa da lesão neurológica decorrente da lesão hipóxico-isquêmica. Esta geralmente é causada pela hipoxemia e isquemia. A asfixia denota uma diminuição da troca gasosa, que resulta em deficiência de $\mathrm{O}_{2}$ sanguíneo e excesso de dióxido de carbono $\left(\mathrm{CO}_{2}\right)$, levando à acidose. A persistência da asfixia sempre resulta em hipotensão e isquemia (Rivkin,1997).

O evento causador da asfixia pode ocorrer no período anteparto, intraparto ou pós- parto. As lesões anteparto, como a hemorragia materna, levando à hipotensão fetal, contribuem em $20 \%$ dos casos de EIH. Os eventos intra-parto, como descolamento prematuro de placenta, ruptura 
uterina, parto traumático, podem ser responsáveis por $35 \%$ dos casos de EHI. Outros $35 \%$ dos RN com sinais de EIH, marcadores de estresse ante ou intra-parto, como: diabetes materno, restrição do crescimento ou infecção materna, não são encontrados. Dificuldades pós-parto, como comprometimento cardiovascular, apnéias recorrentes e persistência da circulação fetal, são observados em aproximadamente $10 \%$ dos casos de EIH (Rivkin,1997).

\subsubsection{Repercussões sobre o Sistema Nervoso Central}

O feto reage à déficiência de $\mathrm{O}_{2}$, através da ativação do sistema adrenérgico-simpático e redistribuição do débito cardíaco para órgãos vitais, como: coração, cérebro e glândulas supra-renais. A diminuição do $\mathrm{O}_{2} \mathrm{e}$ aumento do dióxido de carbono levam à vasodilatação do leito vascular cerebral e hiperperfusão. A persistência da hipoxemia acaba com as reservas de energia, o que ocasiona redução do débito cardíaco e da pressão arterial, levando a uma perda da autoregulação cerebral e consequente diminuição do fluxo sanguíneo cerebral. A presença de hipoxia e isquemia acabam levando à lesão tecidual (Berger; Garnier,2000).

A função normal do cérebro depende de um adequado suprimento de oxigênio para manutenção do metabolismo de energia. Assim, durante a hipoxemia moderada, o feto é capaz de manter níveis adequados de ATP, aumentando a taxa de glicólise anaeróbia; já uma aguda redução do suprimento de $\mathrm{O}_{2}$ levará a uma quebra do metabolismo energético do 
cérebro em alguns minutos. Os gradientes de Sódio ( $\mathrm{Na}$ ), potássio (K) e Ca através das membranas celulares não poderá mais ser regulado pela bomba de $\mathrm{Na} / \mathrm{K}$, que não é capaz de funcionar sem energia. A célula depletada de energia favorece a entrada de $\mathrm{Na}$ e $\mathrm{Cloro}(\mathrm{Cl})$ e água, levando ao edema celular (citotóxico) (Berger; Garnier,2000).

A perda de potencial de membrana leva também a um influxo maciço de Ca para o interior da célula, com lesão celular por ativação de proteases, lipases e endonucleases (Berger; Garnier,2000).

A lesão neuronal é causada, em parte, pela excessiva liberação e reduzida captação de glutamato, que se seguem à asfixia. O glutamato ativa receptores pós-sinápticos, que formam canais iônicos permeáveis a cátions. O receptor N-metil-D-aspartato (NMDA) é particularmente importante no desenvolvimento da lesão neuronal pós-asfixia. Altas concentrações de glutamato causam abertura dos canais NMDA, permitindo excessiva entrada de Ca para dentro do neurônio, com lesão neuronal irreversível. O cérebro imaturo é particularmente sensível à excessiva liberação do glutamato, uma vez que uma maior proporção de receptores NMDA está presente no cérebro humano em desenvolvimento, comparado ao cérebro adulto (Levene et al.,1995; Berger; Garnier,2000).

Durante a fase de isquemia, a quebra da fosforilação oxidativa, rapidamente diminui as reservas de fosfatos de alta energia, com acúmulo de adenosina e hipoxantina. Durante a reperfusão, esses produtos são metabolizados pela xantina oxidase, com produção de xantina e ácido úrico. A quebra da hipoxantina pela xantina oxidase na presença de $\mathrm{O}_{2}$, produz os 
radicais superóxido. Além disso, o aumento do $\mathrm{Ca}$ intracelular, que ocorre durante a isquemia, ativa a NO-sintetase, que produz o óxido nítrico. Este acaba gerando radicais livres, com piora da lesão tecidual (Berger; Garnier,2000).

\subsubsection{Repercussões metabólicas}

Algumas repercussões da asfixia já estão bem estabelecidas, como a hipoglicemia, causada principalmente pela redução dos estoques de glicogênio, decorrente do metabolismo anaeróbio. Também a acidose metabólica, com redução do $\mathrm{pH}$ sanguíneo e dos níveis séricos de bicarbonato e elevação das concentrações séricas de lactato (Martin-Ancel et al.,1995).

A hiponatremia também pode estar presente, por secreção inapropriada de hormônio antidiurético (Martin-Ancel et al.,1995).

Em relação ao metabolismo do $\mathrm{Mg}$, os estudos ainda são controversos e há poucos referentes à homeostase do $\mathrm{Mg}$ em $\mathrm{RN}$ com asfixia perinatal grave.

A presença de níveis séricos diminuídos de $M g$ nas $1 \underline{\text { as }} 48$ horas foi demonstrada em RN com ElH grave (Ilves et al.,2000). Concentrações séricas de $\mathrm{Mg}$ menores nas $1 \underline{\text { as }} 72$ horas de vida em RN com Apgar 1 으 min $<6$ em relação ao grupo controle, também foram observadas por Tsang et al.(1974). Da mesma forma, verificou-se menor conteúdo de Mg em eritrócitos de RN com EIH, quando comparados ao grupo controle (Harrison; Peat,1997). 
Esse menor valor do Mg poderia ser devido ao aumento da quebra endógena de glicogênio e proteínas, decorrentes da hipoxia, o que geraria uma sobrecarga de $\mathrm{P}$, resutando em hipocalcemia e hipomagnesemia, provavelmente pelo aumento da deposição de Ca no osso, diminuição da ação da paratireóide e aumento da ação da calcitonina (Tsang et al.,1974).

A administração de maiores quantidades de bicarbonato para correção da acidose, pode estar associada a um movimento do $\mathrm{Ca}$ e $\mathrm{Mg}$, do sangue para o osso, e a uma diminuição da reabsorção óssea (Tsang et al.,1974).

O PTH é o principal fator determinante do movimento de $\mathrm{Ca}$ do osso para o líquido extracelular e sua ação pode estar diminuída na presença de um aumento do $\mathrm{P}$ e/ou diminuição do $\mathrm{Mg}$. Além disso, a hipoxia também poderia diminuir a capacidade funcional das glândulas paratireóides (Tsang et al.,1974).

Hipermagnesemia esteve presente em RNT com asfixia grave, mas sem sinais de EIH ou com sinais de EIH leve (Ilves et al.,2000). Em animais submetidos à asfixia perinatal, foi observado um aumento dos níveis séricos de $\mathrm{Mg}$, possivelmente induzido pela presença de acidose (Classen et al.,1971).

A insuficiência renal aguda, secundária à asfixia, poderia diminuir a excreção renal de Mg e reduzir a reabsorção de $\mathrm{Na}$ e Ca (Ilves et al.,2000). Além disso, a hipermagnesemia poderia ser consequente à quebra temporária de ATP, induzida pela elevada demanda energética e liberação do Mg intracelular (Olofsson et al.,2001). 


\subsection{Justificativa da Pesquisa}

A importância do $\mathrm{Mg}$ como íon participante de diversas funções celulares, com repercussões sobre vários órgãos e sistemas, mas principalmente sobre o metabolismo corpóreo em geral, torna o estudo deste no período perinatal uma necessidade, por se tratar de uma fase na qual o resultado final depende de interação entre fatores maternos, placentários e fetais.

Considerando-se que o Mgi é a fração biologicamente ativa do $\mathrm{Mg}$, o desenvolvimento recente de um eletrodo íon-seletivo permitiu a determinação rápida das concentrações de Mgi em pequenas amostras de sangue, o que possibilitou a realização de estudos para determinação desta fração no período neonatal e incorporou avanços no conhecimento dos mecanismos de ação do Mg (Marcus et al.,1997).

A presença de alguns distúrbios no período neonatal, como o Crescimento Intra-uterino Restrito e a Asfixia Perinatal, com várias repercussões importantes sobre o $\mathrm{RN}$, poderiam potencialmente levar a distúrbios da homeostase do $\mathrm{Mg}$, ainda não totalmente esclarecidos. A presença de hipo ou hipermagnesemia associada a essas condições, poderia acarretar uma maior morbidade. Assim, tornam-se necessárias investigações que visem analisar os valores de Magnésio iônico e total, bem como se estabelecer medidas de detecção precoce destas alterações. 
2 - OBJETIVOS 


\subsection{Objetivo Geral}

Analisar, em recém-nascidos de termo, a influência do crescimento intrauterino restrito e da asfixia perinatal, sobre os níveis séricos de Magnésio iônico e total, durante a primeira semana de vida.

\subsection{Objetivos Específicos}

Em RNT, sem CIUR:

2.2.1 Descrever os níveis de $\mathrm{Mg}$ iônico e total em sangue de cordão umbilical, 3으 e 7으 dias de vida;

2.2.2 Comparar os valores obtidos com os de RNT com CIUR;

2.2.3 Comparar os valores obtidos entre os RNT, com e sem asfixia perinatal. 
3-CASUÍSTICA E MÉTODOS 


\subsection{Casuística}

Conduziu-se um estudo prospectivo, no qual foram incluídos 95 RNT, no período de 11/05/2001 a 10/06/2003: 89 admitidos no Berçário Anexo à Maternidade, da Divisão de Pediatria Clínica Intensiva e Neonatal do Instituto da Criança "Prof. Pedro de Alcântara", do Hospital das Clínicas da Faculdade de Medicina da Universidade de São Paulo (BAM-HC-FMUSP) e $6 \mathrm{RN}$ de duas unidades neonatais, situadas no Hospital Geral de Pedreira e Hospital Estadual de Interlagos.

Esta pesquisa foi aprovada pelas Comissões de Ética do Departamento de Pediatria e pela de Análise de Projetos de Pesquisa - CAPPesq, da Diretoria Clínica do Hospital das Clínicas e da Faculdade de Medicina da USP. Além destas, também teve aprovação das Comissões de Ética dos referidos Hospitais.

Recebeu auxílio pesquisa da Fundação de Amparo à Pesquisa do Estado de São Paulo - FAPESP - processo n 2000/13481-7.

\section{Critérios de inclusão :}

- Recém-nascido de termo (Idade gestacional entre 37 e 41 6/7 semanas); 
- Termo de Consentimento Livre e Esclarecido, assinado pelos pais ou responsáveis.

\section{Critérios de exclusão :}

- Más-formações maiores, anomalias genéticas, infecções congênitas;

- Gemelaridade;

- Realização de exsanguineotransfusão na $1^{\text {a }}$ semana de vida;

- Doença materna capaz de interferir no metabolismo do Mg, como o diabetes mellitus ou gestacional e hiperparatireoidismo;

- Uso de medicações, durante a gestação ou parto, que pudessem afetar o metabolismo do $\mathrm{Mg}$, como o sulfato de $\mathrm{Mg}$.

Foram considerados como RNT, aqueles com idade gestacional compreendida entre 37 e 41 6/7 semanas, segundo critérios da Organização Mundial de Saúde, em 1961. A idade gestacional ao nascimento foi definida pela data da última menstruação, quando esta diferiu em até 2 semanas em relação à indicada pela ultra-sonografia fetal, caso esta tivesse sido realizada até 20 semanas de gestação. $\mathrm{Na}$ ausência desta ou se esta foi realizada após essa idade gestacional, a informação materna indicou a idade gestacional definitiva, se diferiu da apontada pelo método de Capurro (1978) em até 2 semanas. Quando esta diferença foi maior, o método de avaliação neonatal foi o escolhido. 
Os RN admitidos no estudo foram divididos em dois grupos de estudo :

\section{- Grupo I :}

Constituído por RNT sem CIUR;

\section{- Grupo II :}

Constituído por RNT com CIUR.

O diagnóstico de CIUR baseou-se num peso de nascimento situado abaixo do percentil 10 para a curva de referência e, além disso, numa relação entre o peso de nascimento e o peso estimado no percentil 50 para cada idade gestacional, inferior a 0,85 (Índice de Kramer,1989). Os valores de referência para os percentis 10 e 50 foram obtidos a partir do estudo de Ramos (1983).

Cada um desses grupos foi subdividido em 2 subgrupos, de acordo com a presença (Grupos lb e llb) ou não (Grupos la e lla) de asfixia perinatal.

O critério utilizado para determinação da presença de asfixia perintal foi o Apgar de 5 o minuto de vida $\leq 6$, associado à presença de uma ou mais das seguintes características:

- pH de sangue de cordão umbilical $<7,2$;

- sequelas neurológicas no período neonatal imediato e/ou USG transfontanela anormal;

- disfunção de um ou mais órgãos. 


\subsection{Desenho do Estudo}

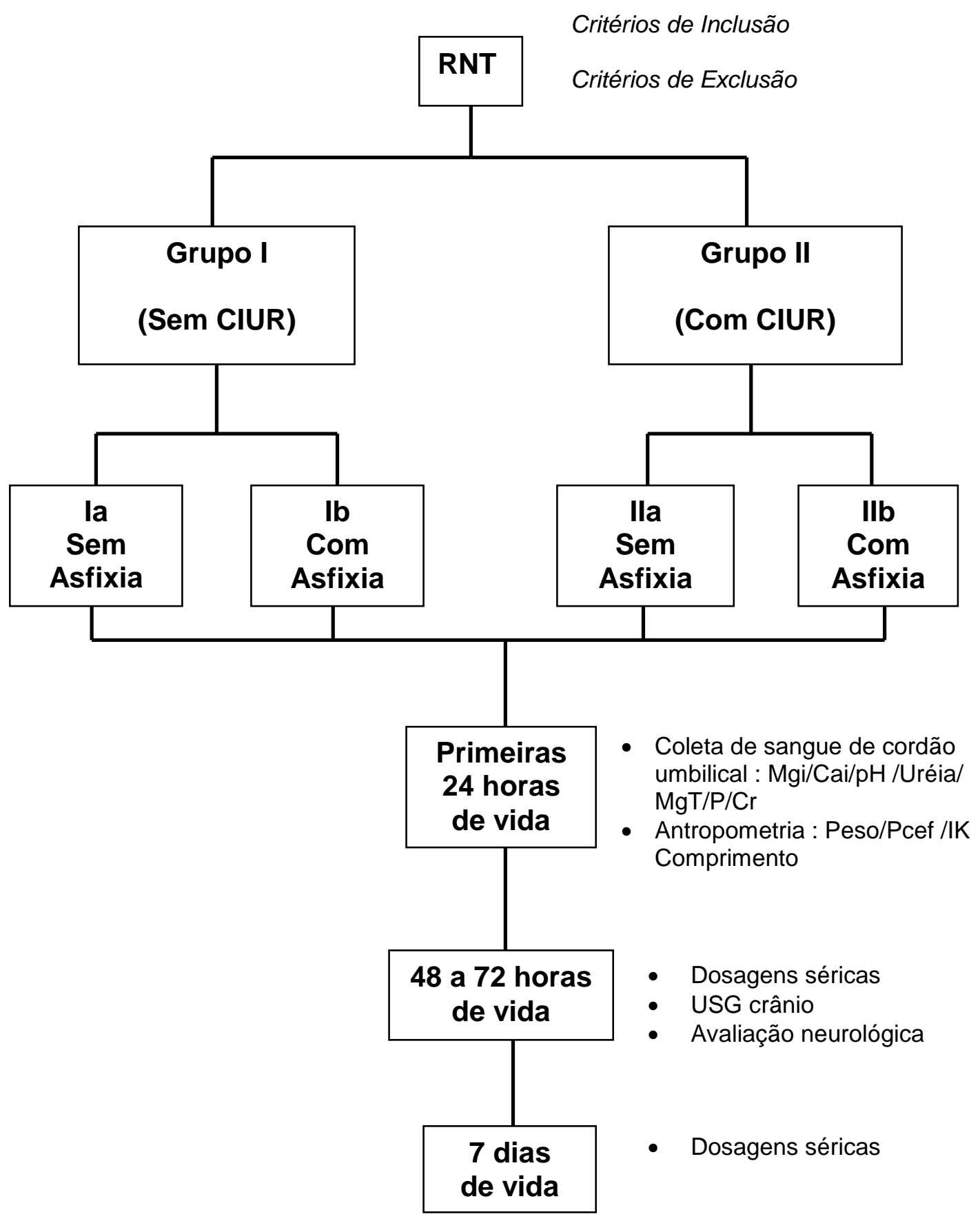




\subsection{Métodos}

\subsubsection{Informações sobre a gestação, características maternas e parto}

Foram obtidas pelas anotações do prontuário materno, completadas pela informação verbal fornecida pela mãe à autora, utilizando-se, para registro, formulário estruturado, conforme Anexo $\mathrm{A}$.

\subsubsection{Informações sobre a evolução pós-natal do RN}

As informações sobre a evolução do RN na sala de parto e no período de internação no Berçário foram obtidas pelas anotações feitas no prontuário do RN e/ou acompanhadas pela autora, utilizando-se para registro, formulário estruturado conforme Anexo $\mathrm{A}$. Todos os $\mathrm{RN}$ foram reanimados ao nascimento, conforme a rotina do BAM-HC-FMUSP e seguiram os procedimentos de rotina do Berçário.

Os RN sem asfixia perinatal, receberam aleitamento materno exclusivo. Os com asfixia, permaneceram em jejum nas primeiras 48 horas de vida, recebendo soro glicosado sem eletrólitos. Após, iniciaram nutrição parenteral composta de uma oferta de $\mathrm{Mg}$ de aproximadamente $1 \mathrm{mEq} / \mathrm{kg} / \mathrm{dia}$.

\subsubsection{Medidas antropométricas}

A avaliação antropométrica, com exceção do peso, foi efetuada nas primeiras 24 horas de vida do RN, após sua estabilização clínica. 
- Peso

A medida do peso foi realizada após o nascimento, em balança Filizola, com precisão de 5 gramas.

\section{- Comprimento}

Foi medido com antropômetro de madeira, calibrado em $\mathrm{mm}$, tendo uma parte fixa, colocada na posição cefálica, e outra móvel, na posição dos pés. O RN era posicionado em decúbito dorsal, com a cabeça centralizada, joelhos estendidos, do vértex ao calcâneo.

\section{- Perímetro cefálico}

A medida foi realizada, utilizando-se fita métrica inextensível, passandoa pela região acima dos sulcos supra-orbitários e pela região mais saliente do osso occipital.

\section{- Relação P/P50}

Foi calculada através da razão entre o peso encontrado e o estimado do percentil 50 para determinada idade gestacional. O diagnóstico de CIUR foi feito após o nascimento, na presença de uma razão $<0,85$ (Kramer et al.,1999). 


\subsubsection{Avaliação laboratorial}

Foram realizadas determinações de Magnésio iônico(Mgi), Cálcio iônico(Cai), Uréia(U), pH, Magnésio Total(MgT), Fósforo(P) e Creatinina(Cr), em sangue de cordão umbilical, no 3e e no 7ํ dias de vida, no Laboratório do Instituto da Criança, Hospital das Clínicas, FMUSP.

O volume total de sangue obtido em cada coleta foi de $2 \mathrm{ml}$, que foi dividido em 2 alíquotas:

- $1 \mathrm{ml}$ em seringa heparinizada (S-Monovette ${ }^{\circledR}$ para gasometria com $50 U$ l de heparina de lítio/ml sangue, balanceada com Ca; SARSTEDT), para dosagem de Mgi, Cai, U e pH. Esta amostra foi encaminhada ao laboratório em recipiente térmico, resfriado com gelo e a análise foi realizada, em até 1 hora após essa coleta.

- $1 \mathrm{ml}$ em tubo seco com gel para dosagem de P, Cr e MgT. Após retração do coágulo, com o material em temperatura ambiente durante 1 hora, o soro foi separado por centrifugação durante 10 minutos, a $3000 \mathrm{rpm}$, sendo a seguir aliquotado em 2 tubos Eppendorfs com cerca de $500 \mu$ cada e armazenado em temperatura $\mathrm{a}-20^{\circ} \mathrm{C}$. 


\subsubsection{Técnica de coleta de sangue}

\section{- Sangue de cordão umbilical:}

Realizada punção de vaso sanguíneo na face fetal da placenta, logo após sua extração, pela própria autora ou por outro profissional médico qualificado.

- 3o dia de vida (48-72 horas de vida):

Realizada coleta sangüínea pela própria autora, em vaso sanguíneo superficial de fácil acesso, programando-se a coleta para o momento em que era realizada punção venosa para dosagens laboratoriais de rotina nesses RN.

- 70 dia de vida :

A coleta sangüínea do 7ํㅡ dia de vida era realizada de maneira igual à do 3o dia de vida. Nos RN que já haviam obtido alta hospitalar, esta coleta era realizada em consulta de rotina. 


\subsubsection{Determinações laboratoriais}

\subsection{Magnésio iônico / Cálcio iônico / pH / Uréia}

Essas determinações foram feitas pela técnica do eletrodo íon-seletivo, através do equipamento NOVA Stat Profile M Analyzer - NOVA Biomedical Corporation, Waltham, Massachusetts (Nova Biomedical, Stat Profile M Reference Manual, 1998).

\section{- Magnésio iônico e Cálcio iônico}

A medida foi feita através da utilização de eletrodos, com membranas permeáveis seletivas a um único íon de interesse da amostra. Esta permeabilidade seletiva estabelece um potencial elétrico, à medida que o íon abandona seu local na solução. A magnitude deste potencial elétrico é determinada pela diferença de concentração entre os 2 lados da membrana (Nova Biomedical, Stat Profile M Reference Manual, 1998; Dollberg et al.,2001).

- $\mathrm{pH}$

$\mathrm{O} \mathrm{pH}$ foi medido, usando-se uma membrana de vidro seletiva ao íon hidrogênio. Um lado do vidro ficava em contato com uma solução com pH constante e o outro, em contato com a solução de pH desconhecido. Uma 
variação no potencial era desenvolvida, proporcional à diferença de pH entre as soluções. Essa variação no potencial foi medida contra um eletrodo de referência de potencial constante. A magnitude da diferença de potencial era a medida do pH da solução (Nova Biomedical, Stat Profile M Reference Manual,1998; Dollberg et al.,2001).

\section{- Uréia}

O Analisador Stat Profile M utiliza a urease, que foi quimicamente ligada à membrana, para catalisar a conversão da uréia, presente na amostra à amônia e $\mathrm{CO}_{2}$. No pH da amostra, a amônia se converte predominantemente no íon amônio, detectado por um eletrodo seletivo a este íon. A medida é, então, correlacionada à concentração de uréia, presente na amostra original via equação de Nernst (Nova Biomedical, Stat Profile M Reference Manual, 1998; Dollberg et al.,2001).

\subsection{Magnésio Total / Fósforo / Creatinina}

\section{- Magnésio Total}

Determinado pelo Método Colorimétrico de ponto de viragem no equipamento Cobas Mira-Roche Diagnostic System, Inc. Em solução alcalina, o Mg forma um complexo púrpura com o azul de xilidilo. A concentração de Mg foi medida fotometricamente, através da diminuição da 
absorbância de azul de xilidilo (Roche Diagnostic Systems,2000; Farrell,1990b).

\section{- Fósforo}

Dosado pelo Método Colorimétrico Ultra-violeta, pelo Molibdato de amônia, no equipamento Cobas Integra. O fósforo inorgânico reage com o molibdato de amônia, na presença de ácido sulfúrico, formando o fosfomolibdato. A concentração de fosfomolibdato formada é diretamente proporcional á concentração de fósforo inorgânico. Este é medido através da determinação do aumento da absorbância a 340 nm (Farrell,1990a).

\section{- Creatinina}

A dosagem da creatinina sérica foi realizada pela reação cinética tamponada de Jaffé, sem desproteinização, através de automação do equipamento Cobas Integra (Jaffé,1886 APUD Murray,1990).

Este método é baseado na reação de Jaffé, que ocorre entre a creatinina e o íon picrato em meio alcalino, dando origem ao complexo amarelo-vermelho picrato-creatinina. A taxa de formação do corante é diretamente proporcional à concentração de creatinina da amostra, sendo medida pelo aumento da absorbância a um comprimento de onda de $512 \mathrm{~nm}$ (Murray, 1990). 
Para evitar superestimação da creatinina, pela presença de outros compostos plasmáticos, são realizadas modificações, através de substâncias que reduzem o efeito de cromógenos, com o objetivo de aumentar a especificidade para creatinina no plasma (Murray,1990).

\subsubsection{Ultra-sonografia transfontanela}

O exame foi realizado por médico radiologista, em todos os $\mathrm{RN}$ incluídos no estudo, no 2o ou 3ㅇ dia de vida.

Foram considerados como anormais, os achados de aumento difuso da ecogenicidade cerebral, secundário ao edema do cérebro infartado; presença de hemorragia intra ou periventricular além de possíveis lesões focais(Rivkin,1997).

\subsubsection{Avaliação Neurológica}

Foi realizada em todos os $\mathrm{RN}$ incluídos no estudo, no 2 ㅇ ou 3 ㅇa de vida, por Neurologista Pediátrico.

O quadro neurológico da encefalopatia hipóxico-isquêmica (hipotonia/hipertonia, crises convulsivas, alteração dos reflexos tendinosos profundos ou de Moro, coma ou estupor) foi considerado indicativo da presença de asfixia perinatal grave (Rivkin,1997). 


\subsubsection{Análise Estatística}

O $\mathbf{n}$ foi calculado baseado na pressuposição de que os grupos a serem comparados teriam uma diferença na média das concentrações séricas de Mgi de aproximadamente $30 \%$. Para um $\alpha=5 \%$ e um poder de teste de $80 \%$, considerando-se como média do grupo controle $0,23 \mathrm{mmol} / \mathrm{l}$, com um desvio padrão de $0,08 \mathrm{mmol} / \mathrm{l}$, o $\mathbf{n}$ calculado foi de $20 \mathrm{RN}$ em cada grupo.

As médias foram comparadas pelo teste $\mathrm{t}$ de Student, quando as suposições do teste não foram satisfeitas, usou-se o teste não paramétrico de Mann-Whitney.

Para a análise das variáveis contínuas, utilizou-se o Anova one-way ou Kruskall-Wallis.

A comparação de proporções foi realizada pelo Teste Exato de Fischer ou Teste de Qui-Quadrado.

As correlações entre os valores de Mgi e Cai, P, U, Cr, MgT e pH, basearam-se no coeficiente de Correlação de Pearson.

Considerou-se estatisticamente significantes os valores de $p$ menores do que 0,05 .

Os dados foram processados no software Sigma Stat e os gráficos elaborados no Sigma Plot (SIGMA PLOT ${ }^{\circledR}$ Scientific Graphing Software for Windows $^{\text {TM }}$ User's Manual,1994; Fletcher,1996; SIGMA STAT® Statistical Software User's Manual,1997; Dória Filho,1999). 
4 - RESULTADOS 


\subsection{Características da População Estudada}

Foram admitidos no período de estudo, compreendido entre 11 de maio de 2001 e 10 de junho de 2003, no Berçário Anexo à Maternidade, 3.560 recém-nascidos de termo. $32 \mathrm{RN}(1,04 \%)$ apresentaram escore de Apgar no 5o minuto de vida $\leq 6$

Foram incluídos neste estudo 95 RNT, 89 nascidos no Berçário Anexo à Maternidade e 6 RNT, com asfixia perinatal, provenientes do Hospital Geral de Pedreira e do Hospital Geral de Interlagos.

Os RN foram divididos em 2 grupos :

- Grupo I - constituído por 50 RN (52,6\%), sem CIUR;

- Grupo II - constituído por 45 RN (47,4\%), com CIUR.

Cada grupo foi subdidvidido em 2 subgrupos, de acordo com a presença ou não de asfixia perinatal:

- Grupo la : $30 \mathrm{RN}(31,6 \%)$, sem CIUR e sem asfixia perinatal.

- Grupo lb : $20 \mathrm{RN}(21,0 \%)$, sem CIUR e com asfixia perinatal.

- Grupo Ila : $40 \mathrm{RN}(42,1 \%)$, com CIUR e sem asfixia perinatal.

- Grupo IIb : 5 RN (5,3\%), com CIUR e asfixia perinatal.

A idade média das mães foi de $26,36( \pm 1,18)$ anos. 
Em relação ao tipo de parto, 58(61,0\%) mães foram submetidas ao parto cesárea, e 37(39,0\%) ao parto vaginal.

Patologias prévias à gestação, estavam presentes em 31(32,6\%) mães, sendo as mais frequentes: Hipertensão Arterial Sistêmica(HAS), epilepsia, asma, litíase renal e febre reumática.

Patologias durante a gestação ocorreram em 22(23,2\%) mães, sendo a Doença Hipertensiva específica da Gestação (DHEG) a mais frequente. Foi feito o uso de medicação durante a gestação em $22(23,2 \%$ mães. 0 medicamento mais frequentemente utilizado foi o $\alpha$-metil dopa.

Os RN apresentaram uma média de peso de nascimento de $2779,63( \pm 506,63) \mathrm{g}$ e Idade Gestacional média de $39,41( \pm 0,83)$ semanas. 0 comprimento médio foi de $46,58( \pm 2,41) \mathrm{cm}$ e o perímetro cefálico médio ao nascimento foi de $33,43( \pm 1,35) \mathrm{cm}$. A relação $P / P_{50}$ foi $\geq 0,85$ em $50(52,6 \%)$ $\mathrm{RN}$ e $<0,85$ em $45(47,4 \%)$

Destes, 62 RN(65,3\%) eram do sexo masculino e 33(34,7\%), feminino.

O tempo médio de internação foi de 12,1( $\pm 9,3)$ dias.

Foi realizado exame neurológico em $80(84,2 \%) \mathrm{RN}$, sendo $68(85,0 \%)$ normais. A ultra-sonografia(USG) transfontanela foi realizada em $79(83,2 \%) R N$, sendo $65(82,3 \%)$ exames normais.

Entre os grupos, não houve diferença quanto à idade materna, presença de patologias prévias à gestação e ao uso de medicação durante a gestação.

Houve diferenças em relação ao tipo de parto $(p=0,006)$ e à presença de patologias durante a gestação $(p=0,033)$ entre os grupos la (sem CIUR, sem 
asfixia) e Ila (com CIUR, sem asfixia), com maior número de partos cesárea e mães com patologias, como DHEG, CIUR e oligoâmnio no grupo com crescimento intra-uterino restrito. Houve também maior número de partos cesárea no grupo lb (sem CIUR, com asfixia) em relação ao la (sem CIUR, sem asfixia $)(p=0,018)$.

As características maternas, segundo o grupo de estudo, estão descritas na TABELA 1 e, de forma mais detalhada, no Anexo $\mathrm{C}(\mathrm{C} 1-\mathrm{C} 4)$.

TABELA 1 - CARACTERÍSTICAS MATERNAS, DE ACORDO COM O GRUPO DE ESTUDO

\begin{tabular}{|c|c|c|c|c|}
\hline Características & $\begin{array}{c}\text { Grupo } \\
\text { la } \\
\mathrm{n}=30\end{array}$ & $\begin{array}{c}\text { Grupo } \\
\text { lb } \\
n=20 \\
\end{array}$ & $\begin{array}{c}\text { Grupo } \\
\text { lla } \\
\mathrm{n}=40 \\
\end{array}$ & $\begin{array}{c}\text { Grupo } \\
\mathrm{Ilb} \\
\mathrm{n}=5 \\
\end{array}$ \\
\hline \multirow[t]{2}{*}{ Idade(anos) } & 25,97 & 25,40 & 28,08 & 26,00 \\
\hline & $\mathrm{DP}=6,75$ & $\mathrm{DP}=7,61$ & $\mathrm{DP}=7,57$ & $\mathrm{DP}=10,37$ \\
\hline \multicolumn{5}{|l|}{ Parto } \\
\hline Cesárea & $11(36,7 \%)^{*}$ & $15(75,0 \%)$ & $29(72,5 \%)$ & $3(60,0 \%)$ \\
\hline Vaginal & $19(63,3 \%)$ & $5(25,0 \%)$ & $11(27,5 \%)$ & $2(40,0 \%)$ \\
\hline $\begin{array}{c}\text { Patologias prévias à } \\
\text { gestação }\end{array}$ & $12(40,0 \%)$ & $3(15,0 \%)$ & $16(40,0 \%)$ & - \\
\hline $\begin{array}{c}\text { Patologias durante a } \\
\text { gestação }\end{array}$ & $3(10,0 \%)^{\star \star}$ & $4(20,0 \%)$ & $14(35,0 \%)$ & $1(20,0 \%)$ \\
\hline DHEG & $3(10,0 \%)$ & $4(20,0 \%)$ & $5(12,5 \%)$ & - \\
\hline CIUR & - & - & $8(20,0 \%)$ & $1(20,0 \%)$ \\
\hline Oligoâmnio & - & - & $6(15,0 \%)$ & $1(20,0 \%)$ \\
\hline Uso de medicação & $5(16,7 \%)$ & $4(20,0 \%)$ & $13(32,5 \%)$ & - \\
\hline $\begin{array}{l}\text { a/desvio padrão(DP) } \\
\text { lência/frequência relativa }\end{array}$ & & $\begin{array}{l}{ }^{*} p<0,05 \\
{ }^{* *} p<0,0\end{array}$ & $\begin{array}{l}\text { Grupos la } \\
\text { : Grupos la }\end{array}$ & a; la x lb \\
\hline
\end{tabular}


Dentre os RN, não houve diferença entre os grupos em relação ao sexo. A Idade gestacional dos $\mathrm{RN}$ do grupo Ila (com CIUR, sem asfixia) foi menor do que a dos RN do grupo la (sem CIUR, sem asfixia) $(p<0,001)$. Apgar 5은 minuto $\leq 6$ esteve presente em maior número de $\mathrm{RN}$ com asfixia em relação aos sem asfixia $(p<0,001)$.

Os grupos diferiram, também, quanto ao tempo de internação, que foi maior nos grupos com asfixia (lb e llb) do que nos sem asfixia (la e lla) ( $p<0,001)$ e no grupo Ila (com CIUR, sem asfixia) em relação ao la (sem CIUR, sem asfixia) $(p=0,031)$.

Alterações na USG transfontanela estiveram presentes em maior número de RN dos grupos lb (sem CIUR, com asfixia) e Ilb (com CIUR, com asfixia) em relação ao la (sem CIUR, sem asfixia) e Ila (com CIUR, sem asfixia) (Grupos la $x$ lb : $p=0,008$; Ila $\times$ llb: $p=0,012)$. O exame neurológico também foi anormal em maior número de $\mathrm{RN}$ dos grupos com asfixia em relação aos sem asfixia (Grupos la x lb:p=0,001; Grupos Ila x Ilb:p=0,005).

As características dos RN, estão descritas na TABELA 2 e nos Anexos $D(D 1-D 4)$ e $E(E 1-E 4)$. 
TABELA 2 - CARACTERÍSTICAS DOS RN, DE ACORDO COM O GRUPO DE ESTUDO

\begin{tabular}{|c|c|c|c|c|}
\hline Características & $\begin{array}{c}\text { Grupo la } \\
n=30\end{array}$ & $\begin{array}{c}\text { Grupo lb } \\
n=20\end{array}$ & $\underset{n=40}{\text { Grupo Ila }}$ & $\begin{array}{c}\text { Grupo Ilb } \\
n=5\end{array}$ \\
\hline $\begin{array}{l}\text { Idade Gestacional } \\
\text { (semanas) }\end{array}$ & $\begin{array}{c}39,65^{\star} \\
\mathrm{DP}=1,23\end{array}$ & $\begin{array}{c}39,66 \\
D P=1,88\end{array}$ & $\begin{array}{c}38,20 \\
D P=0,97\end{array}$ & $\begin{array}{c}40,11 \\
D P=2,03\end{array}$ \\
\hline Sexo masculino & $21(70,0 \%)$ & $14(70,0 \%)$ & $22(55,0 \%)$ & $5(100,0 \%)$ \\
\hline $\begin{array}{c}\text { Apgar } 5 \circ \text { minuto } \\
>6 \\
\leq 6\end{array}$ & $\begin{array}{c}30(100,0 \%) \bullet \bullet \\
-\end{array}$ & $20(100,0 \%)$ & $\begin{array}{c}40(100,0 \%) \bullet \bullet \\
-\end{array}$ & $5(100,0 \%)$ \\
\hline $\begin{array}{c}\text { Tempo de Internação } \\
\text { (dias) }\end{array}$ & $\begin{array}{c}3,53^{\star *} \\
\mathrm{DP}=1,31\end{array}$ & $\begin{array}{c}20,3 \\
D P=25,7\end{array}$ & $\begin{array}{c}4,58^{\star *} \\
\mathrm{DP}=2,34\end{array}$ & $\begin{array}{c}20,0 \\
D P=14,71\end{array}$ \\
\hline $\begin{array}{c}\text { Exame neurológico } \\
\text { Normal } \\
\text { Anormal }\end{array}$ & $22(100,0 \%) \boldsymbol{\Lambda}$ & $\begin{array}{l}12(60,0 \%) \\
8(40,0 \%)\end{array}$ & $\begin{array}{c}32(97,0 \%) \boldsymbol{\Lambda} \\
1(3,0 \%)\end{array}$ & $\begin{array}{l}2(40,0 \%) \\
3(60,0 \%)\end{array}$ \\
\hline $\begin{array}{c}\text { USG transfontanela } \\
\text { Normal } \\
\text { Anormal }\end{array}$ & $\begin{array}{c}21(95,5 \%) \\
1(4,5 \%)\end{array}$ & $\begin{array}{l}12(60,0 \%) \\
8(40,0 \%)\end{array}$ & $\begin{array}{l}30(93,7 \%) \\
2(6,3 \%)\end{array}$ & $\begin{array}{l}2(40,0 \%) \\
3(60,0 \%)\end{array}$ \\
\hline \multicolumn{5}{|l|}{ - média / desvio padrão(DP) } \\
\hline \multicolumn{5}{|c|}{ - frequência / frequência relativa } \\
\hline \multicolumn{5}{|l|}{${ }^{*} p<0,001$ : Grupos la x Ila } \\
\hline \multicolumn{5}{|c|}{ •• $p<0,001$ :Grupos la $x$ Ib; Ila $x$ Ilb } \\
\hline \multicolumn{5}{|c|}{${ }^{\star \star} p<0,05$ : Grupos la X Ila; la X Ib; Ila X Ilb } \\
\hline$\Delta$ p<0,05: Grupos la X lb; II & & & & \\
\hline - $p<0,05$ : Grupos la x Ib; II & & & & \\
\hline
\end{tabular}

Em relação às características antropométricas, os grupos la (sem CIUR, sem asfixia) x lla (com CIUR, sem asfixia) e lb (sem CIUR, com asfixia) x llb (com CIUR, com asfixia) diferiram quanto ao peso ao nascimento $(\mathrm{p}<0,001)$, comprimento $(p<0,001)$, perímetro cefálico(la $x$ Ila : $p<0,001 ; \mathrm{lb} \times \mathrm{llb}$ : $p=0,025)$ e relação $P / P_{50}(p<0,001)$, conforme o desejado pelo próprio desenho do estudo. Observou-se maior peso ao nascimento, comprimento, perímetro cefálico e $\mathrm{RN}$ com relação $\mathrm{P} / \mathrm{P}_{50} \geq 0,85$ nos grupos sem restrição do crescimento. 
As características antropométricas estão descritas na TABELA 3 e no Anexo F(F1-F4).

TABELA 3 - CARACTERÍSTICAS ANTROPOMÉTRICAS AO NASCIMENTO DOS RN

\begin{tabular}{|c|c|c|c|c|}
\hline Características & $\begin{array}{l}\text { Grupo la } \\
\qquad n=30\end{array}$ & $\begin{array}{c}\text { Grupo lb } \\
\qquad n=20\end{array}$ & $\begin{array}{l}\text { Grupo lla } \\
n=40\end{array}$ & $\begin{array}{c}\text { Grupo Ilb } \\
\qquad n=5\end{array}$ \\
\hline Peso & $3180,00^{*}$ & $3251,75^{\star}$ & 2287,75 & 2399,00 \\
\hline (gramas) & $\mathrm{DP}=280,59$ & $\mathrm{DP}=215,65$ & $\mathrm{DP}=177,50$ & $\mathrm{DP}=373,90$ \\
\hline Comprimento & $48,62^{*}$ & $48,70^{*}$ & 44,69 & 44,30 \\
\hline (cm) & $\mathrm{DP}=1,42$ & $\mathrm{DP}=1,28$ & $\mathrm{DP}=1,79$ & $\mathrm{DP}=2,23$ \\
\hline Perímetro Cefálico & $34,25^{\star}$ & $34,80^{\star *}$ & 31,85 & 32,8 \\
\hline (cm) & $\mathrm{DP}=1,10$ & $\mathrm{DP}=1,0$ & $\mathrm{DP}=1,03$ & $\mathrm{DP}=1,79$ \\
\hline \multicolumn{5}{|l|}{$\mathbf{P} / \mathbf{P}_{50}$} \\
\hline$\geq 0,85$ & $30(100,0 \%)^{*}$ & $20(100,0 \%)^{*}$ & - & - \\
\hline$<0,85$ & - & - & $40(100,0 \%)$ & $5(100,0 \%)$ \\
\hline nédia / desvio padrã & & ${ }^{*} p<0,00$ & Grupos la x II & $x \mathrm{Ilb}$ \\
\hline frequência / frequênci & elativa & ${ }^{* *} p<0,0$ & Grupos Ib x II & \\
\hline
\end{tabular}

Os valores de Magnésio iônico(Mgi) e Total(MgT), Cálcio iônico(Cai), Fósforo(P), pH, Uréia(U) e Creatinina(Cr), observados nos diferentes grupos de estudo, assim como a comparação entre eles, serão apresentados a seguir, sob a forma de tabelas e/ou gráficos e, de forma mais detalhada nos Anexos $\mathrm{G}$ a N.

As TABELAS 13 a 16 e os GRÁFICOS 5 a 11, mostram a correlação entre os níveis médios de Mgi e MgT, Cai, $\mathrm{P}, \mathrm{pH}, \mathrm{U}$ e $\mathrm{Cr}$, nos diferentes grupos de estudo. 
TABELA 4 - NÍVEIS MÉDIOS DE MAGNÉSIO IÔNICO (Mgi) E MAGNÉSIO TOTAL (MgT) NA 1 a SEMANA DE VIDA EM RNT SEM CIUR (GRUPO la)

\begin{tabular}{cccc}
\hline & Cordão umbilical & 3ㅇ dia & 7ㅇ dia \\
\hline Mgi & 0,23 & 0,22 & 0,20 \\
$(\mathbf{m m o l} / \mathbf{L})$ & $\mathrm{DP}=0,09$ & $\mathrm{DP}=0,07$ & $\mathrm{DP}=0,06$ \\
& $(\mathrm{n}=27)$ & $(\mathrm{n}=21)$ & $(\mathrm{n}=20)$ \\
$\mathbf{M g T}$ & $1,67^{*}$ & & \\
$(\mathbf{m g} / \mathbf{d l})$ & $\mathrm{DP}=0,25$ & 1,80 & 1,86 \\
& $(\mathrm{n}=28)$ & $\mathrm{DP}=0,29$ & $\mathrm{DP}=0,25$ \\
& $(\mathrm{n}=22)$ & $(\mathrm{n}=20)$ \\
\hline
\end{tabular}

- média / desvio padrão(DP)

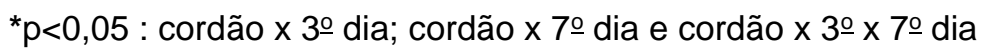

TABELA 5 - NÍVEIS MÉdIOS DE MAGNÉSIO IÔNICO (Mgi) E MAGNÉSIO TOTAL (MgT) NA 1a SEMANA DE VIDA EM RNT COM CIUR (GRUPO lla)

\begin{tabular}{cccc}
\hline & Cordão umbilical & 3 dia & 7ㅇ dia \\
\hline $\mathbf{M g i}$ & 0,33 & 0,34 & 0,31 \\
$(\mathbf{m m o l} / \mathbf{L})$ & $\mathrm{DP}=0,11$ & $\mathrm{DP}=0,10$ & $\mathrm{DP}=0,08$ \\
& $(\mathrm{n}=34)$ & $(\mathrm{n}=35)$ & $(\mathrm{n}=20)$ \\
$\mathbf{M g} \mathbf{T}$ & 1,83 & 1,82 & 1,96 \\
$(\mathbf{m g} / \mathbf{d l})$ & $\mathrm{DP}=0,39$ & $\mathrm{DP}=0,40$ & $\mathrm{DP}=0,41$ \\
& $(\mathrm{n}=39)$ & $(\mathrm{n}=35)$ & $(\mathrm{n}=22)$ \\
\hline
\end{tabular}

- média / desvio padrão(DP) 
GRÁFICO 1 - CONCENTRAÇÕES SÉRICAS DE MgT NA 1a SEMANA DE VIDA EM RNT SEM CIUR (GRUPO la)

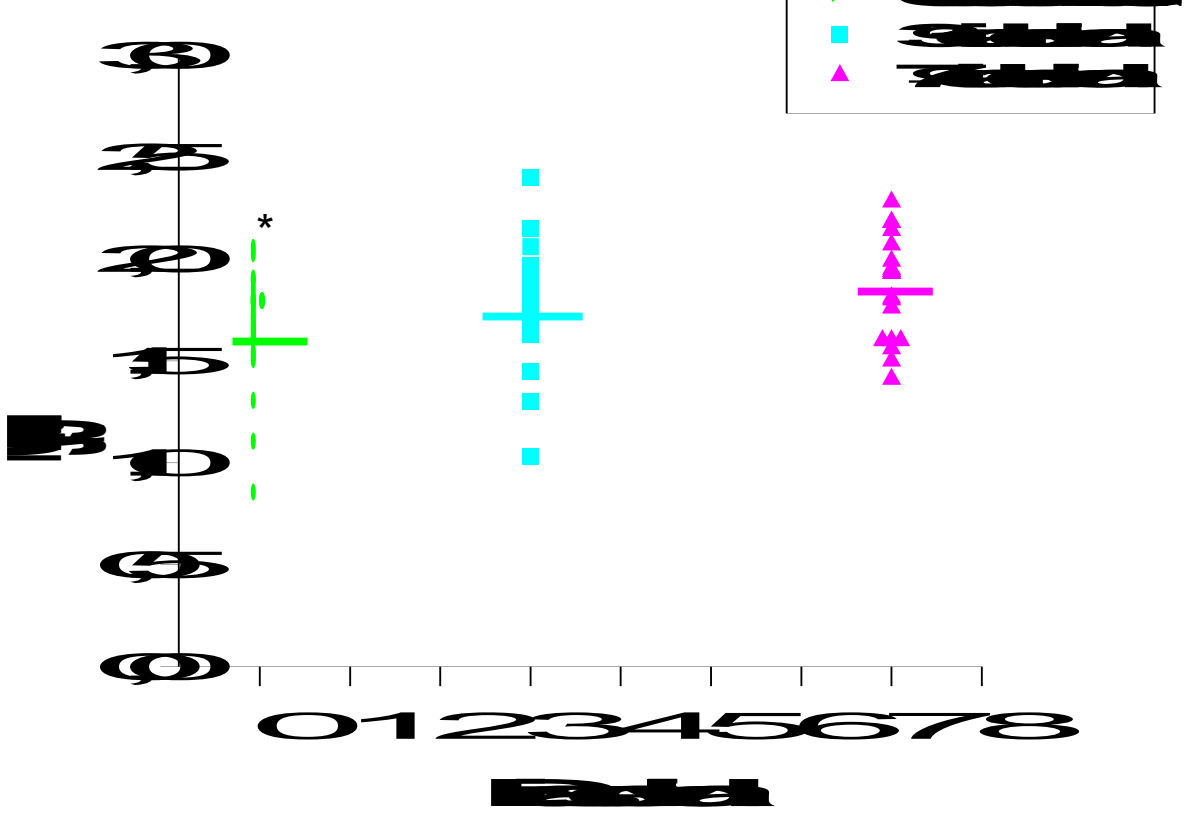

* $p<0,05$ : cordão x 3ํ dia; cordão x 70 dia; cordão $\times 3^{\circ} \times 7^{\circ}$ dia de vida

GRÁFICO 2 - CONCENTRAÇÕES SÉRICAS DE Mgi NA 1a SEMANA DE VIDA EM RNT SEM CIUR (GRUPO la)

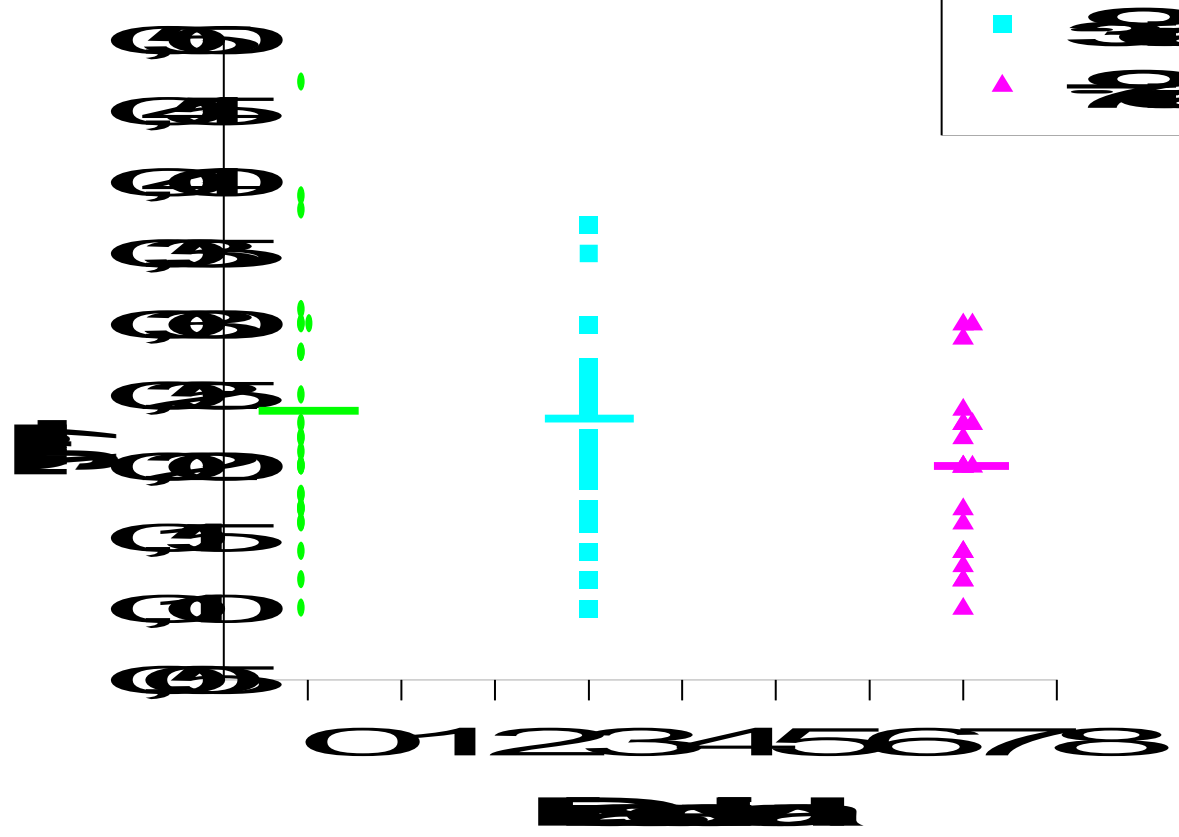


TABELA 6 - NÍVEIS MÉDIOS DE MAGNÉSIO IÔNICO (Mgi) E MAGNÉSIO TOTAL(MgT) NA 1a SEMANA DE VIDA EM RNT SEM CIUR, COM ASFIXIA PERINATAL (GRUPO lb)

\begin{tabular}{lccc}
\hline & Cordão umbilical & 3ㅇ dia & 7ㅇ dia \\
\hline Mgi & $0,21^{*}$ & 0,28 & 0,28 \\
$(\mathbf{m m o l} / \mathbf{L})$ & $\mathrm{DP}=0,07$ & $\mathrm{DP}=0,11$ & $\mathrm{DP}=0,09$ \\
& $(\mathrm{n}=18)$ & $(\mathrm{n}=18)$ & $(\mathrm{n}=17)$ \\
& & & \\
$\mathbf{M g T}$ & 1,78 & 1,91 & 2,18 \\
$\mathbf{( m g / d l )}$ & $\mathrm{DP}=0,47$ & $\mathrm{DP}=0,68$ & $\mathrm{DP}=0,72$ \\
& $(\mathrm{n}=20)$ & $(\mathrm{n}=19)$ & $(\mathrm{n}=19)$ \\
\hline
\end{tabular}

- média / desvio padrão(DP)

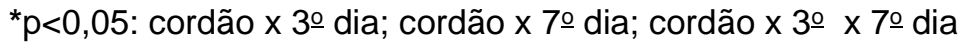

TABELA 7 - NÍVEIS MÉDIOS DE MAGNÉSIO IÔNICO (Mgi) E MAGNÉSIO TOTAL (MgT) NA 1a SEMANA DE VIDA EM RNT COM CIUR, COM ASFIXIA PERINATAL (GRUPO Ilb)

\begin{tabular}{cccc}
\hline & Cordão umbilical & 3ㅇ dia & 7ㅇ dia \\
\hline Mgi & 0,27 & 0,32 & 0,34 \\
$(\mathbf{m m o l} / \mathbf{L})$ & $\mathrm{DP}=0,10$ & $\mathrm{DP}=0,10$ & $\mathrm{DP}=0,14$ \\
& $(\mathrm{n}=4)$ & $(\mathrm{n}=5)$ & $(\mathrm{n}=4)$ \\
$\mathbf{M g T}$ & 1,73 & & \\
$(\mathbf{m g} / \mathbf{d l})$ & $\mathrm{DP}=0,27$ & 2,10 & 2,28 \\
& $(\mathrm{n}=4)$ & $\mathrm{DP}=0,62$ & $\mathrm{DP}=0,61$ \\
& $(\mathrm{n}=5)$ & $(\mathrm{n}=5)$ \\
\hline
\end{tabular}

- média / desvio padrão(DP) 
GRÁFICO 3 - CONCENTRAÇÕES MÉDIAS DE MgT (CORDÃO UMBILICAL, 3ㅇ E 7ํำ DIAS DE VIDA) NOS DIFERENTES GRUPOS DE ESTUDO

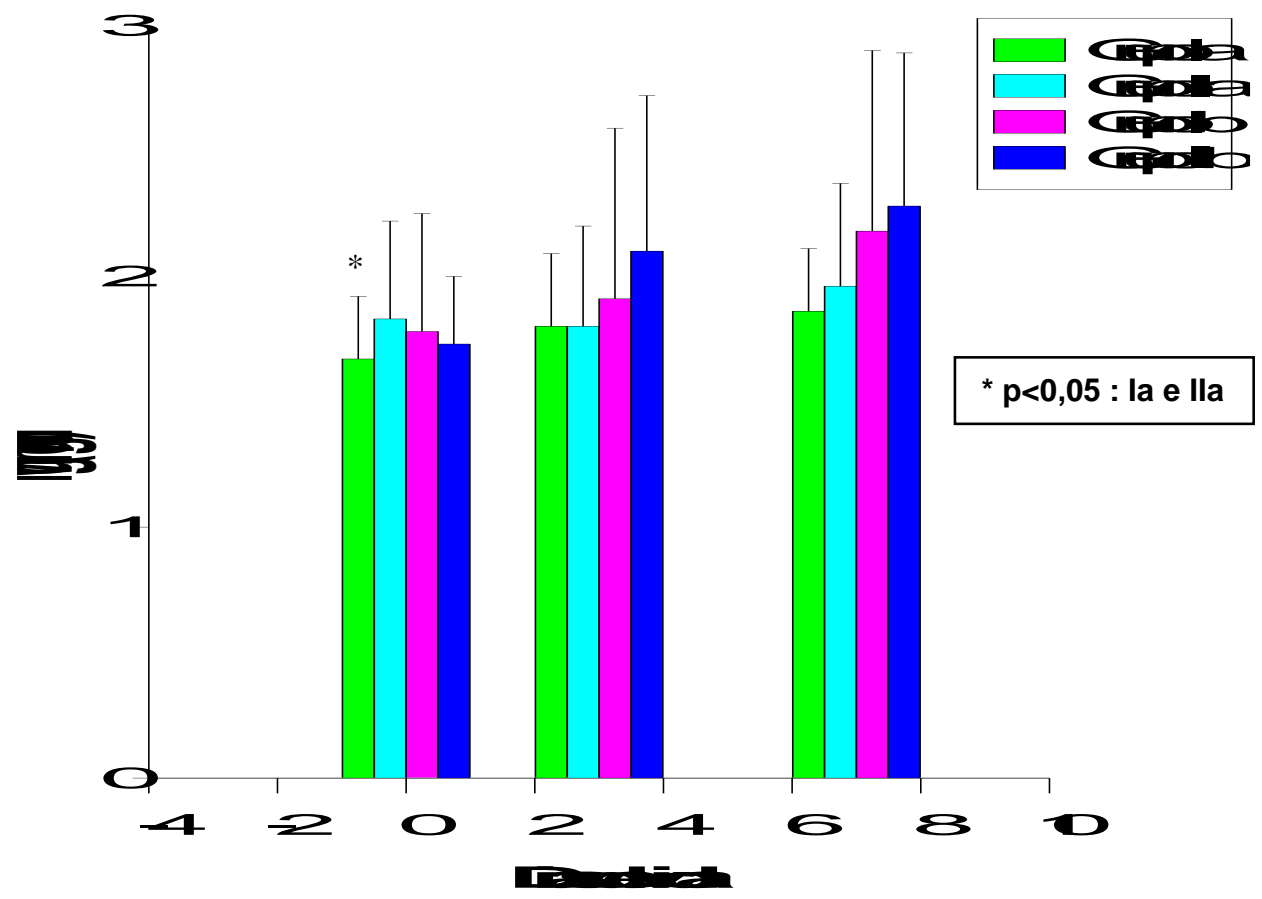

GRÁFICO 4 - CONCENTRAÇÕES MÉDIAS DE Mgi (CORDÃO UMBILICAL, $3^{\circ}$ E $7^{\circ}$ DIAS DE VIDA) NOS DIFERENTES GRUPOS DE ESTUDO

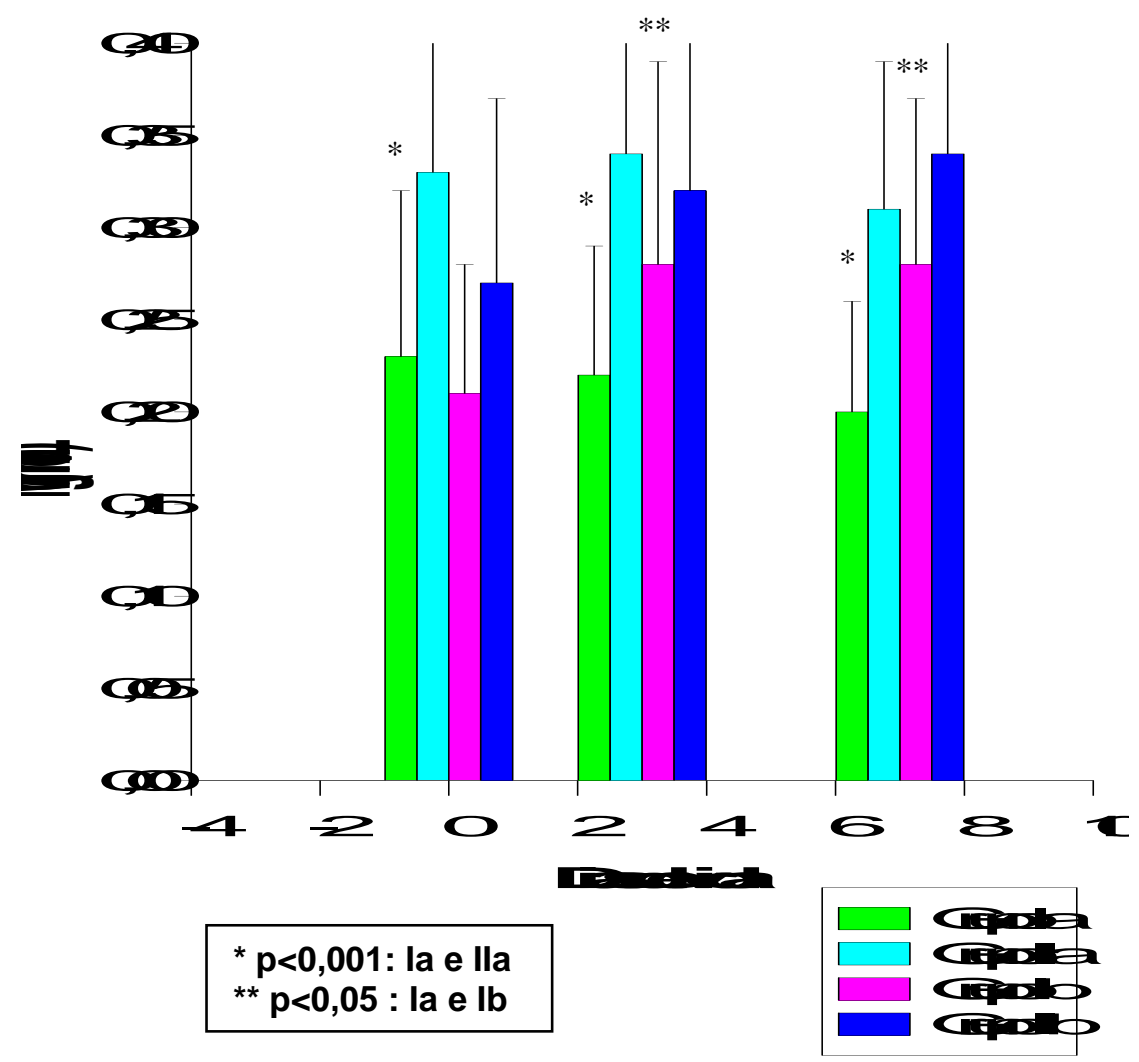


TABELA 8 - NÍVEIS MÉDIOS DE CÁLCIO IÔNICO (Cai) NA 1a SEMANA DE VIDA, NOS DIFERENTES GRUPOS DE ESTUDO

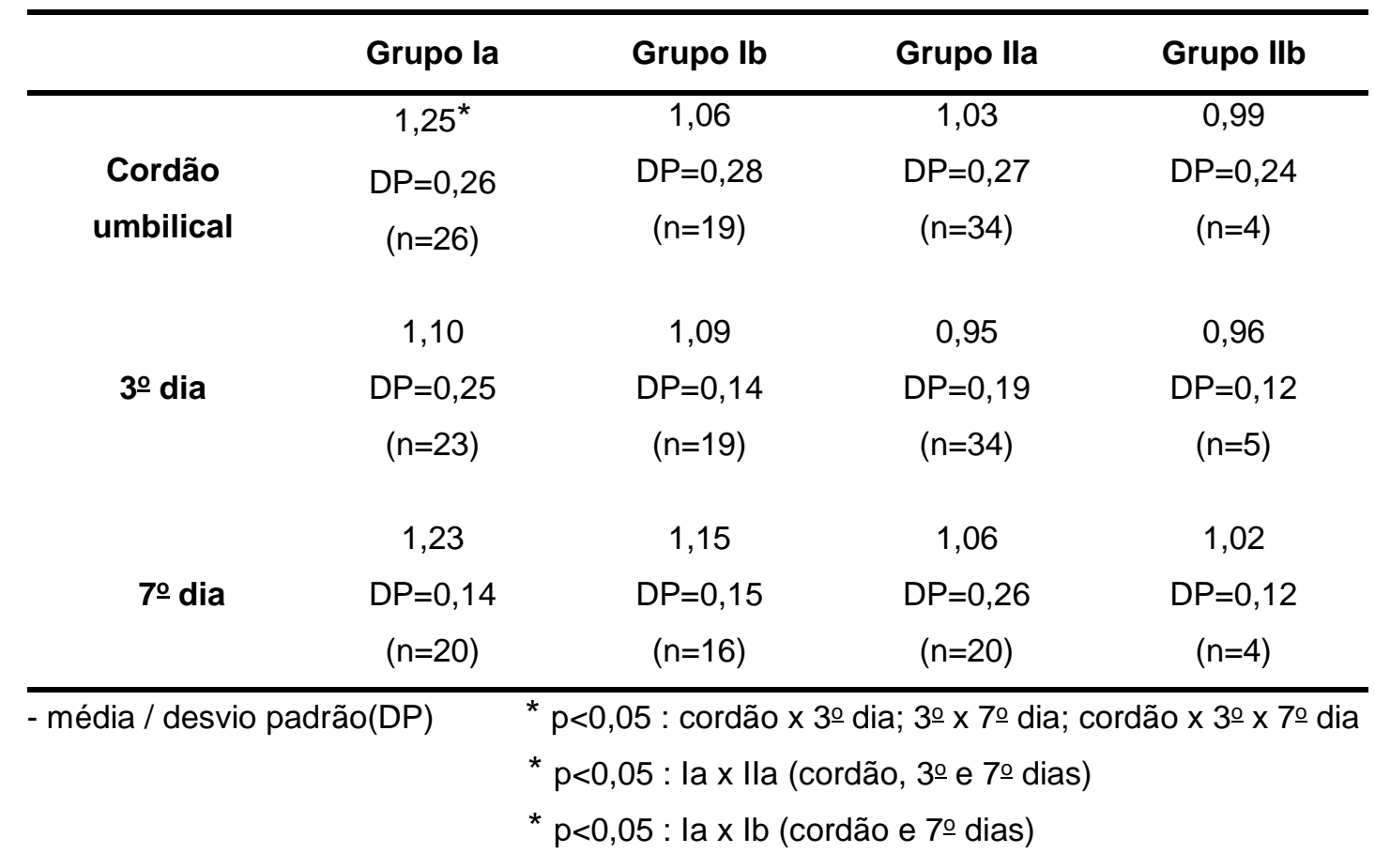

TABELA 9 - NÍVEIS MÉdIOS DE FÓSFORO (P) NA 1a SEMANA DE VIDA, NOS DIFERENTES GRUPOS DE ESTUDO

\begin{tabular}{ccccc}
\hline & Grupo la & Grupo lb & Grupo lla & Grupo Ilb \\
\hline Cordão & $6,03 \bullet$ & $6,55^{*}$ & $5,45 \bullet \bullet$ & 5,80 \\
Umbilical & $\mathrm{DP}=1,16$ & $\mathrm{DP}=2,38$ & $\mathrm{DP}=0,90$ & $\mathrm{DP}=1,18$ \\
& $(\mathrm{n}=28)$ & $(\mathrm{n}=20)$ & $(\mathrm{n}=39)$ & $(\mathrm{n}=4)$ \\
& & & & \\
& 6,66 & 5,65 & 6,17 & 5,34 \\
30 dia & $\mathrm{DP}=1,06$ & $\mathrm{DP}=1,01$ & $\mathrm{DP}=0,81$ & $\mathrm{DP}=1,91$ \\
& $(\mathrm{n}=23)$ & $(\mathrm{n}=19)$ & $(\mathrm{n}=34)$ & $(\mathrm{n}=5)$ \\
& & & & \\
& 7,68 & 6,65 & 6,55 & 7,40 \\
70 dia & $\mathrm{DP}=0,93$ & $\mathrm{DP}=1,41$ & $\mathrm{DP}=0,88$ & $\mathrm{DP}=1,89$ \\
& $(\mathrm{n}=19)$ & $(\mathrm{n}=19)$ & $(\mathrm{n}=22)$ & $(\mathrm{n}=5)$ \\
& & & & \\
\hline
\end{tabular}

- média / desvio padrão(DP)

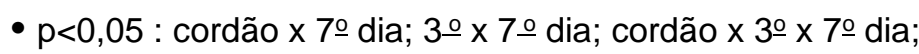

la $\times$ lla (cordão e 7으 dias); la $\times$ lb (3ㅇ e 70 dias)

${ }^{*} \mathrm{p}<0,05:$ : ㅇ $\times$ 7으 dia

•• p<0,001 : cordão x 3 dia; cordão x 7ㅇ dia; cordão x 3ํ x 7ㅇ dia 
TABELA 10 - NÍVEIS MÉdIOS DE pH NA 1a SEMANA DE VIDA, NOS DIFERENTES GRUPOS DE ESTUDO

\begin{tabular}{ccccc}
\hline & Grupo la & Grupo Ib & Grupo Ila & Grupo Ilb \\
\hline Cordão & $7,29 \bullet$ & $7,26 \bullet \bullet$ & $7,33^{*}$ & 7,36 \\
umbilical & $\mathrm{DP}=0,10$ & $\mathrm{DP}=0,22$ & $\mathrm{DP}=0,08$ & $\mathrm{DP}=0,12$ \\
& $(\mathrm{n}=26)$ & $(\mathrm{n}=19)$ & $(\mathrm{n}=34)$ & $(\mathrm{n}=4)$ \\
& & & & \\
30 dia & 7,41 & 7,41 & 7,43 & 7,46 \\
& $\mathrm{DP}=0,08$ & $\mathrm{DP}=0,03$ & $\mathrm{DP}=0,04$ & $\mathrm{DP}=0,06$ \\
& $(\mathrm{n}=23)$ & $(\mathrm{n}=19)$ & $(\mathrm{n}=35)$ & $(\mathrm{n}=5)$ \\
70 dia & 7,42 & 7,44 & 7,40 & 7,43 \\
& $\mathrm{DP}=0,03$ & $\mathrm{DP}=0,04$ & $\mathrm{DP}=0,05$ & $\mathrm{DP}=0,03$ \\
& $(\mathrm{n}=19)$ & $(\mathrm{n}=16)$ & $(\mathrm{n}=22)$ & $(\mathrm{n}=4)$ \\
\hline
\end{tabular}

- média / desvio padrão(DP)

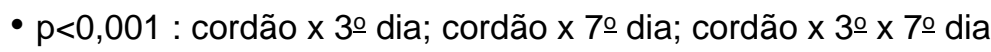

$\bullet p<0,05$ : cordão $\times 70$ dia

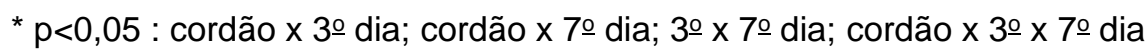

TABELA 11 - NÍVEIS MÉdIOS DE URÉIA (U) NA 1a SEMANA DE VIDA, NOS DIFERENTES GRUPOS DE ESTUDO

\begin{tabular}{ccccc}
\hline & Grupo la & Grupo lb & Grupo lla & Grupo Ilb \\
\hline Cordão & 11,20 & 11,64 & $13,84 \bullet \bullet$ & 11,0 \\
umbilical & $\mathrm{DP}=9,16$ & $\mathrm{DP}=3,63$ & $\mathrm{DP}=6,52$ & $\mathrm{DP}=2,65$ \\
& $(\mathrm{n}=15)$ & $(\mathrm{n}=14)$ & $(\mathrm{n}=25)$ & $(\mathrm{n}=3)$ \\
& & & & \\
30 dia & 8,73 & 8,75 & 12,82 & 13,0 \\
& $\mathrm{DP}=5,54$ & $\mathrm{DP}=3,55$ & $\mathrm{DP}=8,36$ & $\mathrm{DP}=2,45$ \\
& $(\mathrm{n}=15)$ & $(\mathrm{n}=12)$ & $(\mathrm{n}=28)$ & $(\mathrm{n}=4)$ \\
& 8,80 & 11,10 & 10,47 & 10,7 \\
70 dia & $\mathrm{DP}=3,46$ & $\mathrm{DP}=7,00$ & $\mathrm{DP}=8,86$ & $\mathrm{DP}=1,16$ \\
& $(\mathrm{n}=10)$ & $(\mathrm{n}=10)$ & $(\mathrm{n}=17)$ & $(\mathrm{n}=3)$ \\
\hline
\end{tabular}

- média / desvio padrão(DP)

•. p $<0,05$ : cordão $\times 7$ ㅇ dia 
TABELA 12 - NÍVEIS MÉDIOS DE CREATININA (CR) NA 1a SEMANA DE VIDA, NOS DIFERENTES GRUPOS DE ESTUDO

\begin{tabular}{ccccc}
\hline & Grupo la & Grupo Ib & Grupo Ila & Grupo Ilb \\
\hline Cordão & $0,64 \bullet \bullet$ & $0,93 \bullet \bullet$ & $0,72^{*}$ & $0,86 \bullet$ \\
Umbilical & $\mathrm{DP}=0,30$ & $\mathrm{DP}=0,68$ & $\mathrm{DP}=0,20$ & $\mathrm{DP}=0,11$ \\
& $(\mathrm{n}=28)$ & $(\mathrm{n}=19)$ & $(\mathrm{n}=39)$ & $(\mathrm{n}=4)$ \\
& 0,38 & 0,66 & 0,47 & 0,58 \\
30 dia & $\mathrm{DP}=0,16$ & $\mathrm{DP}=1,31$ & $\mathrm{DP}=0,16$ & $\mathrm{DP}=0,25$ \\
& $(\mathrm{n}=22)$ & $(\mathrm{n}=18)$ & $(\mathrm{n}=34)$ & $(\mathrm{n}=4)$ \\
& 0,32 & 0,33 & 0,30 & 0,43 \\
70 dia & $\mathrm{DP}=0,13$ & $\mathrm{DP}=0,16$ & $\mathrm{DP}=0,16$ & $\mathrm{DP}=0,17$ \\
& $(\mathrm{n}=16)$ & $(\mathrm{n}=19)$ & $(\mathrm{n}=21)$ & $(\mathrm{n}=5)$ \\
\hline
\end{tabular}

- média / desvio padrão(DP)

•• p<0,05 : cordão x 3ㅇ dia; cordão x 70 dia; cordão x 3우 7 으 dia;

la $\times$ Ila (cordão umbilical); la $\times$ lb (cordão umbilical)

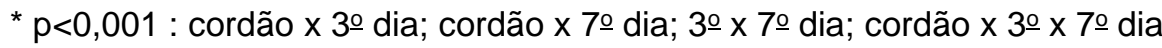

- $p<0,05$ : cordão $\times 7$ 으 dia; cordão $\times 3$ 우 7 ํ dia

TABELA 13 - CORRELAÇÃO ENTRE OS NÍVEIS MÉDIOS DE MAGNÉSIO IÔNICO (Mgi) E MAGNÉSIO TOTAL (MgT), CÁLCIO IÔNICO (Cai), FÓSFORO(P), pH, URÉIA (U) E CREATININA (Cr) NO GRUPO la (SEM CIUR, SEM ASFIXIA PERINATAL)

\begin{tabular}{lccccccc}
\hline & Cordão umbilical & \multicolumn{2}{c}{ 3ㅇ de vida } & \multicolumn{2}{c}{ 70 dia de vida } \\
\hline & $\mathbf{r}$ & $\mathbf{p}$ & $\mathbf{r}$ & $\mathbf{p}$ & $\mathbf{r}$ & $\mathbf{p}$ \\
$\mathbf{M g T}$ & $-0,061$ & 0,768 & $-0,424$ & 0,071 & 0,088 & 0,729 \\
$\mathbf{C a i}$ & $-\mathbf{0 , 4 7 1}$ & $\mathbf{0 , 0 1 5}$ & $-0,244$ & 0,299 & $-0,339$ & 0,169 \\
$\mathbf{P}$ & $-0,284$ & 0,159 & $-0,332$ & 0,165 & $-0,392$ & 0,108 \\
$\mathbf{p H}$ & 0,003 & 0,989 & $-0,307$ & 0,188 & 0,179 & 0,476 \\
$\mathbf{U}$ & 0,308 & 0,264 & 0,064 & 0,829 & $-0,368$ & 0,295 \\
$\mathbf{C r}$ & 0,136 & 0,507 & $-0,256$ & 0,305 & 0,079 & 0,790 \\
\hline
\end{tabular}


GRÁFICO 5 - CORRELAÇÃo ENTRE OS NÍVEIS MÉDIOS DE Mgi E Cai EM RNT SEM CIUR (GRUPO la) (CORDÃO UMBILICAL)

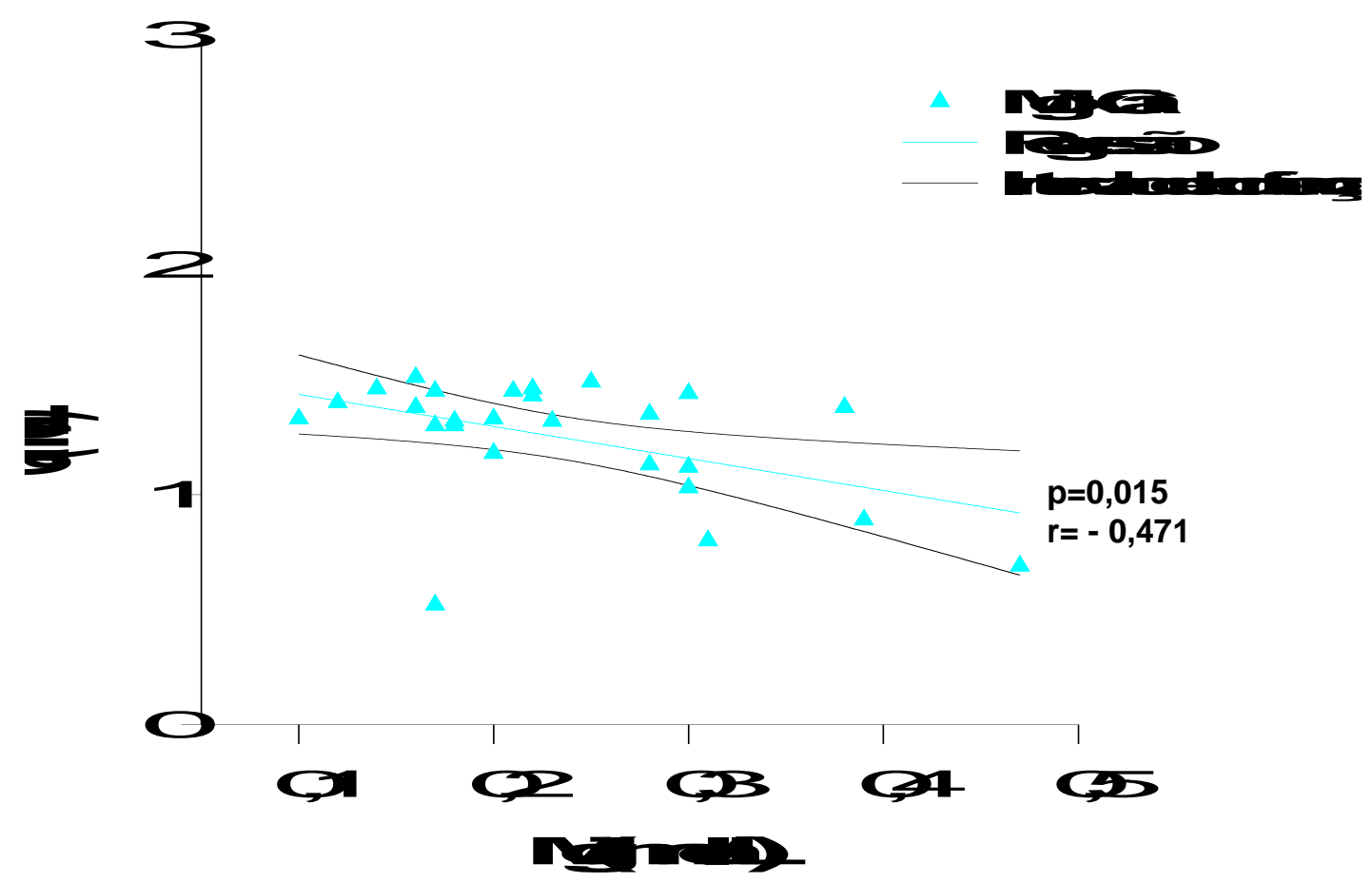

TABELA 14 - CORRELAÇÃo ENTRE OS NÍVEIS MÉDIOS DE MAGNÉSIO IÔNICO (Mgi) E MAGNÉSIO TOTAL (MgT), CÁLCIO IÔNICO (Cai), FÓSFORO(P), pH, URÉIA (U) E CREATININA (CR) NO GRUPO Ila (COM CIUR, SEM ASFIXIA PERINATAL)

\begin{tabular}{cccccccc}
\hline & Cordão umbilical & \multicolumn{2}{c}{ 30 dia de vida } & \multicolumn{2}{c}{ 7음 dia de vida } \\
\hline MgT & $\mathbf{r}$ & $\mathbf{p}$ & $\mathbf{r}$ & $\mathbf{p}$ & $\mathbf{r}$ & $\mathbf{p}$ \\
$\mathbf{C a i}$ & 0,260 & 0,145 & $-0,156$ & 0,386 & 0,370 & 0,119 \\
$\mathbf{P}$ & 0,056 & 0,755 & 0,328 & 0,058 & 0,128 & 0,590 \\
$\mathbf{p H}$ & $-0,040$ & 0,827 & $-0,194$ & 0,288 & $-0,204$ & 0,401 \\
$\mathbf{U}$ & $-0,147$ & 0,414 & $-0,047$ & 0,790 & $-\mathbf{0 , 4 9 5}$ & $\mathbf{0 , 0 2 7}$ \\
$\mathbf{C r}$ & 0,262 & 0,206 & $-0,159$ & 0,420 & 0,366 & 0,148 \\
\hline
\end{tabular}


GRÁFICO 6 - CORRELAÇÃO ENTRE OS NÍVEIS MÉDIOS DE Mgi E pH EM RNT COM CIUR (GRUPO Ila) (7음 DIA DE VIDA)

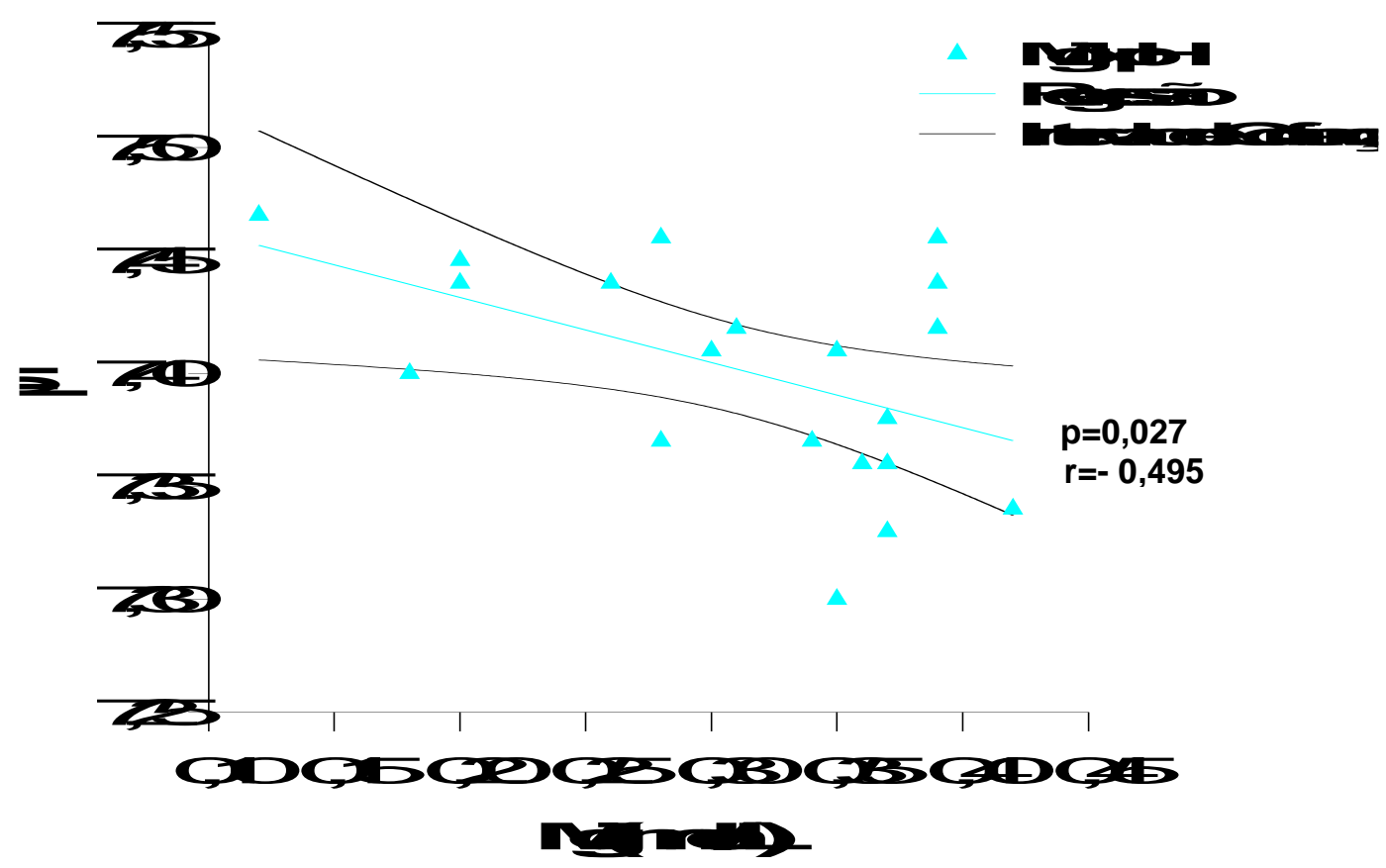

GRÁFICO 7 - CORRELAÇÃO ENTRE OS NÍVEIS MÉDIOS DE Mgi E CREATININA EM RNT COM CIUR (GRUPO Ila) (7으 DIA DE VIDA)

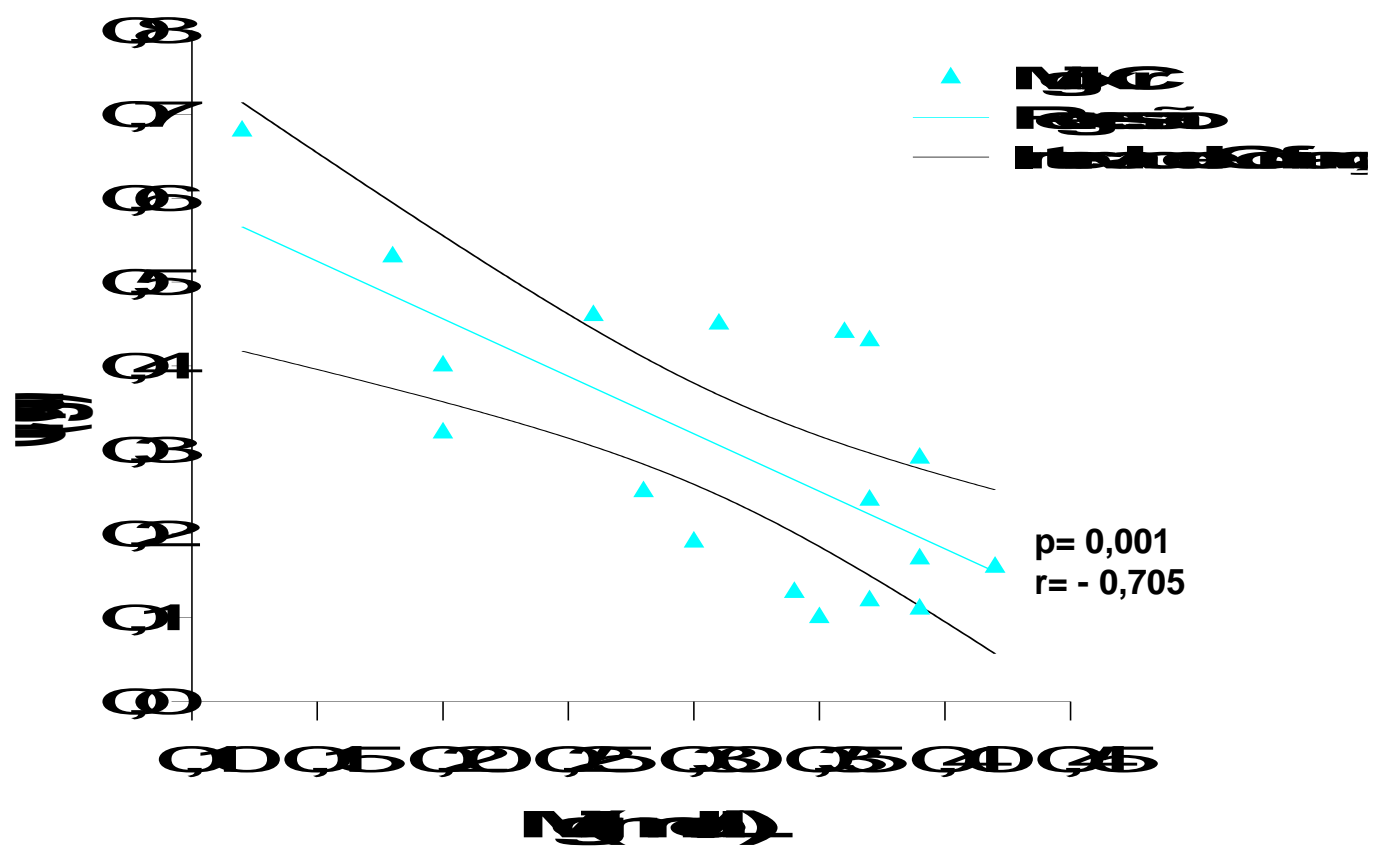


TABELA 15 - CORRELAÇÃO ENTRE OS NÍVEIS MÉDIOS DE MAGNÉSIO IÔNICO (Mgi) E MAGNÉSIO TOTAL (MgT), CÁLCIO IÔNICO (Cai), FÓSFORO(P), pH, URÉIA (U) E CREATININA (CR) NO GRUPO Ib (SEM CIUR, COM ASFIXIA PERINATAL)

\begin{tabular}{cccccccc}
\hline & Cordão umbilical & \multicolumn{2}{c}{ 30 dia de vida } & \multicolumn{2}{c}{ 70 dia de vida } \\
\hline MgT & $\mathbf{r}$ & $\mathbf{p}$ & $\mathbf{r}$ & $\mathbf{p}$ & $\mathbf{r}$ & $\mathbf{p}$ \\
$\mathbf{C a i}$ & 0,188 & 0,455 & $\mathbf{0 , 5 0 1}$ & $\mathbf{0 , 0 4 1}$ & 0,423 & 0,091 \\
$\mathbf{P}$ & 0,234 & 0,365 & $-0,158$ & 0,532 & $-0,086$ & 0,751 \\
$\mathbf{p H}$ & 0,184 & 0,464 & $-0,018$ & 0,946 & $-0,164$ & 0,529 \\
$\mathbf{U}$ & $-0,136$ & 0,603 & $-0,194$ & 0,442 & $-0,021$ & 0,939 \\
$\mathbf{C r}$ & $-0,275$ & 0,363 & 0,426 & 0,191 & $\mathbf{0 , 8 9 5}$ & $\mathbf{0 , 0 0 1}$ \\
\hline
\end{tabular}

GRÁFICO 8 - CORRELAÇÃO ENTRE OS NÍVEIS MÉDIOS DE Mgi E MgT EM RNT SEM CIUR COM ASFIXIA PERINATAL (GRUPO Ib) (3 DIA DE VIDA)

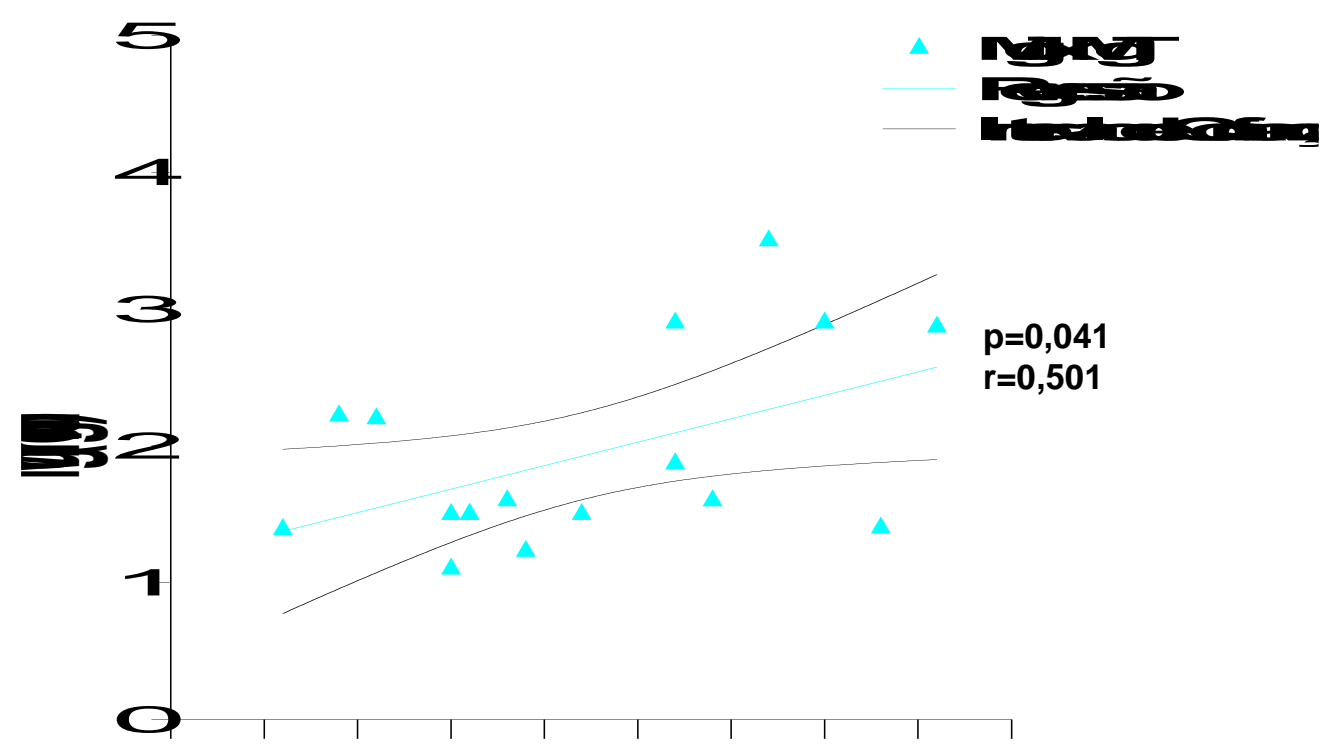

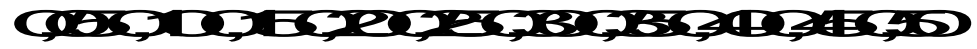

ITr. 
GRÁFICO 9 - CORRELAÇÃO ENTRE OS NÍVEIS MÉDIOS DE Mgi E URÉIA EM RNT SEM CIUR COM ASFIXIA PERINATAL (GRUPO Ib) (70 DIA DE VIDA)

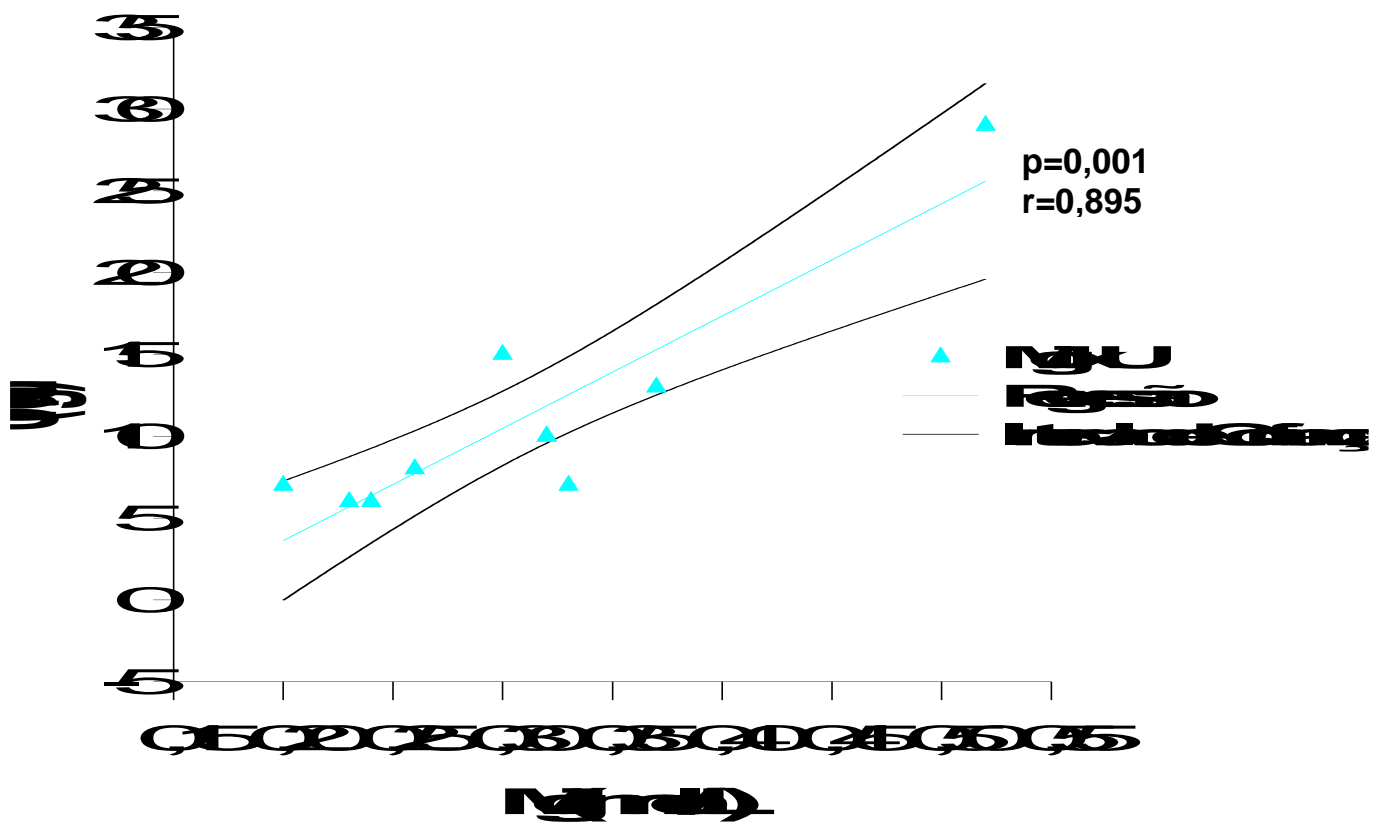

GRÁFICO 10 - CORRELAÇÃo ENTRE OS NÍVEIS MÉDIOS DE Mgi E CREATININA EM RNT SEM CIUR COM ASFIXIA PERINATAL(GRUPO Ib)(7 DIA DE VIDA)

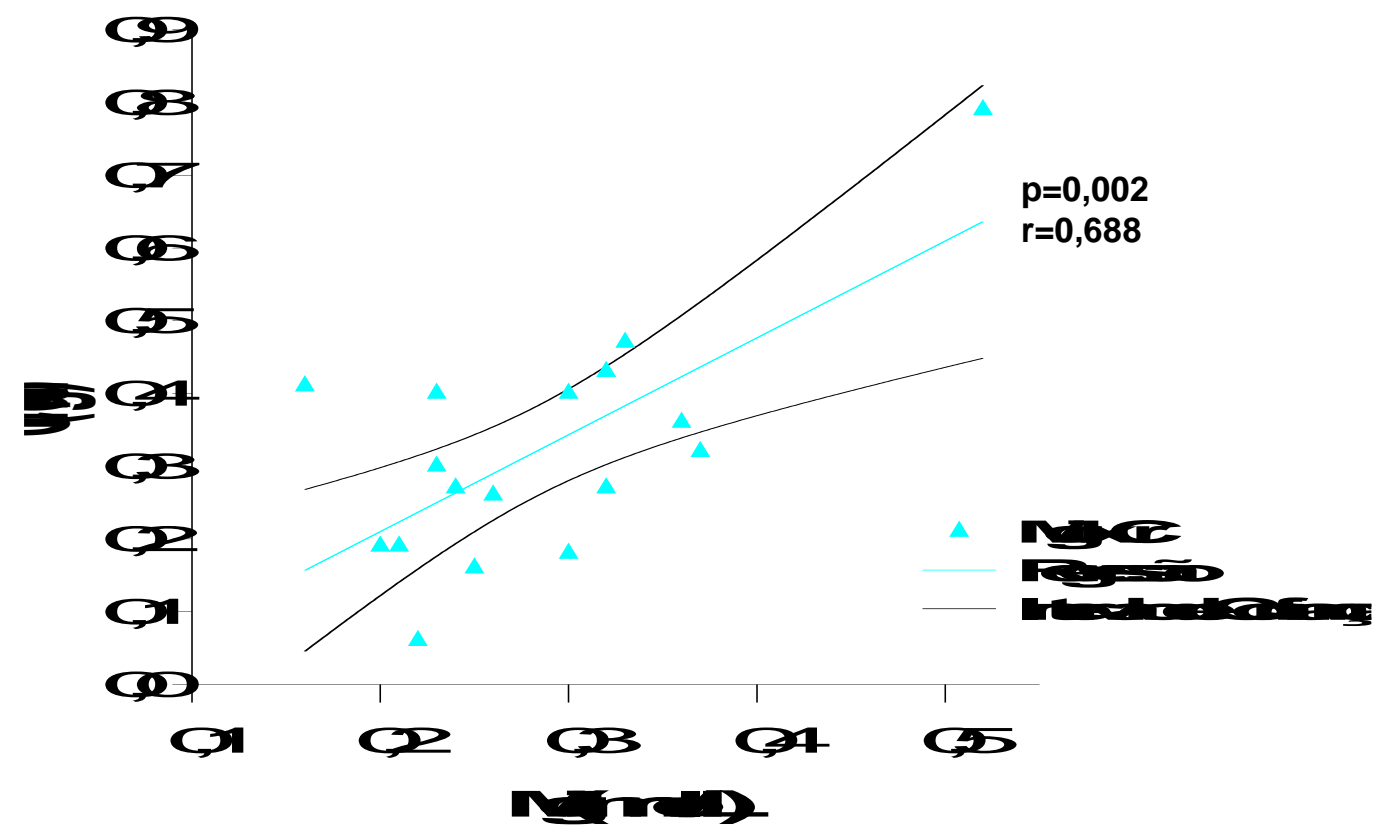


TABELA 16 - CORRELAÇÃO ENTRE OS NÍVEIS MÉDIOS DE MAGNÉSIO IÔNICO (Mgi) E MAGNÉSIO TOTAL (MgT), CÁLCIO IÔNICO (Cai), FÓSFORO(P), pH, URÉIA (U) E CREATININA (CR) NO GRUPO IIb (COM CIUR, COM ASFIXIA PERINATAL)

\begin{tabular}{cccccccc}
\hline & Cordão umbilical & \multicolumn{2}{c}{ 30 dia de vida } & \multicolumn{2}{c}{ 70 dia de vida } \\
\hline MgT & $\mathbf{r}$ & $\mathbf{p}$ & $\mathbf{r}$ & $\mathbf{p}$ & $\mathbf{r}$ & $\mathbf{p}$ \\
$\mathbf{C a i}$ & 0,834 & 0,166 & 0,038 & 0,950 & 0,747 & 0,253 \\
$\mathbf{P}$ & $-0,389$ & 0,611 & $-0,652$ & 0,233 & $-\mathbf{0 , 9 6 4}$ & $\mathbf{0 , 0 3 6}$ \\
$\mathbf{p H}$ & $-0,415$ & 0,585 & $-0,796$ & 0,107 & 0,716 & 0,284 \\
$\mathbf{U}$ & $-0,401$ & 0,599 & $-0,768$ & 0,130 & $-0,786$ & 0,214 \\
$\mathbf{C r}$ & $-0,966$ & 0,166 & $-0,120$ & 0,880 & 0,327 & 0,788 \\
\hline
\end{tabular}

GRÁFICO 11 - CORRELAÇÃO ENTRE OS NÍVEIS MÉdIOS DE Mgi E Cai EM RNT COM CIUR E ASFIXIA PERINATAL (GRUPO Ilb) (7음A DE VIDA)

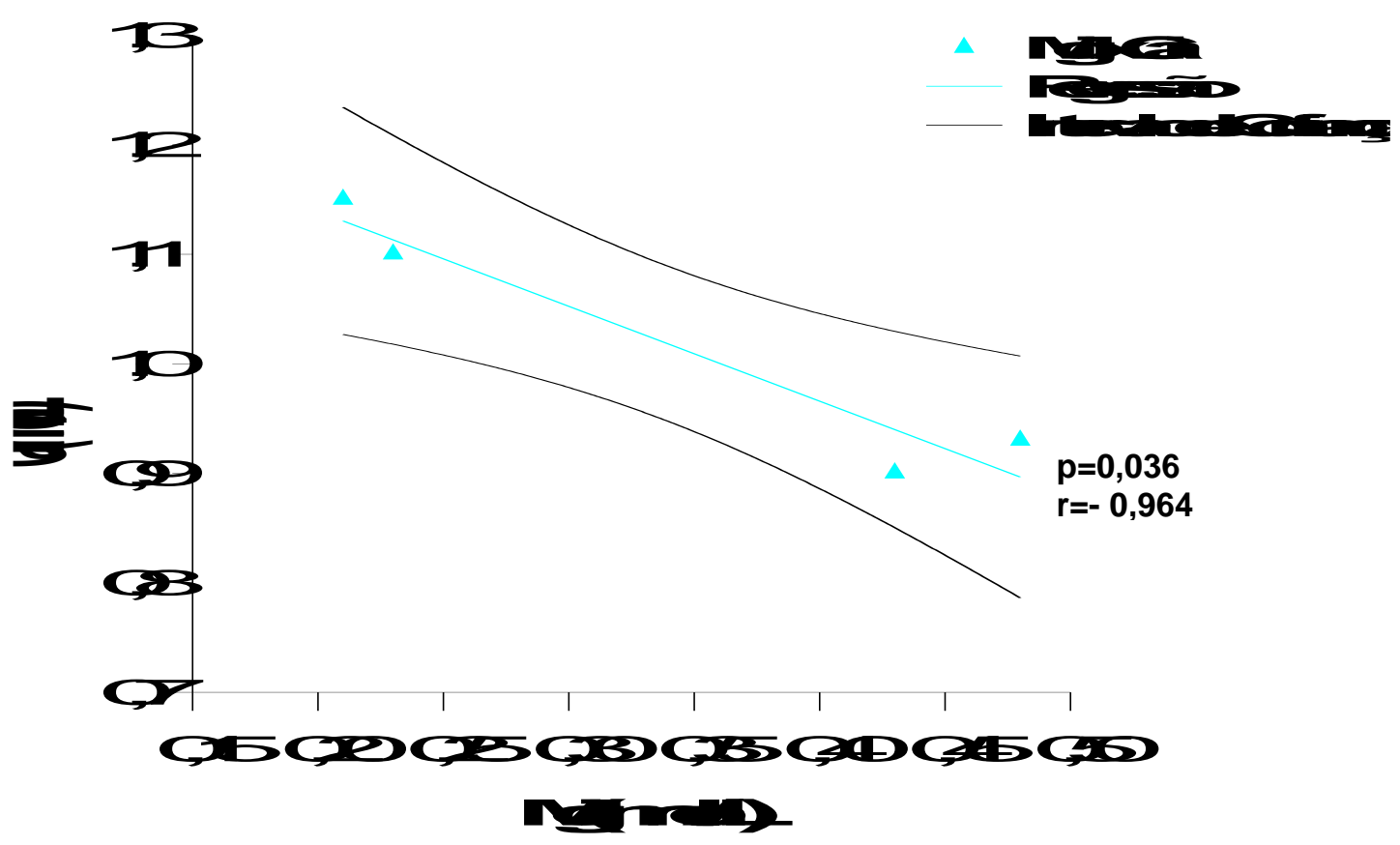


5 - DISCUSSÃO 
O Mg é o segundo cátion intracelular mais comum depois do $\mathrm{K} \mathrm{e}$ desempenha inúmeras funções no organismo (Altura,1994). Apesar de sua importância, o conhecimento de sua homeostase não é completo, decorrente principalmente da dificuldade de acesso a seus estoques intracelulares e da ausência, até alguns anos atrás, de métodos laboratoriais confiáveis para medida da fração iônica.

O período neonatal é uma fase de risco potencial para o desenvolvimento de distúrbios do $\mathrm{Mg}$, pois o $\mathrm{RN}$ resulta da ação de uma série de eventos que ocorreram nos períodos intra-uterino, intra-parto e pós-natal imediato.

O estudo do comportamento do Mg neste período tornou-se possível, com o desenvolvimento de técnicas laboratoriais, que permitiram a medida de sua fração fisiologicamente ativa, em pequenas alíquotas de sangue.

\subsection{Discussão da casuística e métodos}

\subsubsection{Casuística}

A seleção da casuística incluiu inicialmente apenas os RNT, com idade gestacional ao nascimento superior ou igual a 37 semanas. Excluiu-se, assim, os RNPT que poderiam apresentar distúrbios da homeostase do Mg, 
decorrentes da menor idade gestacional, já que a passagem placentária de Mg é maior no último trimestre da gestação (Tsang,1972b).

Os critérios de inclusão e exclusão foram elaborados, a fim de excluir RN com alterações que pudessem interferir na homeostase do $\mathrm{Mg}$, dentre eles, más-formações e infecções congênitas, filhos de mães diabéticas e/ou com distúrbios da paratireóide, filhos de mães que receberam sulfato de $\mathrm{Mg}$ ou outras medicações que pudessem interferir no metabolismo do Mg e RN que foram submetidos à exsanguineotransfusão na 1a semana de vida.

O hiper ou hipoparatireoidismo materno resulta em alterações das concentrações séricas de $\mathrm{Ca}$ na mãe e no feto e consequente supressão/estimulação das paratireóides do RN (Tsang,1973b).

O diabetes mellitus está comumente associado à deficiência crônica de Mg na mãe e no RN, secundária à glicosúria materna, com consequente aumento da perda urinária de $\mathrm{Mg}$, podendo levar ao hipoparatireoidismo neonatal (Rude,2001)

O tratamento com sulfato de magnésio em mães com pré-eclâmpsia grave ou eclâmpsia, pode levar à hipermagnesemia materna e fetal (Cruikshank et al.,1979).

Várias drogas, como: furosemida, aminoglicosídeos, anfotericina B, digoxina, pentamidina e ciclosporina, inibem a reabsorção de Mg e também podem levar à hipomagnesemia crônica materna e fetal (Mclean,1994; Saris et al.,2000). 
Por outro lado, a exsanguineotransfusão com sangue citratado pode levar à formação de complexos de $\mathrm{Mg}$ e $\mathrm{Ca}$, com consequente hipocalcemia e hipomagnesemia (Rude,2001).

\subsubsection{Desenho do Estudo}

O presente estudo foi delineado de forma prospectiva, o que permitiu uma análise fidedigna da evolução dos níveis séricos de $\mathrm{Mg}$ ao longo da 1 a semana de vida nos diferentes grupos de estudo, além do acompanhamento clínico, neurológico e ultrassonográfico dos $\mathrm{RN}$ e o estabelecimento da presença ou não da asfixia perinatal.

A realização da coleta e análise sangüínea em sangue de cordão umbilical, 3ํ e 7ํㅡ dias, também permitiu a observação da correlação entre os diferentes parâmetros estudados e o Mg, em diferentes momentos de adaptação do RN à vida extra-uterina.

Foram incluídos 30 RNT no grupo la (sem CIUR, sem asfixia) e 40 RNT no grupo Ila (com CIUR, sem asfixia). Através de análise estatística, foi programada inicialmente a inclusão de $20 \mathrm{RN}$ em cada grupo de estudo. No entanto, houve perdas, principalmente no 70 dia de vida, por falta de comparecimento materno à consulta, além da decorrente de dificuldades técnicas, como coleta de volume de sangue insuficiente ou dificuldade de coleta de sangue, sendo necessária a inclusão de mais RN para se obter o n programado. 
No grupo Ilb (com CIUR, com asfixia), houve a inclusão de apenas 5 casos, devido à falta do nascimento de $\mathrm{RN}$ que se encaixassem neste grupo, mesmo após a ampliação da coleta em outros Hospitais.

\subsubsection{Métodos}

\subsubsection{Avaliação da presença de CIUR}

O peso ao nascimento abaixo do percentil 10 é uma medida que indica presença de um padrão de crescimento intra-uterino inferior ao considerado adequado. Entretanto, ao se estabelecer um ponto de corte, erroneamente, se define alguns fetos ou $\mathrm{RN}$ normais como tendo crescimento restrito e, alguns com CIUR, como normais (Rondó,1998; Larsen,2001).

A classificação baseada no estado nutricional e não no peso ao nascimento, permite diferenciar o $\mathrm{RN}$ malnutrido, com maior risco de morbidade e mortalidade perinatal do RN pequeno, mas normal, sem patologias que pudessem ocasionar distúrbios da homeostase do $\mathrm{Mg}$ (Patterson; Pouliot, 1987).

Por outro lado, ao se utilizar o termo crescimento intra-uterino restrito, procurou-se englobar os $\mathrm{RN}$ que apresentaram um processo intra-útero, capaz de modificar seu potencial de crescimento e de levar a alterações importantes no período neonatal, como hipoglicemia e hipotermia (Altman; Hytten,1989). O menor suprimento materno à placenta ou a redução da transferência placentária de substratos, leva a uma menor oferta de oxigênio 
e nutrientes ao feto, com consequente distúrbio do crescimento e potencial interferência na homeostase do Mg (Pollack; Divon,1992).

Teoricamente, o CIUR pode ser definido como um crescimento inferior ao potencial genético de crescimento fetal. Contudo, na prática clínica, o potencial de crescimento individual e a taxa de crescimento intra-uterino não estão bem definidos e, assim, não há indicadores - padrão para o diagnóstico desta condição (Larsen,2001).

Algumas medidas quantitativas podem ser utilizadas para avaliar o grau de comprometimento nutricional do $\mathrm{RN}$, como: a relação $\mathrm{P} / \mathrm{P}_{50}$, a medida da prega cutânea, da circunferência do braço e das relações peso/comprimento, como o Índice de Massa Corpórea e o Índice Ponderal (Yau,1992; Beattie; Johnson,1994).

No presente estudo, inicialmente considerou-se a presença de CIUR quando o peso ao nascimento estava abaixo do percentil 10 da Curva de Ramos (1983), já que este foi aferido logo após o nascimento, na mesma ocasião em que foi realizada a primeira coleta sangüínea para as dosagens laboratoriais, permitindo a decisão quanto à inclusão ou não do $\mathrm{RN}$ no estudo, além da obtenção do consentimento materno.

Como se objetivou estudar os $\mathrm{RN}$ que tivessem sofrido restrição ao crescimento intra-uterino, associou-se um segundo critério de classificação nutricional, isto é, a relação $P / P_{50}<0,85$, tentando-se, desta maneira, eliminar os $\mathrm{RN}$ pequenos, porém normais, e procurando selecionar $\mathrm{RN}$ que tivessem maior probabilidade de ter CIUR. 


\subsubsection{Avaliação da presença de asfixia perinatal}

O escore de Apgar é um método rápido e de fácil acesso ao estado clínico do RN e fornece importantes informações acerca da efetividade da reanimação ao nascimento. No entanto, é importante se reconhecer que alguns fatores podem alterar alguns elementos do Índice de Apgar, como o tônus, cor e irritabilidade reflexa. O RN prematuro, o uso de alguns medicamentos pela mãe, más-formações neuromusculares ou cerebrais podem influenciar nas notas, na ausência de hipoxia (AAP,1996).

O Índice de Apgar de 7 a 10 no 5o minuto é considerado normal e de 4-6 é intermediário $(A A P, 1996)$ e, este, embora sem correlação com a presença de lesão neurológica, é provavelmente um resultado da hipoxia (AAP,1996). A opção do corte em $\leq 6$ no valor do Apgar de 5으 minuto, teve como objetivo afastar os RN que não sofreram asfixia perinatal.

Outros parâmetros tornam mais provável o diagnóstico de asfixia perinatal grave, como: a presença de acidose metabólica ou mista em sangue de cordão umbilical, manifestações neurológicas no $\mathrm{RN}$ e a disfunção de múltiplos órgãos (Martin-Ancel,1995; AAP,1996 ).

Alguns autores referem que a presença de um $\mathrm{pH}$ em sangue de cordão umbilical <7,2 é anormal (Anslow,1998). A AAP(1996) considera que, para o diagnóstico de asfixia perinatal grave, o suficiente para resultar em lesão neurológica, seria a presença de um $\mathrm{pH}<7,0$.

É importante destacar, que graus de hipoxia insuficientes para causar lesão neurológica, talvez pudessem acarretar alterações na homeostase do 
Mg, secundárias à presença de acidose, lesão tecidual ou alteração da função renal (Forfar,1976; Ilves et al.,2000).

Alguns autores referem aumento das concentrações séricas de $\mathrm{Mg}$ na presença de quadros mais leves de $\mathrm{EIH}$ e, diminuição, nos quadros mais graves, sendo esta a possível responsável pela lesão neurológica mais grave (Ilves et al.,2000; Harrison;Peat,1997).

Para determinação da influência da asfixia perinatal sobre o Mg, optouse por selecionar os $\mathrm{RN}$ com diagnóstico de asfixia perinatal grave, determinada pela presença de um Índice de Apgar de 5ㅇ $\min \leq 6$ associado à um dos seguintes critérios : $\mathrm{pH}$ de sangue de cordão umbilical < 7,2; disfunção de um ou mais órgãos; anormalidades, decorrentes da hipoxia, da USG transfontanela e/ou do exame neurológico.

Excluíram-se, assim, os casos com rápida recuperação, que poderiam não levar a distúrbios do $\mathrm{Mg}$ e foram incluídos os $\mathrm{RN}$ que apresentavam prováveis critérios clínicos e bioquímicos de asfixia perinatal, com um grande espectro de efeitos clínicos, desde ausentes a graves.

\subsubsection{Avaliação laboratorial}

\section{- Magnésio Total}

Menos de 1\% do Mg corpóreo total está localizado no sangue e, assim a medida do MgT é pouco representativa de sua atividade metabólica. Os sintomas clínicos podem não se correlacionar aos níveis de MgT (Marcus et 
al.,1997). Além disso, este pode estar normal na presença de concentrações diminuídas de Mgi (Munoz et al.,2000).

A medida do $\mathrm{MgT}$, no entanto, é a única disponível na maioria dos laboratórios. Vários métodos são utilizados para esta medida, como a espectrometria de absorção atômica e métodos complexométricos, utilizando vários reagentes, como o azul de xilidilo (Saris et al.,2000).

\section{- Magnésio lônico}

Aproximadamente $99 \%$ do Mg corpóreo total está localizado no intracelular, principalmente em ossos, músculos e tecidos moles, sendo o acesso ao conteúdo corpóreo de Mg uma fonte de dificuldade para clínicos e pesquisadores (Elin,1987; Mimouni,1996).

A medida do Mg intracelular, principalmente nas células sanguíneas, é um método caro e restrito a pesquisadores e não há estudos que demonstrem que a concentração de $\mathrm{Mg}$, presente em eritrócitos e células mononucleares represente uma estimativa real do conteúdo total de $\mathrm{Mg}$ (Mimouni,1996).

A maioria das técnicas utilizadas em laboratórios são geralmente restritas à medida do $\mathrm{MgT}$. Contudo, é a fração livre ou ionizada que é a fisiologicamente ativa. Inicialmente, para medida desta fração, utilizava-se a determinação de $\mathrm{Mg}$ no ultrafiltrado livre de proteínas. Entretanto, este método é caro e requer grande volume de sangue, além de não distinguir 
entre o Mg livre e a fração ligada a anions orgânicos e inorgânicos (Altura;Altura,1995).

O uso de radioisótopos e da ressonância magnética nuclear, também têm sido utilizados para estimativa do Mg livre, mas também trata-se de método custoso e de difícil acesso (Saris et al.,2000).

Assim, foram desenvolvidos os eletrodos íon-seletivos, capazes de atuar na presença de níveis de Cai e outras possíveis interferências, encontradas no sangue de pacientes normais ou doentes. Além disso, a medida é facil de ser realizada, com obtenção de resultados em menos de 2 minutos (Altura;Altura,1995).

Os níveis de Mgi não se alteram, se medidos em plasma, sangue ou soro. A concentração sanguínea de Mgi é equivalente à medida intracelularmente em várias células, como: miócitos da musculatura lisa vascular e cardíacos, células endoteliais e epiteliais, atráves da técnica de ressonância magnética nuclear (Altura;Altura,1995; Saris et al.,2000).

A variação dos níveis normais de Mgi é pequena em relação à de $M g T$, o que permite uma melhor discriminação entre pacientes normais e anormais, ou variações de um mesmo paciente com o tempo (Altura;Altura,1995).

Algumas recomendações devem ser seguidas, a fim de se minimizar os erros na determinação do Mgi. A amostra deve ser obtida, preferencialmente, sem uso de torniquete e sem realização de "ordenha" (Saris et al.,2000). 
A concentração de Mgi também irá depender do $\mathrm{pH}$ da solução, principalmente devido ao aumento da ligação do Mgi à albumina, com o aumento do $\mathrm{pH}$. Assim, o sangue deve ser colhido de maneira anaeróbia, a fim de evitar perda de CO2. Há um aumento de 1 a 2\% no Mgi a cada diminuição de 0,1 no pH (Altura;Altura,1995; Saris et al.,2000).

A influência da heparina pode ser atribuída à sua ligação ao $\mathrm{Mg}$. Quando se utiliza heparina líquida, o plasma é diluído pelo volume de heparina e, quando se utiliza heparina seca, pode ocorrer uma leve transferência de água dos eritrócitos e diluir o plasma, para restaurar o equilíbrio osmótico. Assim, deve se utilizar o mínimo de heparina necessário que, em concentrações de até $40 \mathrm{U} / \mathrm{ml}$, produzirá um erro de menos de 1,5\% nas concentrações de Mgi, o que é clinicamente aceitável (Altura;Altura,1995; Saris et al.,2000).

A comparação, entre diferentes tipos de heparina, mostrou que a heparina lítica, em uma concentração de 200 UI/L, produziu um mínimo desvio negativo na concentração de Mgi e um desvio negativo de 0,064mmol/L na concentração de Cai, quando comparada à medida destes em seringa sem heparina (Lyon et al.,1995).

A presença de intralípide não parece alterar significativamente os níveis de Mgi. Já a de acetato, bicarbonato, citrato, lactato ou fosfato, poderá ligar quantidades significativas de Mgi (Altura;Altura,1995).

O resfriamento da amostra é necessário, se esta não puder ser encaminhada em 15 minutos após a coleta, já que a glicólise, principalmente 
das células sanguíneas, causa a formação de ácido lático e mudança de pH (Altura;Altura,1995).

Neste estudo, utilizou-se para a coleta sangüínea, seringas com heparina lítica em concentração de $50 \mathrm{Ul} / \mathrm{ml}$ de sangue. A amostra foi colhida anaerobicamente e foi encaminhada ao laboratório em recipiente térmico em até 1 hora após a coleta.

\subsection{Discussão dos resultados}

\subsubsection{Características da população estudada}

Em relação às características maternas, verificou-se que o diagnóstico de CIUR durante a gestação esteve presente em somente $8(20,0 \%)$ das mães do Grupo Ila (com CIUR, sem asfixia perinatal), sendo que, destas, $32(80,0 \%)$, realizaram pré-natal. Esses dados estão de acordo com a literatura, que referem que o diagnóstico de CIUR durante a gestação é insatisfatório, sendo que mais de $50 \%$ dos fetos com CIUR são diagnosticados somente após o nascimento (Kliegman,1997)(TABELA 1).

A presença de oligoâmnio foi maior nesse grupo em relação aos outros grupos de estudo, já que a medida do volume de líquido amniótico tem grande valor no diagnóstico do CIUR, estando presente em até $96 \%$ dos casos de oligoâmnio (Bittar et al.,2002).

A presença de DHEG também foi maior no grupo Ila (com CIUR, sem asfixia). Apesar de alguns autores inicialmente referirem uma associação 
entre a presença de DHEG e diminuição das concentrações séricas de Mg, esta é controversa, e não foi confirmada após a realização da dosagem de Mgi com a técnica do eletrodo íon-seletivo nestas pacientes (Altura;Altura,1995; Handwerker et al.,1995) (TABELA 1).

O maior número de partos cesárea neste grupo também pode ser justificada pela maior indicação de interrupção da gestação ao atingir o termo, decorrente do risco fetal, pela frequente associação entre a presença de CIUR, oligoâmnio e sofrimento fetal. Por este mesmo motivo, podemos observar que a idade gestacional ao nascimento dos RN com CIUR foi menor do que a dos outros grupos (TABELA 1).

O maior tempo de internação nos grupos com asfixia em relação aos sem asfixia, foi decorrente do jejum inicial a que estes $\mathrm{RN}$ foram submetidos, devido à asfixia, além da presença de possíveis complicações, como: insuficiência respiratória, renal e sequelas neurológicas. Também foi maior no grupo com CIUR em relação ao sem CIUR, por complicações desta condição, como hipoglicemia e do tempo necessário para atingir o peso de alta, de aproximadamente $2000 \mathrm{~g}$ (TABELA 2).

Foi realizado exame neurológico em $84,0 \%$ e USG transfontanela em $83,0 \%$ dos RN incluídos no estudo. Alguns RN dos grupos sem asfixia não puderam ser submetidos a essa avaliação, principalmente por dificuldades técnicas, impossibilidade de agendamento com médico neurologista, visando se evitar atrasos da alta do RN (TABELA 2).

Somente $1 \mathrm{RN}$ no Grupo Ila (com CIUR, sem asfixia) apresentou exame neurológico anormal, com diagnóstico de hiperexcitabilidade e tremores que, 
no acompanhamento, não se repetiram. Em relação a USG transfontanela, 2 RN do grupo Ila (com CIUR, sem asfixia) e 1 do Grupo la (sem CIUR, sem asfixia) apresentaram achado de cisto de plexo coróide(2) e hiperecogenicidade periventricular(1) e permaneceram em acompanhamento com Neurologista Pediátrico (Anexo E).

O Apgar de 5을 minuto foi maior do que 6 em todos os RN do grupo sem asfixia e nenhum destes RN apresentaram manifestações clínicas, alterações ao exame neurológico e da USG transfontanela, decorrentes de um possível processo asfíxico. Já no grupo com asfixia, o Apgar foi $\leq 6$ em todos os RN, havendo alterações do exame neurológico e da USG em 40,0\% dos RN do grupo lb (sem CIUR, com asfixia) e em $60,0 \%$ dos $\mathrm{RN}$ do grupo Ilb (com CIUR, com asfixia) (TABELA 2). A presença de manifestações clínicas decorrentes da asfixia, como: crise convulsiva, isquemia miocárdica, oligúria, insuficiência respiratória, síndrome de hipertensão pulmonar persistente, síndrome de aspiração meconial estiveram presentes em $13 \mathrm{RN}(65,0 \%)$ do grupo lb (sem CIUR, com asfixia) e em $4(80,0 \%)$ do grupo Ilb (com CIUR, com asfixia).

Em relação às características antropométricas, verificou-se maior peso, comprimento e perímetro cefálico ao nascimento nos grupos sem CIUR (la e Ib) em relação aos grupos com CIUR (Ila e Ilb), como era o desejado pelo próprio desenho do estudo (TABELA 3). A razão $P / P_{50}$ foi maior do que 0,87 em todos os $\mathrm{RN}$ do grupo sem CIUR e variou de 0,61 a 0,84 no grupo com CIUR(Anexo F). 


\subsubsection{Magnésio Total}

Embora os níveis de MgT em diferentes idades já estejam estabelecidos, estes não são tão úteis clinicamente como os níveis de Mgi, que refletem de maneira mais fidedigna a atividade intracelular do íon (Marcus et al.,1997).

A evolução dos níveis séricos de MgT no período neonatal, ao longo da 1a semana de vida, apresenta resultados conflitantes. Alguns estudos referem um aumento gradativo dos níveis de $\mathrm{MgT}$ até 48 horas de vida, com manutenção até o 70 dia (Hillman et al.,1977; Geven et al.,1993; Cook;Mimouni,1997). Outros autores, no entanto, referem não haver alteração destes valores nas $1 \underline{\text { as }} 12$ horas de vida (David et al.,1981) ou na 1a semana de vida (Bajpai et al.,1966).

Neste estudo, verificou-se um aumento progressivo, de maneira estatisticamente significante, nas concentrações séricas de MgT no grupo controle(la), ao longo da 1a semana de vida (TABELA 4).

A análise demonstrou diferença estatisticamente significante nas concentrações de MgT em cordão umbilical entre os grupos la e lla $(p<0,05)$, tendo o grupo com CIUR maiores valores. No entanto, no 3 o e 70 dias de vida, não houve diferenças nas concentrações de $\mathrm{MgT}$ entre estes dois grupos (GRÁFICO 5), o que pode indicar que o CIUR não reduziu o MgT intra-útero, como citado por alguns autores. 
Não houve diferença nas concentrações evolutivas de MgT nos grupos Ila (com CIUR, sem asfixia), Ib (sem CIUR, com asfixia) e Ilb (com CIUR, com asfixia) (TABELAS 5 a 7).

Os valores normais de referência são de 1,46 a 2,20 mg/dl, semelhantes aos encontrados neste estudo, no grupo controle (la)(TABELA 4).

\subsubsection{Magnésio iônico}

Os estudos sobre a evolução dos níveis séricos de Mgi, na 1a semana de vida, são escassos. Já nas 1as 24 horas de vida, Cook; Mimouni (1997) demonstraram não haver alteração nas concentrações de Mgi.

Há poucos estudos em relação aos níveis normais de Mgi no período neonatal. Marcus et al.(1997) e Cook; Mimouni(1997) referem valor médio para o Mgi de $0,48 \mathrm{mmol} / \mathrm{L}(0,40$ a 0,56$)$, tendo utilizado para esta medida 0 eletrodo do NOVA 8.

Já Dollberg et al.(2001), verificaram valor médio para o Mgi em sangue de cordão umbilical de $0,28 \mathrm{mmol} / \mathrm{L}(0,12$ a 0,40$)$ e, com $\pm 2-4$ horas de vida, de $0,30 \mathrm{mmol} / \mathrm{L}(0,20$ a 0,40$)$, utilizando para as medidas, o eletrodo do NOVA M. Este é mais específico e interage pouco com outros cátions, produzindo, assim, menores valores do que o NOVA 8 (Dollberg et al.,2001).

Neste estudo, a medida do Mgi foi realizada através do eletrodo do NOVA M e foram obtidos valores médios de Mgi no grupo la (sem CIUR, sem asfixia), dentro da faixa de normalidade descrita anteriormente $(0,20$ 0,40mmol/L) e sem variação significativa no decorrer da 1 a semana de vida 
(TABELA 4). As determinações desses níveis devem ser interpretadas com cuidado, em função do tipo de eletrodo usado para medida (Dollberg et al.,2001).

A análise do grupo Grupo Ila (com CIUR, sem asfixia), mostrou níveis médios de Mgi nos três momentos de coleta maiores do que no grupo la $(p<0,001)$ (GRÁFICO 4). Este achado contraria a hipótese de alguns autores, que referem menores níveis de Magnésio em RN com CIUR, em decorrência do processo de desnutrição intra-uterina (Tsang,1972b). No entanto, todos os estudos realizados até o momento, basearam seus achados nas concentrações de MgT e não nas de Mgi.

Os maiores níveis de Mgi observados nesses RN talvez possam ser justificados pela presença de flutuações da oxigenação e $\mathrm{pH}$ intra-uterinas, como elementos do processo de restrição nutricional, o que poderia levar a um desvio do Mg do intra para o extracelular, apesar de não terem sido observadas diferenças nos níveis de pH entre os grupos sem e com CIUR (Tsang,1972a; Wicks,1999).

Além disso, a redução da transferência placentária de Ca poderia causar uma elevação secundária do $\mathrm{PTH}$, com repercussão sobre as concentrações de Mgi. A menor massa renal existente nesses RN, está associada a uma menor produção de $1,25(\mathrm{OH})_{2} \mathrm{D}$ e à "resistência" ao PTH, com aumento ainda maior das concentrações séricas deste hormônio, o que poderia agravar a desmineralização óssea e levar a uma elevação da concentração plasmática de Mg (Namgung et al.,1993). 
No grupo lb (sem CIUR, com asfixia), os níveis séricos de Mgi foram significantemente maiores do que no grupo la (sem CIUR, sem asfixia) no $3 \circ(p=0,027)$ e $7 \stackrel{\circ}{(p<0,001)}$ dias de vida, sem diferença nos níveis em sangue de cordão umbilical ( $p=0,32)$ (GRÁFICO 4).

A presença de maiores níveis de Mgi em cordão umbilical de RN com sinais de $\mathrm{EIH}$, secundária à asfixia perinatal, foi justificada pela quebra temporária do ATP, induzida pela elevada demanda energética, devido à hipoxia-isquemia e liberação do $\mathrm{Mg}$ intracelular, já que os níveis de $\mathrm{pH}$ não foram diferentes em relação ao grupo sem asfixia (Olofsson et al.,2001). A lesão celular, decorrente da asfixia, também poderia causar liberação do Mg intracelular, com aumento das concentrações séricas deste íon (Forfar,1976; Ilves et al.,2000)

É importante ressaltar que há poucos estudos sobre o comportamento da fração iônica do $\mathrm{Mg}$ em $\mathrm{RN}$ com asfixia perinatal, sendo as análises baseadas em dados sobre o MgT.

\subsubsection{Relação entre Mgi e outros indicadores}

\subsubsection{Magnésio lônico e Total}

Foi observada uma correlação positiva entre os níveis de Mgi e MgT no 3o dia de vida no grupo Ib (sem CIUR, com asfixia) ( $p=0,041 ; r=0,501)$, demonstrando uma tendência a um aumento concomitante das frações 
iônica e total, a partir dessa idade, quando, provavelmente, existe uma tendência a maior estabilização metabólica (TABELA 15; GRÁFICO 9).

\subsubsection{Magnésio lônico e Cálcio iônico}

Alguns estudos referem um aumento gradativo nas concentrações de Cai ao longo da $1 \underline{\text { a }}$ semana de vida (Nelson et al.,1987). No entanto, a maioria dos autores referem que as menores concentrações de Ca estão presentes no $2^{\circ}$ ou $3 \stackrel{0}{ }$ dia de vida, com resolução espontânea da hipocalcemia após (Tsang et al.,1973a; Nelson et al., 1987).

Observou-se neste estudo, no grupo la (sem CIUR, sem asfixia), uma diminuição significativa das concentrações de Cai nas 1ㅗㅡ 48-72 horas de vida e um aumento no 7ํ dia de vida $(p<0,05)$. Estes níveis foram significantemente maiores do que no grupo com CIUR(Ila) e com asfixia perinatal(Ib)(TABELA 8).

A presença de menores níveis de Ca no grupo com asfixia (Ila) talvez, possa ser consequente à estimulação da secreção de calcitonina e ao hipoparatireoidismo funcional, na presença de hipoxemia (Tsang et al.,1974; Mimouni et al.,1990).

Já a ocorrência de um fluxo útero-placentário reduzido em $\mathrm{RN}$ com CIUR, poderia ser responsável pela diminuição do transporte de $\mathrm{Ca}$, com redução dos níveis séricos deste íon (Tsang,1972b; Namgung et al.,1993).

Os valores normais de Cai descritos são de 1,21 a 1,46 mmol/L. Utilizando-se o eletrodo NOVA-M, estes níveis em cordão umbilical variam 
entre 1,01 a 1,26 mmol/L, semelhantes aos aqui encontrados (Dollberg et al.,2001)(TABELA 8).

Quanto às análises de correlação entre o Cai e o Mgi, o fato de ter-se obtido uma correlação negativa entre estes ao nascimento, no grupo la (sem CIUR e sem asfixia perinatal) $(p=0,015 ; r=-0,471)$ (TABELA 13; GRÁFICO 6) reflete o resultado da homeostase materna e fetal desses elementos. Já a correlação obtida no $7 \stackrel{0}{0}$ dia, no grupo com asfixia perinatal e CIUR $(p=0,036$; r=-0,964) (TABELA 16; GRÁFICO 12), provavelmente reflete as modificações ocorridas na homeostase desses íons, em função dessas patologias, a asfixia perinatal e o CIUR.

Deve-se enfatizar, no entanto, que o significado clínico desta correlação fica muito enfraquecido pelo número muito reduzido de casos nesse grupo.

\subsubsection{Magnésio iônico e Fósforo}

Alguns autores referem que as concentrações séricas de $P$ têm uma tendência a diminuir durante a 1a semana de vida (Nelson et al.,1987). Outros apresentam uma pequena diminuição nos níveis no $1 \stackrel{\circ}{\text { a }} 2 \stackrel{0}{\circ}$ dia de vida, embora permaneçam ainda relativamente altos e possam aumentar durante a 1a semana de vida (David; Anast, 1974; Pitkin, 1985; Namgung; Tsang, 1998). Esta predisposição à hiperfosfatemia no RN, poderia ser decorrente do aumento da gliconeogênese, com liberação de P endógeno ou a uma baixa taxa de filtração glomerular, com redução da excreção de $P$ (Namgung;Tsang,1998). 
Verificou-se nos grupos la (sem CIUR, sem asfixia) e lla (com CIUR, sem asfixia), um aumento gradativo das concentrações séricas de $P$, ao longo da 1a semana de vida (TABELA 9).

Em RN com CIUR são referidos níveis menores de $\mathrm{P}$, na 1a semana de vida, em relação aos sem CIUR, de acordo com os resultados deste estudo, que poderia ser decorrente da redução do transporte placentário de $\mathrm{P}$ (Namgung et al.,1993).

A asfixia perinatal é associada a um aumento dos níveis séricos de $P$, possivelmente por aumento da quebra endógena de glicogênio e proteína tecidual, na presença de inadequada excreção urinária de P (Tsang et al., 1973a). Verificou-se, no entanto, que no 3 e $7 \underline{0}$ dias de vida as concentrações de $\mathrm{P}$ no grupo la (sem CIUR, sem asfixia) foram significantemente maiores do que no grupo lb (sem CIUR, com asfixia). A diminuição dos níveis no 3o dia de vida e a ausência de níveis maiores que no grupo controle podem ser atribuídas, talvez, ao jejum de 48 horas a que estes RN são habitualmente submetidos, recebendo uma baixa oferta de P.

Os valores iniciais descritos na literatura são de $6,2 \mathrm{mg} / \mathrm{dl}(3,7$ a 8,1), aumentando para $8,1 \mathrm{mg} / \mathrm{dl}$ com 1 semana de vida, semelhante aos encontrados neste estudo no grupo la (sem CIUR, sem asfixia) (Namgung;Tsang, 1998) (TABELA 9).

Em relação ao Mgi, não se obteve nenhuma correlação com os níveis de P. 


\subsubsection{Magnésio iônico e pH}

Observou-se um aumento gradativo do $\mathrm{pH}$ ao longo da 1a semana de vida nos grupos sem asfixia, não havendo diferença nos níveis de pH entre os grupos sem e com asfixia, o que poderia estar indicando que os casos incluídos no grupo com asfixia, tivessem apresentado asfixia leve ou moderada, com rápida recuperação, não afetando os valores de $\mathrm{pH}$ (TABELA 10).

Por outro lado, este resultado pode demonstrar, que o pH não deve ser utilizado como critério único para determinação da presença de asfixia perinatal grave (AAP,1996; Casey et al., 2001).

É esperado que, o aumento do $\mathrm{pH}$ ao longo da 1a semana de vida, ocasione uma entrada de Mg para o interior da célula, com diminuição de suas concentrações séricas, como pode ser verificado no grupo lla (com CIUR, sem asfixia), no qual houve uma relação inversa entre o $\mathrm{pH}$ e o Mgi no 7으 dia de vida ( $p=0,027 ; r=-0,495)$ (TABELA 14; GRÁFICO 7).

No estudo de Dollberg et al.(2001) foram encontrados níveis de pH em cordão umbilical de RNT saudáveis, que variaram de 7,19 a 7,42, semelhantes aos aqui encontrados (TABELA 10).

\subsubsection{Magnésio iônico e Creatinina}

Durante a 1a semana de vida, à medida que há um aumento progressivo da taxa de filtração glomerular, há uma diminuição dos níveis de creatinina, 
como observado neste estudo, em todos os grupos. Espera-se também que haja uma diminuição concomitante das concentrações de Mgi, em função do aumento da excreção renal (Wicks,1999).

Verificou-se esta relação positiva no 7 ํ dia de vida no grupo lb (sem CIUR, com asfixia) $(p=0,002 ; r=0,688)$ (TABELA 15; GRÁFICO 11). No entanto, no grupo Ila (com CIUR, sem asfixia), no 7으 dia de vida, observouse uma relação inversa $(p=0,001 ; r=-0,705)$, talvez causada pelos maiores níveis de Mgi neste grupo durante toda a 1aㅡ semana de vida, que passariam a se correlacionar com a creatinina somente após o estabelecimento da função renal, no 7o dia de vida (TABELA 14; GRÁFICO 8).

Estes níveis foram significantemente menores no grupo la (sem CIUR, sem asfixia) em relação aos grupo lla (com CIUR, sem asfixia) e lb (sem CIUR, com asfixia) em sangue de cordão umbilical, talvez refletindo algum grau de comprometimento renal secundário à hipoxia a que estes $\mathrm{RN}$ foram submetidos (TABELA 12).

\subsubsection{Magnésio iônico e Uréia}

O aumento da taxa de filtração glomerular que ocorre no decorrer da $1 \underline{a}$ semana de vida, leva a uma diminuição dos níveis de Mgi, que se reflete em uma relação positiva entre os níveis de Mgi e uréia no 7ํㅡ dia de vida no grupo Ib (sem CIUR, com asfixia) ( $p=0,001 ; r=0,895)$ (TABELA 15; GRÁFICO 10). 
A análise da Uréia sanguínea apresentou resultados $<10 \mathrm{mg} / \mathrm{dl}$ em várias determinações, sendo estes desconsiderados para inclusão no estudo, o que pode ter reduzido muito, em alguns grupos, o número de determinações desta, prejudicando a análise de outras possíveis relações entre esta e o Mgi.

\subsection{Considerações finais}

O Magnésio desempenha importante papel na modulação de funções de transporte e receptores, atividades enzimáticas, metabolismo energético, síntese de proteínas e ácidos nucleicos, e proteção de membranas biológicas (Marcus et al.,1997; Duran et al.,1998).

Apesar de sua importância, o conhecimento de sua homeostase não é completo, principalmente por dificuldade de acesso a seus estoques intracelulares e da ausência de métodos laboratoriais disponíveis para medida da fração iônica. O desenvolvimento recente de eletrodos íonseletivos para o Mgi, permitiu a determinação rápida das concentrações deste íon em pequenas amostras de sangue, o que possibilitou a realização de estudos para determinação dessa fração no período neonatal e incorporou avanços no conhecimento dos mecanismos de ação do $\mathrm{Mg}$ (Marcus et al.,1997).

Há poucos estudos sobre a homeostase do Mg no período neonatal e, principalmente sobre o comportamento da fração iônica. Além disso, é possível que situações clínicas, características deste período, como o CIUR, 
com várias repercussões importantes sobre o RN, poderiam potencialmente levar a desvios da homeostase do $\mathrm{Mg}$, ainda não totalmente esclarecidos.

O padrão de nutrição intra-uterina, conforme sugerem os resultados deste estudo, pode influenciar o Mgi durante a 1a semana de vida, embora maiores evidências não tivessem sido por nós detectadas, provavelmente pela não predominância de $\mathrm{RN}$ com ClUR grave $\left(\mathrm{P} / \mathrm{P}_{50}<0,75\right)$, nesta pesquisa.

Da mesma forma, em relação à asfixia perinatal, é possível que a menor proporção de RN com graus mais graves de asfixia, tenha favorecido a menor detecção de anormalidades nas concentrações séricas de Mgi.

A impossibilidade de se obter a casuística inicialmente programada para o grupo com CIUR e com asfixia, quando então se somariam dois fatores potencialmente capazes de modificar a homeostase do Mg, também pode ter colaborado para a ausência de detecção de alterações das concentrações de Mgi neste grupo.

Por outro lado, é possível que, devido ao papel fundamental desempenhado pelo $\mathrm{Mg}$ no controle de funções vitais em nível celular, suas concentrações estejam sob rigoroso controle e, assim, pequenas flutuações sejam rapidamente detectadas e corrigidas, para se evitar danos ao organismo.

Novas pesquisas referentes ao comportamento do Mgi no período neonatal, sob a influência de outros fatores de risco, contribuiriam para que o controle do Mg e seus distúrbios, possa ser feito de maneira mais eficiente e segura, especialmente se forem considerados os $\mathrm{RN}$ com extrema prematuridade. 
6 - CONCLUSÕES 
1. Em recém-nascidos de termo, sem crescimento intra-uterino restrito(CIUR), as concentrações médias de:

- Magnésio Total (MgT) foram menores do que as de RN com CIUR, ao nascimento;

- MgT elevaram-se de forma significante, desde o nascimento até o 7으 dia de vida, enquanto as de Magnésio lônico (Mgi) mantiveram-se;

- MgT não diferiram entre os RN com asfixia perinatal durante a 1a semana de vida;

- Mgi foram significativamente menores do que as de RN com CIUR desde o nascimento até 0 7으 dia de vida e do que as de RN com asfixia perinatal no 3 e 70 dias de vida.

\section{Em RNT sem CIUR,}

- Os níveis médios de Mgi correlacionaram-se inversamente aos de Cai ao nascimento.

\section{Em RNT com CIUR,}

- Os níveis médios de Mgi correlacionaram-se inversamente à creatinina plasmática e $\mathrm{pH}$ no 7 으 dia de vida. 
4. Em RNT sem CIUR com asfixia perinatal,

- Os níveis médios de Mgi correlacionaram-se positivamente à uréia e creatinina no 7으 dia de vida e ao MgT no 3ㅇ dia de vida.

5. Em RNT com CIUR com asfixia perinatal,

- Os níveis médios de Mgi correlacionaram-se inversamente aos de Cai no 7으 dia de vida.

6. Em RN de termo, o crescimento intra-uterino restrito, bem como a asfixia perinatal, podem causar repercussões em diferentes órgãos e sistemas, sendo as metabólicas responsáveis por modificações nas adaptações perinatais hormonais, que se refletiram em concentrações médias de Magnésio, especialmente da fração ionizada, maiores do que as verificadas na ausência destes, apesar de ainda dentro dos padrões aceitos como referência na literatura. 


\section{7 - ANEXOS}




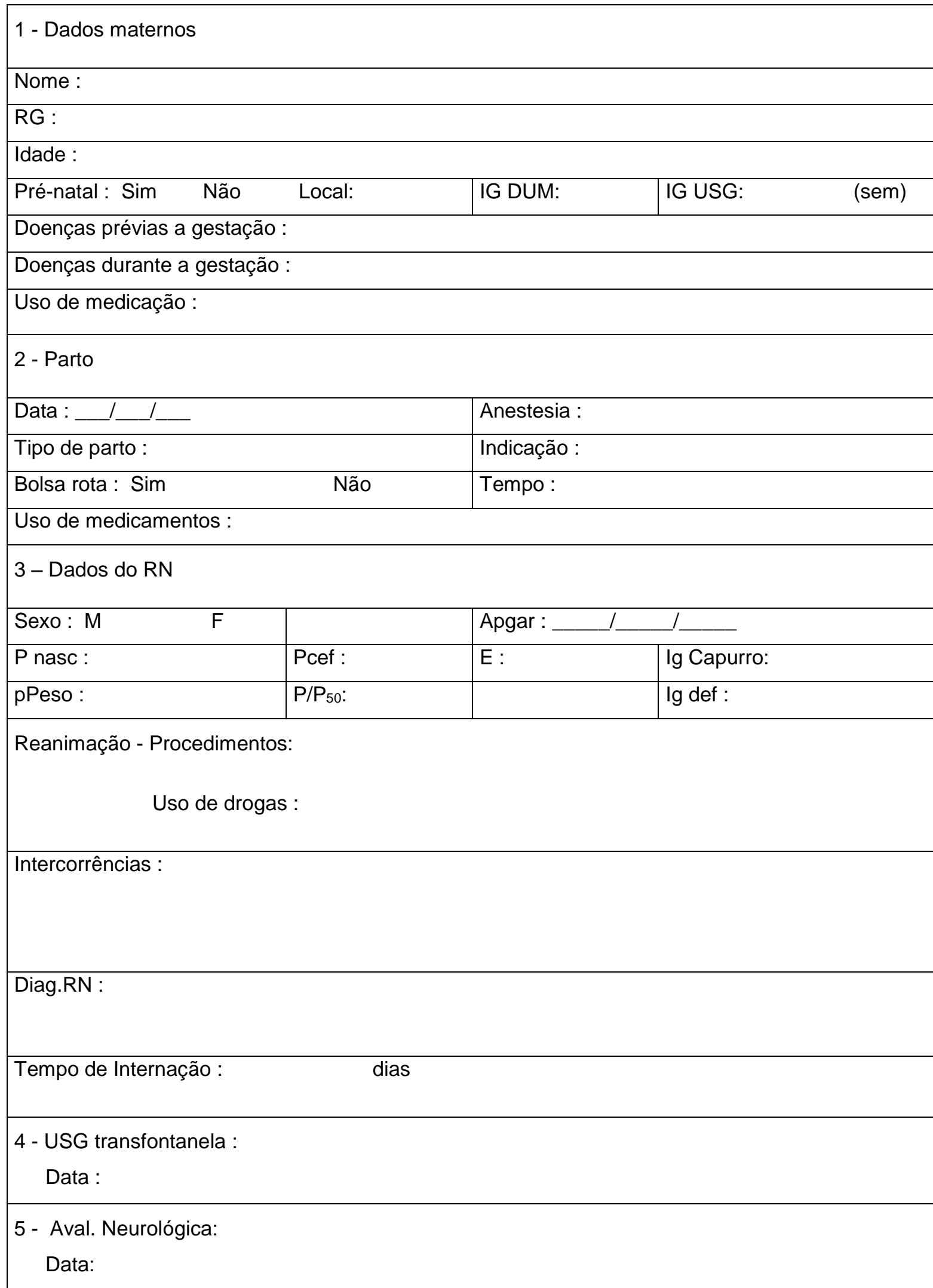


6- Avaliação laboratorial

\begin{tabular}{|l|l|l|l|l|l|l|l|}
\hline & Mgi & $\mathrm{pH}$ & U & Cai & MgT & Cr & $\mathrm{P}$ \\
\hline Cordão & & & & & & & \\
\hline $3^{\circ}$ dia & & & & & & & \\
\hline $7^{\circ}$ dia & & & & & & & \\
\hline
\end{tabular}

7- Avaliação nutricional

\begin{tabular}{|c|c|c|c|c|c|}
\hline & Jejum & Soro de manutenção & NPP & Leite materno & Fórmula \\
\hline $\begin{array}{l}1^{\circ} \text { dia } \\
\text { Peso: }\end{array}$ & & & & & \\
\hline $\begin{array}{l}2^{\circ} \text { dia } \\
\text { Peso: }\end{array}$ & & & & & \\
\hline $\begin{array}{l}3^{\circ} \mathrm{dia} \\
\text { Peso: }\end{array}$ & & & & & \\
\hline $\begin{array}{l}4^{\circ} \text { dia } \\
\text { Peso: }\end{array}$ & & & & & \\
\hline $\begin{array}{l}5^{\circ} \text { dia } \\
\text { Peso: }\end{array}$ & & & & & \\
\hline $\begin{array}{l}6^{\circ} \text { dia } \\
\text { Peso: }\end{array}$ & & & & & \\
\hline $\begin{array}{l}7^{\circ} \text { dia } \\
\text { Peso: }\end{array}$ & & & & & \\
\hline
\end{tabular}




\author{
ANEXO B \\ HOSPITAL DAS CLÍNICAS \\ DA \\ FACULDADE DE MEDICINA DA UNIVERSIDADE DE SÃO PAULO
}

TERMO DE CONSENTIMENTO LIVRE E ESCLARECIDO

(Instruções para preenchimento no verso)

I - DADOS DE IDENTIFICAÇÃO DO SUJEITO DA PESQUISA OU RESPONSÁVEL LEGAL

1. NOME DO PACIENTE .

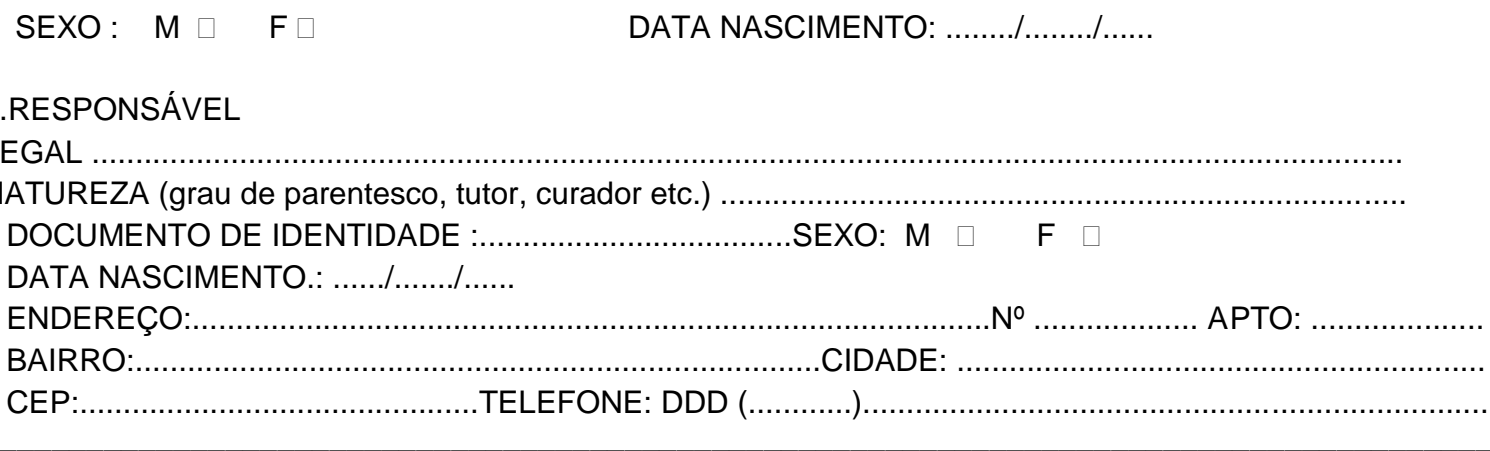

\title{
II - DADOS SOBRE A PESQUISA CIENTÍFICA
}

1. TÍTULO DO PROTOCOLO DE PESQUISA . Influência da asfixia perinatal e do crescimento intrauterino restrito sobre os níveis séricos de Magnésio na primeira semana de vida em recém-nascidos de termo.

2. PESQUISADOR: Naila de Oliveira Elias Barbosa

CARGO/FUNÇÃO: Médica Assistente-Bolsista UNIDADE DO HCFMUSP: Berçário Anexo à Maternidade INSCRIÇÃO CONSELHO REGIONAL № 71231

3. AVALIAÇÃO DO RISCO DA PESQUISA: SEM RISCO $\square$ RISCO MÍNIMO $\square$ RISCO MÉDIO RISCO BAIXO $\square \quad$ RISCO MAIOR

(probabilidade de que o indivíduo sofra algum dano como consequência imediata ou tardia do estudo)

4.DURAÇÃO DA PESQUISA : 3 Anos

\section{III - REGISTRO DAS EXPLICAÇõES DO PESQUISADOR AO PACIENTE OU SEU REPRESENTANTE LEGAL SOBRE A PESQUISA, CONSIGNANDO:}

1.Gostaria de obter sua autorização para inclusão de seu filho em um trabalho que estou realizando no Berçário . Neste estudo, estamos fazendo a medida de várias substâncias no sangue dos bebês, sendo a principal , uma chamada Magnésio, que é muito importante para a saúde do recém-nascido e se conhece ainda pouco sobre o seu comportamento logo após o nascimento. A sua falta pode, por exemplo, levar a alteração do ritmo do coração e convulsões e o seu excesso, a parada respiratória. Maios ou menos 80 recém-nascidos farão parte do estudo. Alguns bebês nasceram sem problemas e outros nasceram com o peso baixo ou demoraram a chorar ,que são os que têm maior risco de sofrerem alterações do magnésio. 
2.Para isto, será preciso realizar três coletas de sangue : a primeira é a do sangue do cordão umbilical que sai junto com a placenta assim que o bebê nasce. A segunda, é no $3^{\circ}$ dia e a terceira no $7^{\circ}$ dia de vida. A quantidade de sangue necessária é pequena, não fazendo falta para o bebê. Procuraremos sempre colher este sangue juntamente com algum exame de rotina. Por exemplo, se seu bebê tiver icterícia (ficar amarelinho) ,serão colhidos juntos, o sangue para o meu estudo e para ver a icterícia ou juntamente com o teste do pezinho ou outros exames necessários. Faremos também ultra-som da cabecinha e pediremos avaliação do neurologista, que são exames que não causam nenhum tipo de dor.

3. Será usada para a coleta uma agulha bem fininha, específica para recém-nascidos e serei sempre eu a colher que tenho uma boa experiência na coleta de sangue de bebês bem pequenos. Normalmente, a gente colhe sangue da mão ou do braço que são locais de fácil e rápido acesso. O bebê pode chorar um pouco, mas somente no momento da coleta . Além do choro, não há outros riscos ou consequências.

4. Com este estudo, poderemos ajudar vários recém-nascidos já que saberemos de antemão quais bebês têm maiores chances de sofrerem alterações desta substância no sangue, evitando que eles venham a ter tremores, convulsões, parada de respiração ou cardíaca, já que um maior controle estará presente desde o nascimento e o início do tratamento será mais rápido. Todos os resultados do seu filho(a) serão informados, e se alterados será iniciado o tratamento ou acompanhamento ,de acordo com o caso.

IV - ESCLARECIMENTOS DADOS PELO PESQUISADOR SOBRE GARANTIAS DO SUJEITO DA PESQUISA: 1.acesso, a qualquer tempo, às informações sobre procedimentos, riscos e benefícios relacionados à pesquisa, inclusive para dirimir eventuais dúvidas. 2. liberdade de retirar seu consentimento a qualquer momento e de deixar de participar do estudo, sem que isto traga prejuízo à continuidade da assistência. 3. salvaguarda da confidencialidade, sigilo e privacidade. 4. disponibilidade de assistência no HCFMUSP, por eventuais danos à saúde, decorrentes da pesquisa.

5. viabilidade de indenização por eventuais danos à saúde decorrentes da pesquisa.

\section{INFORMAÇÕES DE NOMES, ENDEREÇOS E TELEFONES DOS RESPONSÁVEIS PELO ACOMPANHAMENTO DA PESQUISA, PARA CONTATO EM CASO DE INTERCORRÊNCIAS CLÍNICAS E REAÇÕES ADVERSAS.}

Dra. Naila Elias Barbosa 3266-5725/3069-6395/30696081

\section{VI- CONSENTIMENTO PÓS-ESCLARECIDO}

Declaro que, após convenientemente esclarecido pelo pesquisador e ter entendido o que me foi explicado, consinto em participar do presente Protocolo de Pesquisa São Paulo, 
Anexo C - Características maternas nos diferentes grupos de estudo

Anexo C1 - Características maternas no grupo de mães de RNT sem CIUR (Grupo la)

\begin{tabular}{|c|c|c|c|c|c|c|}
\hline $\begin{array}{l}\text { CASO } \\
\mathbf{N}^{\circ}\end{array}$ & $\begin{array}{l}\text { IDADE } \\
\text { (anos) }\end{array}$ & $\begin{array}{l}\text { PATOLOGIAS } \\
\text { PRÉVIAS }\end{array}$ & PRÉ-NATAL & $\begin{array}{l}\text { INTERCORRÊNCIAS } \\
\text { NA GESTAÇÃO }\end{array}$ & $\begin{array}{c}\text { MEDICAÇÕES } \\
\text { UTILIZADAS }\end{array}$ & PARTO \\
\hline 1 & 28 & Paralisia infantil & Sim & - & - & Cesárea \\
\hline 2 & 37 & - & Sim & - & - & Normal \\
\hline 3 & 32 & Câncer maxilar & Sim & - & - & Normal \\
\hline 4 & 36 & - & Não & - & - & Fórceps \\
\hline 5 & 21 & - & Sim & - & - & Normal \\
\hline 6 & 32 & - & Sim & - & - & Cesárea \\
\hline 7 & 31 & - & Não & - & - & Normal \\
\hline 8 & 30 & - & Sim & - & - & Fórceps \\
\hline 9 & 25 & Epilepsia & Sim & - & - & Normal \\
\hline 10 & 17 & - & Não & - & - & Normal \\
\hline 11 & 33 & - & Não & - & - & Cesárea \\
\hline 12 & 26 & Litíase renal & Sim & DHEG & a- metildopa & Cesárea \\
\hline 13 & 24 & Asma & Sim & - & - & Normal \\
\hline 14 & 32 & - & Sim & - & - & Fórceps \\
\hline 15 & 18 & Febre reumática & Sim & - & Penicilina & Normal \\
\hline 16 & 40 & - & Sim & - & - & Cesárea \\
\hline 17 & 16 & - & Sim & DHEG & - & Fórceps \\
\hline 18 & 18 & - & Sim & - & - & Cesárea \\
\hline 19 & 20 & - & Sim & DHEG & a- metildopa & Fórceps \\
\hline 20 & 27 & - & Não & - & - & Fórceps \\
\hline 21 & 22 & - & Sim & - & - & Fórceps \\
\hline 22 & 14 & - & Não & - & - & Normal \\
\hline 23 & 18 & Epilepsia & Sim & - & - & Fórceps \\
\hline 24 & 25 & HAS/Asma & Sim & - & Pindolol & Cesárea \\
\hline 25 & 24 & Litíase renal & Sim & - & - & Cesárea \\
\hline 26 & 25 & - & Não & - & - & Normal \\
\hline 27 & 32 & HAS & Sim & - & - & Cesárea \\
\hline 28 & 31 & Febre reumática & Sim & - & $\begin{array}{l}\alpha \text {-metildopa/ } \\
\text { Penicilina }\end{array}$ & Cesárea \\
\hline 29 & 20 & HAS & Sim & - & - & Cesárea \\
\hline 30 & 25 & - & Sim & - & - & Normal \\
\hline
\end{tabular}

DHEG = Doença Hipertensiva específica da Gestação

HAS = Hipertensão arterial sistêmica 
Anexo C2 - Características maternas no grupo de mães de RNT com CIUR (Grupo lla)

\begin{tabular}{|c|c|c|c|c|c|c|}
\hline $\begin{array}{l}\text { CASO } \\
\mathbf{N}^{\circ}\end{array}$ & $\begin{array}{l}\text { IDADE } \\
\text { (anos) }\end{array}$ & $\begin{array}{l}\text { PATOLOGIAS } \\
\text { PRÉVIAS }\end{array}$ & PRÉ-NATAL & $\begin{array}{l}\text { INTERCORRÊNCIAS } \\
\text { NA GESTAÇÃO }\end{array}$ & $\begin{array}{c}\text { MEDICAÇÕES } \\
\text { UTILIZADAS }\end{array}$ & PARTO \\
\hline 1 & 33 & - & Sim & - & - & Cesárea \\
\hline 2 & 42 & $\begin{array}{l}\text { Infarto agudo do } \\
\text { Miocárdio }\end{array}$ & Sim & DHEG & Propranolol & Cesárea \\
\hline 3 & 40 & - & Sim & DHEG & - & Normal \\
\hline 4 & 33 & $\begin{array}{l}\mathrm{HAC} / \text { Prolapso } \\
\text { mitral }\end{array}$ & Sim & CIUR & $\alpha$-metildopa & Cesárea \\
\hline 5 & 18 & - & Sim & - & - & Fórceps \\
\hline 6 & 38 & - & Não & - & - & Cesárea \\
\hline 7 & 38 & HAC & Sim & CIUR & $\begin{array}{l}\alpha \text {-metildopa } \\
\text { Pindolol }\end{array}$ & Cesárea \\
\hline 8 & 28 & - & Não & - & - & Cesárea \\
\hline 9 & 12 & - & Sim & - & - & Cesárea \\
\hline 10 & 21 & CIV & Sim & ClUR/Oligoâmnio & - & Cesárea \\
\hline 11 & 26 & Epilepsia & Sim & - & - & Normal \\
\hline 12 & 17 & - & Sim & DHEG & - & Cesárea \\
\hline 13 & 24 & - & Sim & CIUR/Oligoâmnio & - & Cesárea \\
\hline 14 & 43 & - & Sim & - & - & Cesárea \\
\hline 15 & 33 & Asma & Sim & DHEG & Salbutamol & Normal \\
\hline 16 & 31 & - & Sim & DHEG & $\alpha$-metildopa & Cesárea \\
\hline 17 & 20 & - & Sim & - & - & Normal \\
\hline 18 & 33 & - & Sim & - & - & Normal \\
\hline 19 & 19 & - & Não & - & - & Fórceps \\
\hline 20 & 30 & - & $\operatorname{Sim}$ & ClUR/Oligoâmnio & - & Cesárea \\
\hline
\end{tabular}

DHEG = Doença Hipertensiva específica da Gestação

$H A C=$ Hipertensão arterial crônica

$\mathrm{CIV}=$ Comunicação Interventricular 
Anexo C2 - Características maternas no grupo de mães de RNT com CIUR (Grupo lla)

\begin{tabular}{|c|c|c|c|c|c|c|}
\hline $\begin{array}{l}\text { CASO } \\
\mathbf{N}^{\circ}\end{array}$ & $\begin{array}{l}\text { IDADE } \\
\text { (anos) }\end{array}$ & $\begin{array}{l}\text { PATOLOGIAS } \\
\text { PRÉVIAS }\end{array}$ & PRÉ-NATAL & $\begin{array}{l}\text { INTERCORRÊNCIAS } \\
\text { NA GESTAÇÃO }\end{array}$ & $\begin{array}{c}\text { MEDICAÇÕES } \\
\text { UTILIZADAS }\end{array}$ & PARTO \\
\hline 21 & 28 & - & Sim & - & AAS & Cesárea \\
\hline 22 & 27 & Epilepsia & Sim & - & Fenobarbital & Cesárea \\
\hline 23 & 26 & - & Não & - & - & Normal \\
\hline \multirow[t]{2}{*}{24} & 30 & $\begin{array}{l}\text { Insuficiência } \\
\text { mitral }\end{array}$ & Sim & - & Propranolol & Fórceps \\
\hline & & /Estenose mitral & & & & \\
\hline 25 & 22 & HAC & Sim & - & - & Cesárea \\
\hline 26 & 31 & - & Não & - & - & Cesárea \\
\hline 27 & 33 & Estenose mitral & Sim & - & Propranolol & Cesárea \\
\hline 28 & 22 & - & Não & - & - & Cesárea \\
\hline 29 & 37 & Psoríase & Sim & - & - & Cesárea \\
\hline 30 & 23 & Epilepsia & Sim & - & Fenobarbital & Cesárea \\
\hline 31 & 27 & - & Sim & - & - & Cesárea \\
\hline 32 & 19 & HAC & Sim & - & Atenolol & Cesárea \\
\hline 33 & 24 & $\mathrm{HAC}$ & Sim & CIUR/Oligoâmnio & $\alpha$-metildopa & Cesárea \\
\hline 34 & 36 & Asma & Sim & Placenta prévia & $\alpha$-metildopa & Cesárea \\
\hline 35 & 27 & - & Sim & CIUR/Oligoâmnio & - & Cesárea \\
\hline 36 & 16 & - & Não & - & - & Cesárea \\
\hline 37 & 39 & CIV & Sim & - & - & Cesárea \\
\hline 38 & 26 & - & Sim & CIUR/Oligoâmnio & - & Normal \\
\hline 39 & 25 & - & Não & - & - & Normal \\
\hline 40 & 26 & - & Sim & - & - & Cesárea \\
\hline
\end{tabular}


Anexo C3 - Características maternas no grupo de RNT sem CIUR com asfixia perinatal (Grupo lb)

\begin{tabular}{|c|c|c|c|c|c|c|}
\hline $\begin{array}{l}\text { CASO } \\
\mathbf{N}^{\circ}\end{array}$ & $\begin{array}{l}\text { IDADE } \\
\text { (anos) }\end{array}$ & $\begin{array}{l}\text { PATOLOGIAS } \\
\text { PRÉVIAS }\end{array}$ & $\begin{array}{l}\text { PRÉ- } \\
\text { NATAL }\end{array}$ & $\begin{array}{l}\text { INTERCORRÊNCIAS } \\
\text { NA GESTAÇÃO }\end{array}$ & $\begin{array}{l}\text { MEDICAÇÃO } \\
\text { UTILIZADA }\end{array}$ & PARTO \\
\hline 1 & 38 & - & Sim & - & - & Cesárea \\
\hline 2 & 15 & - & Sim & - & - & Cesárea \\
\hline 3 & 17 & - & Sim & - & - & Cesárea \\
\hline 4 & 18 & - & Sim & - & - & Cesárea \\
\hline 5 & 26 & - & $\operatorname{Sim}$ & DHEG & $\alpha$-metidopa & Cesárea \\
\hline 6 & 21 & $\begin{array}{c}\text { Insuficiência } \\
\text { Mitral/ FR }\end{array}$ & Sim & - & $\begin{array}{l}\text { Penicilina } \\
\text { benzatina }\end{array}$ & Fórceps \\
\hline 7 & 32 & - & Sim & DHEG & $\alpha$-metildopa & Cesárea \\
\hline 8 & 24 & HAS & Sim & DHEG & - & Cesárea \\
\hline 9 & 18 & - & Não & - & - & Cesárea \\
\hline 10 & 20 & - & Sim & - & - & Normal \\
\hline 11 & 26 & - & Sim & DHEG & Pindolol & Cesárea \\
\hline 12 & 38 & - & Sim & - & - & Cesárea \\
\hline 13 & 34 & - & Sim & - & - & Cesárea \\
\hline 14 & 23 & - & Não & - & - & Cesárea \\
\hline 15 & 28 & - & Sim & - & - & Fórceps \\
\hline 16 & 24 & - & $\operatorname{Sim}$ & - & - & Cesárea \\
\hline 17 & 33 & Nefropatia/HAS & Sim & - & $\begin{array}{c}\text { Pindolol/ } \\
\alpha \text {-metidopa }\end{array}$ & Cesárea \\
\hline 18 & 37 & - & Sim & - & - & Cesárea \\
\hline 19 & 16 & - & Não & - & - & Fórceps \\
\hline 20 & 20 & - & Não & - & - & Fórceps \\
\hline
\end{tabular}

DHEG = Doença Hipertensiva específica da Gestação

$\mathrm{FR}=$ Febre reumática

HAS = Hipertensão arterial sistêmica 
Anexo C4 - Características maternas no grupo de RNT com CIUR e asfixia perinatal (Grupo llb)

\begin{tabular}{ccccccc}
\hline $\begin{array}{c}\text { CASO } \\
\mathbf{N}^{\circ}\end{array}$ & $\begin{array}{c}\text { IDADE } \\
\text { (anos) }\end{array}$ & $\begin{array}{c}\text { PATOLOGIAS } \\
\text { PRÉVIAS }\end{array}$ & PRÉ-NATAL & $\begin{array}{c}\text { INTERCORRÊNCIAS } \\
\text { NA GESTAÇÃO }\end{array}$ & $\begin{array}{c}\text { MEDICAÇÃo } \\
\text { UTILIZADA }\end{array}$ & $\begin{array}{c}\text { TIPO DE } \\
\text { PARTO }\end{array}$ \\
\hline $\mathbf{1}$ & 37 & - & $\operatorname{Sim}$ & CIUR/Oligoâmnio & - & Cesárea \\
$\mathbf{2}$ & 14 & - & $\operatorname{Sim}$ & - & - & Cesárea \\
$\mathbf{3}$ & 30 & - & Não & - & - & Normal \\
$\mathbf{4}$ & 33 & - & Não & - & - & Normal \\
$\mathbf{5}$ & 16 & - & Sim & - & - & Cesárea \\
\hline
\end{tabular}


Anexo D - Características dos Recém-nascidos nos diferentes grupos de estudo

Anexo D1 - Características dos Recém-Nascidos no grupo de RNT sem CIUR (Grupo la)

\begin{tabular}{|c|c|c|c|c|c|}
\hline $\begin{array}{c}\text { CASO } \\
\mathbf{N}^{\circ}\end{array}$ & SEXO & $\begin{array}{c}\text { IG } \\
\text { (semanas) }\end{array}$ & $\begin{array}{l}\text { APGAR } \\
1^{\prime} / 5^{\prime} / 10^{\prime}\end{array}$ & INTERCORRÊNCIAS & $\mathrm{Tl}$ (dias) \\
\hline 1 & M & 37,86 & $8 / 10 / 10$ & Icterícia do RN & 3 \\
\hline 2 & M & 38,14 & $9 / 10 / 10$ & Icterícia do RN & 3 \\
\hline 3 & M & 40,00 & $9 / 10 / 10$ & - & 3 \\
\hline 4 & M & 40,71 & $8 / 9 / 9$ & - & 3 \\
\hline 5 & M & 39,29 & $9 / 10 / 10$ & Icterícia do RN & 3 \\
\hline 6 & M & 39,86 & $9 / 10 / 10$ & - & 3 \\
\hline 7 & $\mathrm{~F}$ & 40,86 & $8 / 9 / 9$ & Desconforto respiratório & 4 \\
\hline 8 & $\mathrm{~F}$ & 40,00 & $9 / 10 / 10$ & Icterícia do RN & 3 \\
\hline 9 & M & 40,29 & $9 / 9 / 10$ & - & 3 \\
\hline 10 & $M$ & 40,14 & $8 / 9 / 9$ & Icterícia do RN & 3 \\
\hline 11 & $M$ & 37,86 & $9 / 9 / 10$ & - & 6 \\
\hline 12 & M & 39,14 & $8 / 9 / 10$ & - & 3 \\
\hline 13 & $M$ & 38,00 & $8 / 9 / 10$ & Icterícia do RN & 3 \\
\hline 14 & M & 38,57 & $9 / 10 / 10$ & - & 3 \\
\hline 15 & M & 38,57 & $9 / 10 / 10$ & Icterícia do $\mathrm{RN}$ & 3 \\
\hline 16 & $M$ & 40,43 & $8 / 9 / 10$ & - & 3 \\
\hline 17 & M & 38,00 & $7 / 10 / 10$ & Desconforto respiratório & 7 \\
\hline 18 & M & 40,43 & $6 / 8 / 10$ & Icterícia do RN/ Desconforto respiratório & 7 \\
\hline 19 & M & 40,14 & $9 / 9 / 10$ & Icterícia do RN & 3 \\
\hline 20 & $\mathrm{~F}$ & 40,00 & $9 / 10 / 10$ & - & 3 \\
\hline 21 & M & 40,29 & $9 / 10 / 10$ & Icterícia do $\mathrm{RN}$ & 3 \\
\hline 22 & M & 42,00 & $8 / 9 / 9$ & Icterícia do RN & 3 \\
\hline 23 & $\mathrm{~F}$ & 41,14 & $9 / 9 / 10$ & Icterícia do RN & 3 \\
\hline 24 & $\mathrm{~F}$ & 39,71 & $9 / 9 / 10$ & - & 3 \\
\hline 25 & M & 40,57 & $8 / 9 / 9$ & - & 3 \\
\hline 26 & $\mathrm{~F}$ & 42,00 & $8 / 9 / 10$ & Icterícia do RN & 3 \\
\hline 27 & $\mathrm{~F}$ & 40,00 & $9 / 10 / 10$ & - & 3 \\
\hline 28 & $\mathrm{~F}$ & 37,00 & 6/9/9 & Desconforto respiratório & 7 \\
\hline 29 & M & 39,57 & $8 / 9 / 9$ & Icterícia do RN & 3 \\
\hline 30 & $\mathrm{~F}$ & 39,00 & $9 / 10 / 10$ & - & 3 \\
\hline
\end{tabular}


Anexo D2 - Características dos Recém-Nascidos no grupo de RNT com CIUR (Grupo lla)

\begin{tabular}{|c|c|c|c|c|c|}
\hline $\begin{array}{c}\text { CASO } \\
\mathrm{N}^{\circ}\end{array}$ & SEXO & $\begin{array}{c}\text { IG } \\
\text { (semanas) }\end{array}$ & $\begin{array}{l}\text { APGAR } \\
1^{\prime} / 5^{\prime} / 10^{\prime}\end{array}$ & INTERCORRÊNCIAS & $\mathrm{TI}$ (dias) \\
\hline 1 & $\mathrm{~F}$ & 41,00 & $9 / 10 / 10$ & Icterícia do RN & 3 \\
\hline 2 & M & 38,43 & $8 / 9 / 9$ & Icterícia do RN & 3 \\
\hline 3 & M & 39,86 & 9/9/9 & Icterícia do RN & 3 \\
\hline 4 & $\mathrm{~F}$ & 37,14 & $8 / 9 / 10$ & Icterícia do RN & 7 \\
\hline 5 & $\mathrm{~F}$ & 39,29 & $8 / 9 / 10$ & - & 5 \\
\hline 6 & M & 38,00 & $9 / 9 / 10$ & - & 3 \\
\hline 7 & $\mathrm{~F}$ & 38,00 & $8 / 9 / 9$ & $\begin{array}{l}\text { Desconforto respiratório/ } \\
\text { Hiperexcitabilidadde }\end{array}$ & 5 \\
\hline 8 & $\mathrm{~F}$ & 38,29 & $9 / 10 / 10$ & - & 8 \\
\hline 9 & M & 39,14 & $6 / 8 / 9$ & Desconforto respiratório & 4 \\
\hline 10 & M & 39,86 & $8 / 9 / 9$ & - & 3 \\
\hline 11 & $\mathrm{~F}$ & 37,57 & $7 / 8 / 8$ & Desconforto respiratório & 3 \\
\hline 12 & $\mathrm{~F}$ & 38,29 & $8 / 10 / 10$ & Icterícia do RN & 3 \\
\hline 13 & M & 38,00 & $8 / 9 / 10$ & Hipoglicemia/Onfalite/lcterícia do RN & 14 \\
\hline 14 & $\mathrm{~F}$ & 37,29 & $8 / 9 / 9$ & - & 3 \\
\hline 15 & $\mathrm{~F}$ & 37,43 & $9 / 10 / 10$ & - & 5 \\
\hline 16 & M & 38,71 & $7 / 9 / 9$ & - & 3 \\
\hline 17 & M & 38,71 & $9 / 9 / 10$ & - & 3 \\
\hline 18 & $\mathrm{~F}$ & 37,00 & $8 / 9 / 9$ & - & 3 \\
\hline 19 & M & 39,43 & $9 / 9 / 10$ & Icterícia do RN & 4 \\
\hline 20 & M & 37,86 & $8 / 9 / 10$ & Icterícia do RN & 4 \\
\hline
\end{tabular}

IG=Idade Gestacional

Tl=Tempo de Internação

$\mathbf{F}=$ Feminino

M=Masculino 
Anexo D2 - Características dos Recém-Nascidos no grupo de RNT com CIUR (Grupo lla)

\begin{tabular}{|c|c|c|c|c|c|}
\hline $\begin{array}{c}\text { CASO } \\
\mathrm{N}^{\circ}\end{array}$ & SEXO & $\begin{array}{c}\text { IG } \\
\text { (semanas) }\end{array}$ & $\begin{array}{l}\text { APGAR } \\
1^{\prime} / 5^{\prime} / 10^{\prime}\end{array}$ & INTERCORRÊNCIAS & $\mathrm{TI}$ (dias) \\
\hline 21 & $\mathrm{~F}$ & 38,43 & $8 / 10 / 10$ & Icterícia do RN & 4 \\
\hline 22 & $\mathrm{~F}$ & 37,00 & $7 / 9 / 9$ & Anemia/Desconforto respiratório & 6 \\
\hline 23 & M & 39,14 & $9 / 10 / 10$ & - & 3 \\
\hline 24 & $\mathrm{~F}$ & 37,29 & $8 / 9 / 10$ & Icterícia do RN & 7 \\
\hline 25 & M & 37,86 & $9 / 10 / 10$ & - & 3 \\
\hline 26 & M & 38,86 & $8 / 9 / 10$ & - & 3 \\
\hline \multirow[t]{2}{*}{27} & $\mathrm{~F}$ & 37,00 & $8 / 9 / 9$ & Desconforto respiratório/ & 6 \\
\hline & & & & Hipoglicemia/Icterícia do RN & \\
\hline 28 & M & 37,00 & $8 / 9 / 9$ & Hipoglicemia/lcterícia do RN & 7 \\
\hline 29 & $\mathrm{~F}$ & 39,00 & $9 / 9 / 10$ & - & 3 \\
\hline 30 & $\mathrm{~F}$ & 39,00 & $6 / 8 / 9$ & - & 5 \\
\hline 31 & $\mathrm{~F}$ & 38,71 & $7 / 9 / 9$ & - & 3 \\
\hline 32 & M & 38,29 & $6 / 9 / 9$ & Desconforto respiratório/lcterícia do RN & 8 \\
\hline 33 & M & 37,00 & $8 / 9 / 9$ & Desconforto respiratório & 3 \\
\hline 34 & $\mathrm{~F}$ & 37,00 & $8 / 9 / 10$ & Icterícia do RN & 3 \\
\hline 35 & M & 39,00 & $8 / 9 / 10$ & Conjuntivite química & 3 \\
\hline 36 & M & 38,00 & $9 / 10 / 10$ & - & 3 \\
\hline 37 & M & 37,00 & $9 / 9 / 10$ & Desconforto respiratório & 5 \\
\hline 38 & M & 38,29 & $8 / 9 / 9$ & Hipoglicemia & 7 \\
\hline 39 & M & 37,86 & $9 / 10 / 10$ & Icterícia do RN & 9 \\
\hline 40 & M & 37,00 & $8 / 9 / 9$ & - & 3 \\
\hline
\end{tabular}

IG=Idade Gestacional

Tl=Tempo de Internação

$\mathbf{F}=$ Feminino

M=Masculino 
Anexo D3 - Características dos Recém-Nascidos no grupo de RNT sem CIUR com asfixia perinatal (Grupo lb)

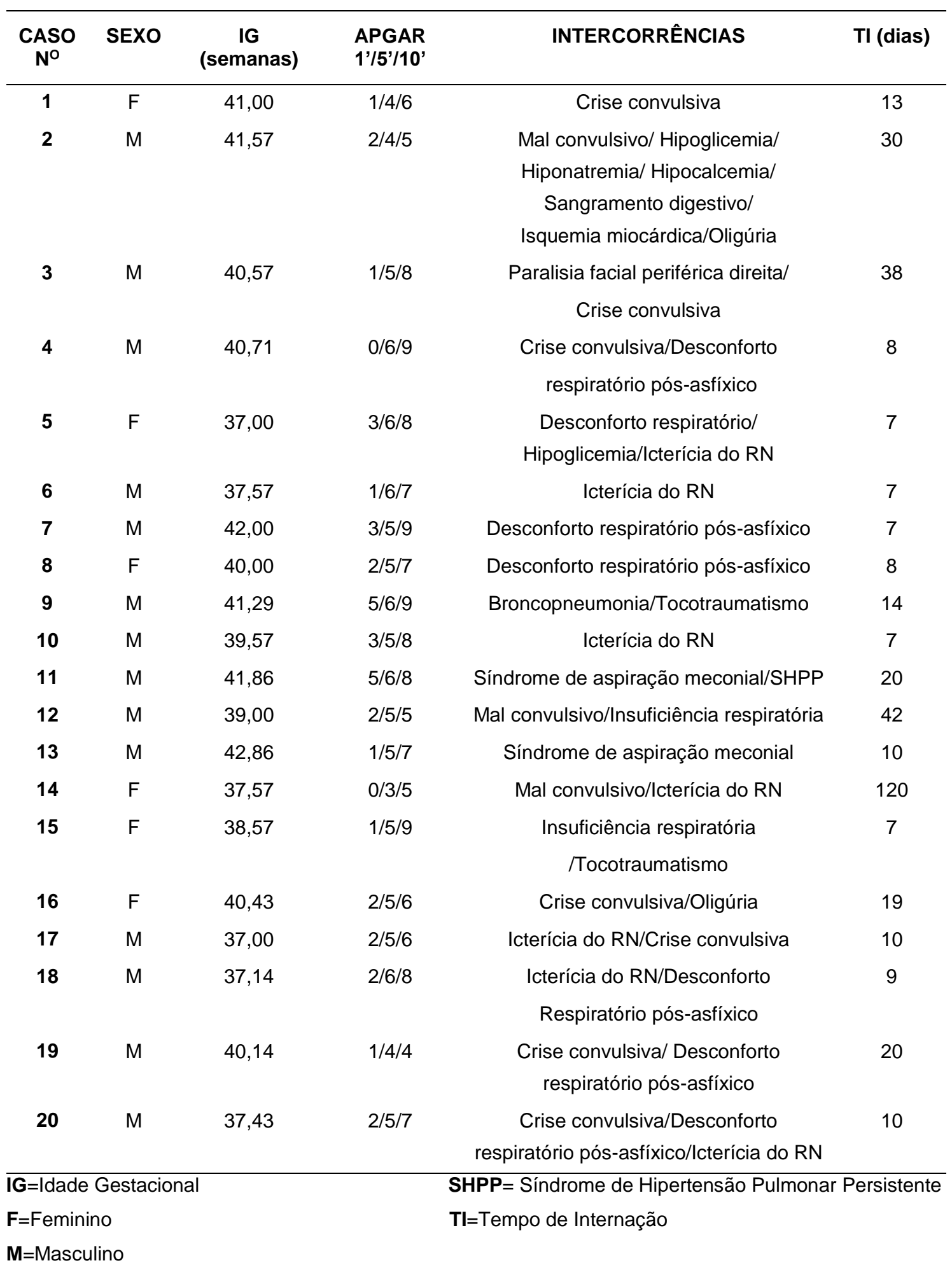


Anexo D4 - Características dos Recém-Nascidos no grupo de RNT com CIUR e asfixia perinatal (Grupo Ilb)

\begin{tabular}{cccccc}
\hline $\begin{array}{c}\text { CASO } \\
\mathbf{N}^{\circ}\end{array}$ & SEXO & $\begin{array}{c}\text { IG } \\
\text { (semanas) }\end{array}$ & $\begin{array}{c}\text { APGAR } \\
\mathbf{1}^{\prime} / \mathbf{5}^{\prime} / 10^{\prime}\end{array}$ & INTERCORRÊNCIAS & TI (dias) \\
\hline $\mathbf{1}$ & $\mathrm{M}$ & 37,86 & $0 / 5 / 6$ & $\begin{array}{c}\text { Convulsão/Síndrome de aspiração } \\
\text { meconial }\end{array}$ & 45 \\
$\mathbf{2}$ & $\mathrm{M}$ & 41,14 & $2 / 6 / 8$ & $\begin{array}{c}\text { Mal convulsivo } \\
\text { Insuficiência respiratória/ }\end{array}$ & 14 \\
$\mathbf{3}$ & $\mathrm{M}$ & 40,00 & $0 / 1 / 6$ & $\begin{array}{c}\text { Oligúria/lcterícia do RN } \\
\text { Insuficiência respiratória }\end{array}$ & 7 \\
$\mathbf{4}$ & $\mathrm{M}$ & 40,14 & $3 / 6 / 8$ & $\begin{array}{c}\text { Crise convulsiva/ } \\
\text { Insuficiência respiratória }\end{array}$ & 20 \\
$\mathbf{5}$ & $\mathrm{M}$ & 41,43 & $3 / 6 / 8$ & &
\end{tabular}

IG=Idade Gestacional

TI=Tempo de Internação

M=Masculino 
Anexo E - Avaliação Neurológica e Ultra-Sonografia (USG) transfontanela nos diferentes grupos de estudo

Anexo E1 - Avaliação Neurológica e USG transfontanela em RNT sem CIUR (Grupo la)

\begin{tabular}{|c|c|c|}
\hline CASO NO & $\begin{array}{c}\text { AVALIAÇÃO } \\
\text { NEUROLÓGICA } \\
\text { n =22 }\end{array}$ & $\begin{array}{l}\text { USG TRANSFONTANELA } \\
\qquad \mathrm{n}=22\end{array}$ \\
\hline 1 & Normal & Normal \\
\hline 2 & Normal & Normal \\
\hline 3 & - & - \\
\hline 4 & Normal & Normal \\
\hline 5 & Normal & Normal \\
\hline 6 & Normal & Cisto de plexo coróide \\
\hline 7 & - & - \\
\hline 8 & Normal & Normal \\
\hline 9 & - & - \\
\hline 10 & Normal & Normal \\
\hline 11 & Normal & Normal \\
\hline 12 & Normal & Normal \\
\hline 13 & Normal & Normal \\
\hline 14 & Normal & Normal \\
\hline 15 & Normal & Normal \\
\hline 16 & - & - \\
\hline 17 & Normal & Normal \\
\hline 18 & Normal & Normal \\
\hline 19 & Normal & Normal \\
\hline 20 & - & - \\
\hline 21 & Normal & Normal \\
\hline 22 & Normal & Normal \\
\hline 23 & - & - \\
\hline 24 & - & - \\
\hline 25 & Normal & Normal \\
\hline 26 & - & - \\
\hline 27 & Normal & Normal \\
\hline 28 & Normal & Normal \\
\hline 29 & Normal & Normal \\
\hline 30 & Normal & Normal \\
\hline
\end{tabular}


Anexo E2 - Avaliação Neurológica e USG transfontanela em RNT com CIUR (Grupo lla)

\begin{tabular}{|c|c|c|}
\hline \multirow[t]{3}{*}{ CASO NO } & AVALIAÇÃO & USG \\
\hline & NEUROLÓGICA & TRANSFONTANELA \\
\hline & $n=33$ & $\mathrm{n}=32$ \\
\hline 1 & Normal & Normal \\
\hline 2 & Normal & Normal \\
\hline 3 & Normal & Normal \\
\hline 4 & Normal & Normal \\
\hline 5 & Normal & Normal \\
\hline 6 & Normal & Normal \\
\hline 7 & Normal & Normal \\
\hline 8 & Normal & Normal \\
\hline 9 & Normal & Normal \\
\hline 10 & - & - \\
\hline 11 & Normal & Normal \\
\hline 12 & Normal & Normal \\
\hline 13 & Normal & Normal \\
\hline 14 & Normal & Normal \\
\hline 15 & Normal & Normal \\
\hline 16 & Normal & Normal \\
\hline 17 & - & - \\
\hline 18 & - & - \\
\hline 19 & - & - \\
\hline 20 & Normal & Normal \\
\hline 21 & Normal & Normal \\
\hline 22 & Normal & Normal \\
\hline 23 & - & - \\
\hline 24 & Normal & Normal \\
\hline 25 & Hiperexcitabilidade + tremores & Normal \\
\hline 26 & Normal & Normal \\
\hline 27 & Normal & Normal \\
\hline 28 & Normal & Normal \\
\hline 29 & Normal & Normal \\
\hline 30 & Normal & Normal \\
\hline 31 & Normal & Cisto de plexo coróide \\
\hline 32 & Normal & Hiperecogenicidade periventricular \\
\hline 33 & - & - \\
\hline 34 & Normal & Normal \\
\hline 35 & Normal & - \\
\hline 36 & Normal & Normal \\
\hline 37 & Normal & Normal \\
\hline 38 & - & - \\
\hline 39 & Normal & Normal \\
\hline 40 & Normal & Normal \\
\hline
\end{tabular}


Anexo E3 - Avaliação Neurológica e USG transfontanela em RNT sem CIUR com asfixia perinatal (Grupo lb)

\begin{tabular}{|c|c|c|}
\hline CASO $\mathrm{N}^{\circ}$ & $\begin{array}{c}\text { AVALIAÇÃo } \\
\text { NEUROLÓGICA } \\
\text { n =20 }\end{array}$ & $\begin{array}{c}\text { USG } \\
\text { TRANSFONTANELA } \\
\mathbf{n}=\mathbf{2 0}\end{array}$ \\
\hline 1 & Hipoatividade & Edema cerebral \\
\hline 2 & Normal & Infarto regiões córtico e subcorticais frontais \\
\hline 3 & Paralisia facial D + hipotonia & Hematoma subdural e subgaleal \\
\hline 4 & Normal & Normal \\
\hline 5 & Hipoatividade & Hemorragia periventricular $E$ \\
\hline 6 & Normal & Normal \\
\hline 7 & Normal & Normal \\
\hline 8 & Normal & Normal \\
\hline 9 & Hipoatividade e sucção débil & Normal \\
\hline 10 & Normal & Normal \\
\hline 11 & Normal & Normal \\
\hline 12 & Hipoativo e hiporeativo & Normal \\
\hline 13 & Normal & Normal \\
\hline 14 & Hipotonia & Edema cerebral \\
\hline 15 & Normal & Edema cerebral \\
\hline 16 & Hipotonia e diminuição da movimentação & $\begin{array}{l}\text { Hemorragia meníngea e áreas isquêmicas } \\
\text { corticais }\end{array}$ \\
\hline 17 & Normal & Áreas isquêmicas corticais \\
\hline 18 & Normal & Normal \\
\hline 19 & Hipotonia & Normal \\
\hline 20 & Normal & Normal \\
\hline
\end{tabular}


Anexo E4 - Avaliação Neurológica e USG transfontanela em RNT com CIUR e asfixia perinatal (Grupo Ilb)

\begin{tabular}{ccc}
\hline CASO No & AVALIAÇÃO & USG \\
& NEUROLÓGICA & TRANSFONTANELA \\
& Hipotonia e hipoatividade & $\mathrm{n}=5$ \\
$\mathbf{1}$ & Hipoatividade e hiporeatividade & Infarto hemorrágico talâmico bilateral \\
$\mathbf{3}$ & Normal & Edema cerebral \\
$\mathbf{4}$ & Normal & Normal \\
$\mathbf{5}$ & Hipoatividade & Normal \\
\hline
\end{tabular}




\section{Anexo F - Características Antropométricas dos Recém-nascidos nos diferentes grupos de estudo}

Anexo F1 - Características Antropométricas dos Recém-Nascidos no grupo de RNT sem CIUR (Grupo la)

\begin{tabular}{|c|c|c|c|c|}
\hline $\begin{array}{l}\text { CASO } \\
\mathbf{N}^{\circ}\end{array}$ & $\begin{array}{c}\text { PESO } \\
(\mathrm{g})\end{array}$ & $\begin{array}{c}\text { COMPRIMENTO } \\
(\mathrm{cm})\end{array}$ & $\begin{array}{c}\text { PERÍMETRO } \\
\text { CEFÁLICO } \\
\text { (cm) }\end{array}$ & $\mathbf{P} / \mathbf{P}_{50}$ \\
\hline 1 & 3050 & 49,0 & 34,5 & 1,00 \\
\hline 2 & 2700 & 48,0 & 35,0 & 0,90 \\
\hline 3 & 3000 & 49,0 & 34,0 & 0,90 \\
\hline 4 & 3550 & 50,0 & 35,5 & 1,04 \\
\hline 5 & 3120 & 48,0 & 35,5 & 1,03 \\
\hline 6 & 3170 & 51,0 & 33,5 & 1,04 \\
\hline 7 & 3060 & 50,0 & 33,0 & 0,90 \\
\hline 8 & 3010 & 47,5 & 32,5 & 0,91 \\
\hline 9 & 3590 & 49,0 & 34,0 & 1,09 \\
\hline 10 & 3020 & 47,0 & 34,0 & 0,92 \\
\hline 11 & 3190 & 47,0 & 35,0 & 1,06 \\
\hline 12 & 3320 & 50,0 & 34,0 & 1,10 \\
\hline 13 & 2910 & 46,5 & 33,5 & 0,97 \\
\hline 14 & 2930 & 47,0 & 33,5 & 0,95 \\
\hline 15 & 3310 & 48,5 & 32,5 & 1,07 \\
\hline 16 & 2920 & 47,0 & 33,5 & 0,87 \\
\hline 17 & 2710 & 48,0 & 33,5 & 0,90 \\
\hline 18 & 3700 & 50,5 & 36,0 & 1,10 \\
\hline 19 & 3550 & 48,5 & 35,0 & 1,08 \\
\hline 20 & 3000 & 49,0 & 34,0 & 0,91 \\
\hline 21 & 3370 & 50,0 & 35,0 & 1,00 \\
\hline 22 & 3190 & 49,0 & 33,5 & 0,92 \\
\hline 23 & 3620 & 50,0 & 33,5 & 1,06 \\
\hline 24 & 2940 & 46,0 & 33,0 & 0,89 \\
\hline 25 & 3190 & 47,0 & 36,5 & 0,94 \\
\hline 26 & 3120 & 49,0 & 35,5 & 0,90 \\
\hline 27 & 3450 & 50,0 & 36,0 & 1,05 \\
\hline 28 & 2760 & 46,5 & 33,0 & 0,99 \\
\hline 29 & 3400 & 50,5 & 35,5 & 0,97 \\
\hline 30 & 3550 & 50,0 & 34,0 & 0,90 \\
\hline
\end{tabular}

$\mathbf{P} / \mathbf{P}_{50}=$ Peso encontrado/Peso estimado do percentil 50 para a IG 
Anexo F2 - Características Antropométricas dos Recém-Nascidos no grupo de RNT com CIUR (Grupo Ila)

\begin{tabular}{|c|c|c|c|c|}
\hline $\begin{array}{l}\text { CASO } \\
\mathbf{N}^{\circ}\end{array}$ & $\begin{array}{l}\text { PESO } \\
(\mathrm{g})\end{array}$ & $\begin{array}{l}\text { COMPRIMENTO } \\
(\mathrm{cm})\end{array}$ & $\begin{array}{l}\text { PERÍMETRO } \\
\text { CEFÁLICO } \\
(\mathrm{cm})\end{array}$ & $\mathbf{P} / \mathbf{P}_{50}$ \\
\hline 1 & 2120 & 45,0 & 31,5 & 0,62 \\
\hline 2 & 2360 & 46,0 & 32,5 & 0,76 \\
\hline 3 & 2560 & 46,0 & 33,5 & 0,77 \\
\hline 4 & 2000 & 44,5 & 31,0 & 0,71 \\
\hline 5 & 2130 & 43,0 & 31,0 & 0,66 \\
\hline 6 & 2340 & 43,5 & 31,0 & 0,78 \\
\hline 7 & 2230 & 44,5 & 33,0 & 0,74 \\
\hline 8 & 2390 & 46,5 & 32,5 & 0,79 \\
\hline 9 & 2220 & 46,5 & 31,5 & 0,69 \\
\hline 10 & 2390 & 47,5 & 31,0 & 0,72 \\
\hline 11 & 2190 & 45,5 & 31,5 & 0,75 \\
\hline 12 & 2320 & 43,5 & 31,0 & 0,77 \\
\hline 13 & 1850 & 42,5 & 30,5 & 0,61 \\
\hline 14 & 2180 & 43,0 & 30,5 & 0,75 \\
\hline 15 & 2050 & 45,0 & 29,5 & 0,71 \\
\hline 16 & 2220 & 43,5 & 32,5 & 0,70 \\
\hline 17 & 2370 & 45,5 & 32,5 & 0,76 \\
\hline 18 & 2200 & 43,0 & 32,0 & 0,78 \\
\hline 19 & 2610 & 48,0 & 32,0 & 0,81 \\
\hline 20 & 2450 & 45,0 & 33,5 & 0,84 \\
\hline
\end{tabular}

$\mathbf{P} / \mathbf{P}_{50}=$ Peso encontrado/Peso estimado do percentil 50 para a IG 
Anexo F2 - Características Antropométricas dos Recém-Nascidos no grupo de RNT com CIUR (Grupo Ila)

\begin{tabular}{|c|c|c|c|c|}
\hline $\begin{array}{l}\text { CASO } \\
\mathbf{N}^{\circ}\end{array}$ & $\begin{array}{l}\text { PESO } \\
(\mathrm{g})\end{array}$ & $\begin{array}{l}\text { COMPRIMENTO } \\
(\mathrm{cm})\end{array}$ & $\begin{array}{l}\text { PERÍMETRO } \\
\text { CEFÁLICO } \\
\text { (cm) }\end{array}$ & $\mathbf{P} / \mathbf{P}_{50}$ \\
\hline 21 & 2360 & 43,0 & 31,5 & 0,76 \\
\hline 22 & 2190 & 42,0 & 30,0 & 0,78 \\
\hline 23 & 2420 & 46,0 & 32,0 & 0,75 \\
\hline 24 & 2100 & 44,0 & 31,5 & 0,75 \\
\hline 25 & 2190 & 41,0 & 33,0 & 0,73 \\
\hline 26 & 2330 & 45,0 & 31,0 & 0,72 \\
\hline 27 & 2130 & 41,5 & 31,0 & 0,71 \\
\hline 28 & 1880 & 43,0 & 31,5 & 0,64 \\
\hline 29 & 2420 & 47,0 & 33,0 & 0,75 \\
\hline 30 & 2540 & 47,0 & 31,0 & 0,79 \\
\hline 31 & 2480 & 45,0 & 32,0 & 0,80 \\
\hline 32 & 2420 & 47,0 & 33,0 & 0,80 \\
\hline 33 & 2250 & 44,0 & 33,0 & 0,80 \\
\hline 34 & 2250 & 44,0 & 32,0 & 0,80 \\
\hline 35 & 2580 & 49,0 & 34,0 & 0,80 \\
\hline 36 & 2440 & 44,0 & 33,0 & 0,81 \\
\hline 37 & 2270 & 45,0 & 31,5 & 0,81 \\
\hline 38 & 2470 & 44,0 & 32,0 & 0,82 \\
\hline 39 & 2380 & 43,5 & 33,0 & 0,79 \\
\hline 40 & 2230 & 45,0 & 31,0 & 0,80 \\
\hline
\end{tabular}

$\mathbf{P} / \mathbf{P}_{50}=$ Peso encontrado/Peso estimado do percentil 50 para a IG 
Anexo F3 - Características Antropométricas dos Recém-Nascidos no grupo de RNT sem CIUR com asfixia perinatal (Grupo lb)

\begin{tabular}{|c|c|c|c|c|}
\hline $\begin{array}{c}\text { CASO } \\
\mathrm{N}^{\circ}\end{array}$ & $\begin{array}{l}\text { PESO } \\
(\mathrm{g})\end{array}$ & $\begin{array}{l}\text { COMPRIMENTO } \\
(\mathrm{cm})\end{array}$ & $\begin{array}{l}\text { PERÍMETRO } \\
\text { CEFÁLICO } \\
\text { (cm) }\end{array}$ & $\mathbf{P} / \mathbf{P}_{50}$ \\
\hline 1 & 3250 & 48,0 & 33,5 & 0,96 \\
\hline 2 & 3430 & 48,0 & 35,0 & 1,00 \\
\hline 3 & 3330 & 48,0 & 36,0 & 0,98 \\
\hline 4 & 3610 & 51,0 & 35,5 & 1,06 \\
\hline 5 & 3020 & 46,0 & 33,0 & 1,08 \\
\hline 6 & 3290 & 49,0 & 35,0 & 1,13 \\
\hline 7 & 3400 & 50,0 & 36,0 & 1,00 \\
\hline 8 & 3200 & 48,0 & 34,5 & 0,97 \\
\hline 9 & 3630 & 51,0 & 36,0 & 1,07 \\
\hline 10 & 3310 & 50,0 & 34,0 & 1,00 \\
\hline 11 & 3530 & 49,0 & 36,0 & 1,02 \\
\hline 12 & 2850 & 48,0 & 34,0 & 0,89 \\
\hline 13 & 3190 & 49,5 & 35,0 & 0,92 \\
\hline 14 & 3005 & 49,0 & 34,0 & 1,04 \\
\hline 15 & 3400 & 48,5 & 35,0 & 1,10 \\
\hline 16 & 3080 & 50,0 & 36,0 & 0,93 \\
\hline 17 & 3320 & 47,5 & 35,5 & 1,19 \\
\hline 18 & 3190 & 48,0 & 35,0 & 1,14 \\
\hline 19 & 3020 & 48,5 & 34,0 & 0,92 \\
\hline 20 & 2980 & 47,0 & 33,0 & 1,03 \\
\hline
\end{tabular}

$\mathbf{P} / \mathbf{P}_{50}=$ Peso encontrado/Peso estimado do percentil 50 para a IG 
Anexo F4 - Características Antropométricas dos Recém-Nascidos no grupo de RNT com CIUR e asfixia perinatal (Grupo Illb)

\begin{tabular}{ccccc}
\hline $\begin{array}{c}\text { CASO } \\
\mathbf{N}^{\circ}\end{array}$ & $\begin{array}{c}\text { PESO } \\
(\mathbf{g})\end{array}$ & $\begin{array}{c}\text { COMPRIMENTO } \\
\mathbf{( c m})\end{array}$ & $\begin{array}{c}\text { PERÍMETRO } \\
\text { CEFÁLICO } \\
\mathbf{( c m )}\end{array}$ & P/ $\mathbf{P}_{50}$ \\
\hline $\mathbf{1}$ & 2020 & 43,5 & 34,0 & 0,68 \\
$\mathbf{2}$ & 2590 & 47,0 & 35,0 & 0,76 \\
$\mathbf{3}$ & 2350 & 45,0 & 33,0 & 0,71 \\
$\mathbf{4}$ & 2100 & 41,0 & 31,0 & 0,61 \\
$\mathbf{5}$ & 2935 & 45,0 & 31,0 & 0,84 \\
\hline
\end{tabular}

$\mathbf{P} / \mathbf{P}_{\mathbf{5 0}}=$ Peso encontrado/Peso estimado do percentil 50 para a IG 
Anexo G - Evolução dos níveis séricos de Magnésio lônico (Mgi) na 1a semana de vida nos diferentes grupos de estudo

Anexo G1 - Evolução dos níveis séricos de Mgi (mmol/L) na 1a semana de vida em RNT sem CIUR (Grupo la)

\begin{tabular}{|c|c|c|c|}
\hline 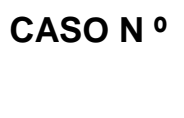 & $\begin{array}{l}\text { CORDÃO UMBILICAL } \\
\qquad n=27\end{array}$ & $\begin{array}{l}\text { 30 DIA DE VIDA } \\
\qquad n=21\end{array}$ & $\begin{array}{l}\text { 70 DIA DE VIDA } \\
\qquad \mathbf{n}=\mathbf{2 0}\end{array}$ \\
\hline 1 & 0,47 & 0,35 & - \\
\hline 2 & 0,30 & 0,37 & 0,23 \\
\hline 3 & - & - & - \\
\hline 4 & 0,39 & 0,27 & - \\
\hline 5 & 0,38 & - & 0,12 \\
\hline 6 & 0,30 & - & 0,20 \\
\hline 7 & 0,17 & 0,26 & 0,24 \\
\hline 8 & 0,23 & 0,25 & 0,20 \\
\hline 9 & 0,20 & 0,20 & - \\
\hline 10 & 0,22 & 0,24 & 0,23 \\
\hline 11 & 0,18 & 0,21 & 0,23 \\
\hline 12 & 0,17 & 0,21 & - \\
\hline 13 & 0,18 & 0,14 & 0,13 \\
\hline 14 & 0,21 & 0,17 & - \\
\hline 15 & 0,14 & 0,14 & 0,10 \\
\hline 16 & 0,10 & 0,12 & 0,14 \\
\hline 17 & 0,30 & 0,30 & 0,29 \\
\hline 18 & 0,28 & 0,24 & 0,30 \\
\hline 19 & - & 0,21 & 0,20 \\
\hline 20 & 0,31 & - & - \\
\hline 21 & 0,17 & 0,17 & 0,16 \\
\hline 22 & 0,25 & - & 0,22 \\
\hline 23 & 0,16 & - & 0,17 \\
\hline 24 & 0,16 & - & 0,14 \\
\hline 25 & 0,12 & 0,10 & 0,12 \\
\hline 26 & - & 0,22 & - \\
\hline 27 & 0,22 & - & - \\
\hline 28 & 0,28 & - & 0,30 \\
\hline 29 & 0,20 & 0,16 & - \\
\hline 30 & 0,20 & 0,19 & 0,20 \\
\hline Média & 0,23 & 0,22 & 0,20 \\
\hline DP & 0,09 & 0,07 & 0,06 \\
\hline
\end{tabular}


Anexo G2 - Evolução dos níveis séricos de Mgi (mmol/L)) na 1a semana de vida em RNT com CIUR (Grupo Ila)

\begin{tabular}{|c|c|c|c|}
\hline CASO $\mathrm{N}$ & $\begin{array}{l}\text { CORDÃO UMBILICAL } \\
\qquad n=34\end{array}$ & $\begin{array}{c}\text { 3으 DIA DE VIDA } \\
n=35\end{array}$ & $\begin{array}{l}\text { 70 DIA DE VIDA } \\
\qquad n=20\end{array}$ \\
\hline 1 & - & 0,27 & - \\
\hline 2 & - & 0,23 & 0,20 \\
\hline 3 & 0,42 & 0,27 & 0,36 \\
\hline 4 & - & 0,40 & 0,39 \\
\hline 5 & 0,21 & 0,32 & 0,18 \\
\hline 6 & 0,24 & 0,26 & 0,12 \\
\hline 7 & 0,62 & 0,29 & 0,35 \\
\hline 8 & 0,35 & 0,31 & 0,28 \\
\hline 9 & 0,31 & 0,31 & - \\
\hline 10 & - & 0,42 & - \\
\hline 11 & 0,37 & - & - \\
\hline 12 & 0,43 & 0,37 & 0,30 \\
\hline 13 & 0,40 & 0,55 & 0,37 \\
\hline 14 & 0,38 & 0,35 & 0,39 \\
\hline 15 & 0,19 & 0,29 & 0,26 \\
\hline 16 & 0,15 & 0,70 & - \\
\hline 17 & 0,36 & 0,31 & - \\
\hline 18 & 0,29 & 0,30 & - \\
\hline 19 & 0,34 & 0,44 & 0,31 \\
\hline 20 & 0,29 & 0,37 & 0,42 \\
\hline 21 & 0,39 & 0,31 & 0,34 \\
\hline 22 & 0,29 & 0,32 & - \\
\hline 23 & 0,28 & - & - \\
\hline 24 & 0,41 & 0,34 & 0,37 \\
\hline 25 & 0,20 & 0,46 & - \\
\hline 26 & 0,20 & 0,22 & 0,20 \\
\hline 27 & 0,41 & 0,35 & 0,37 \\
\hline 28 & - & 0,27 & 0,39 \\
\hline 29 & - & - & - \\
\hline 30 & 0,52 & 0,34 & - \\
\hline 31 & 0,21 & 0,21 & - \\
\hline 32 & 0,42 & 0,30 & 0,35 \\
\hline 33 & 0,36 & 0,23 & - \\
\hline 34 & 0,34 & - & - \\
\hline 35 & 0,35 & 0,32 & - \\
\hline 36 & 0,13 & - & - \\
\hline 37 & 0,36 & 0,33 & - \\
\hline 38 & 0,48 & 0,31 & - \\
\hline 39 & 0,20 & 0,32 & 0,28 \\
\hline 40 & 0,35 & 0,46 & - \\
\hline Média & 0,33 & 0,34 & 0,31 \\
\hline DP & 0,11 & 0,10 & 0,08 \\
\hline
\end{tabular}


Anexo G3 - Evolução dos níveis séricos de $\mathbf{M g i}(\mathrm{mmol} / \mathrm{L})$ na 1a semana de vida em RNT sem CIUR com asfixia perinatal (Grupo lb)

\begin{tabular}{|c|c|c|c|}
\hline CASO $\mathrm{N}$ & $\begin{array}{l}\text { CORDÃO UMBILICAL } \\
\qquad \mathrm{n}=18\end{array}$ & $\begin{array}{c}\text { 3ㅇ DIA DE VIDA } \\
n=18\end{array}$ & $\begin{array}{l}\text { 70 DIA DE VIDA } \\
\qquad n=17\end{array}$ \\
\hline 1 & 0,26 & 0,46 & - \\
\hline 2 & 0,31 & 0,24 & 0,52 \\
\hline 3 & 0,26 & 0,32 & 0,36 \\
\hline 4 & - & 0,34 & 0,32 \\
\hline 5 & 0,25 & 0,27 & 0,30 \\
\hline 6 & 0,23 & - & 0,25 \\
\hline 7 & 0,10 & 0,11 & 0,24 \\
\hline 8 & 0,19 & 0,14 & 0,23 \\
\hline 9 & 0,10 & 0,40 & 0,30 \\
\hline 10 & 0,30 & 0,23 & - \\
\hline 11 & 0,21 & 0,20 & 0,23 \\
\hline 12 & 0,23 & 0,50 & - \\
\hline 13 & - & 0,37 & 0,26 \\
\hline 14 & 0,33 & 0,43 & 0,33 \\
\hline 15 & 0,17 & 0,21 & 0,20 \\
\hline 16 & 0,18 & 0,21 & 0,37 \\
\hline 17 & 0,20 & 0,32 & 0,32 \\
\hline 18 & 0,10 & 0,20 & 0,22 \\
\hline 19 & 0,15 & 0,16 & 0,16 \\
\hline 20 & 0,18 & - & 0,21 \\
\hline Média & 0,21 & 0,28 & 0,28 \\
\hline DP & 0,07 & 0,11 & 0,09 \\
\hline
\end{tabular}


Anexo G4 - Evolução dos níveis séricos de Mgi (mmol/L) na 1a semana de vida em RNT com CIUR e asfixia perinatal (Grupo llb)

\begin{tabular}{|c|c|c|c|}
\hline CASO N $~$ & $\begin{array}{c}\text { CORDÃO UMBILICAL } \\
\mathbf{n = 4}\end{array}$ & $\begin{array}{c}\text { 3 DIA DE VIDA } \\
\mathbf{n = 5}\end{array}$ & $\begin{array}{c}\text { 70 DIA DE VIDA } \\
\mathbf{n = 4}\end{array}$ \\
\hline $\mathbf{1}$ & 0,38 & 0,48 & 0,43 \\
\hline $\mathbf{2}$ & 0,31 & 0,33 & 0,48 \\
\hline $\mathbf{3}$ & 0,22 & 0,28 & 0,23 \\
\hline $\mathbf{4}$ & 0,15 & 0,25 & 0,21 \\
\hline 5 & - & 0,24 & - \\
\hline Média & $\mathbf{0 , 2 7}$ & $\mathbf{0 , 3 2}$ & $\mathbf{0 , 3 4}$ \\
\hline DP & $\mathbf{0 , 1 0}$ & $\mathbf{0 , 1 0}$ & $\mathbf{0 , 1 4}$ \\
\hline
\end{tabular}


Anexo H - Evolução dos níveis séricos de Magnésio total(MgT) na 1a semana de vida nos diferentes grupos de estudo

Anexo H1 - Evolução dos níveis séricos de $\mathbf{M g T}(\mathrm{mg} / \mathrm{dl})$ na 1a semana de vida em RNT sem CIUR (Grupo la)

\begin{tabular}{|c|c|c|c|}
\hline 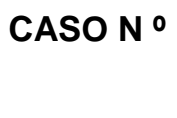 & $\begin{array}{l}\text { CORDÃO UMBILICAL } \\
\qquad n=28\end{array}$ & $\begin{array}{c}\text { 30 DIA DE VIDA } \\
n=22\end{array}$ & $\begin{array}{l}\text { 70 DIA DE VIDA } \\
\qquad n=20\end{array}$ \\
\hline 1 & 1,79 & 1,88 & - \\
\hline 2 & 1,52 & 1,03 & 1,50 \\
\hline 3 & 1,65 & 1,94 & - \\
\hline 4 & 1,60 & 2,06 & - \\
\hline 5 & 1,78 & 1,75 & 2,18 \\
\hline 6 & 1,61 & - & - \\
\hline 7 & 1,79 & 2,06 & 1,76 \\
\hline 8 & 1,68 & 1,71 & 1,81 \\
\hline 9 & 1,70 & 1,45 & - \\
\hline 10 & 1,81 & 1,80 & 1,56 \\
\hline 11 & 1,80 & 1,94 & 2,28 \\
\hline 12 & 1,63 & 1,63 & 1,93 \\
\hline 13 & 1,79 & 1,97 & 1,41 \\
\hline 14 & 2,05 & 1,81 & - \\
\hline 15 & 1,79 & 2,15 & 1,93 \\
\hline 16 & 1,75 & 1,84 & 1,94 \\
\hline 17 & 1,85 & 1,30 & 2,07 \\
\hline 18 & 1,66 & 1,91 & 1,99 \\
\hline 19 & 1,89 & 1,77 & - \\
\hline 20 & 0,85 & - & 1,80 \\
\hline 21 & 1,30 & 1,80 & 1,60 \\
\hline 22 & 1,90 & - & 1,60 \\
\hline 23 & 1,50 & - & 1,60 \\
\hline 24 & 2,02 & - & 1,94 \\
\hline 25 & 1,54 & 1,76 & 2,18 \\
\hline 26 & - & - & - \\
\hline 27 & 1,78 & - & - \\
\hline 28 & 1,72 & 2,40 & 2,14 \\
\hline 29 & 1,10 & 1,70 & - \\
\hline 30 & - & - & 1,95 \\
\hline Média & 1,67 & 1,80 & 1,86 \\
\hline DP & 0,25 & 0,29 & 0,25 \\
\hline
\end{tabular}


Anexo H2 - Evolução dos níveis séricos de $\mathbf{M g T}(\mathrm{mg} / \mathrm{dl})$ na 1a semana de vida em RNT com CIUR (Grupo Ila)

\begin{tabular}{|c|c|c|c|}
\hline CASO N & $\begin{array}{l}\text { CORDÃO UMBILICAL } \\
\qquad n=39\end{array}$ & $\begin{array}{l}\text { 30 DIA DE VIDA } \\
\qquad \mathrm{n}=35\end{array}$ & $\begin{array}{c}\text { 70 DIA DE VIDA } \\
\text { n=22 }\end{array}$ \\
\hline 1 & 2,04 & 1,92 & - \\
\hline 2 & 2,14 & 1,98 & 1,86 \\
\hline 3 & 1,66 & 1,99 & 1,89 \\
\hline 4 & 1,80 & 1,90 & 2,70 \\
\hline 5 & 2,09 & 2,40 & 2,28 \\
\hline 6 & 1,74 & 1,72 & 1,72 \\
\hline 7 & 1,95 & 2,26 & 2,79 \\
\hline 8 & 1,29 & 1,83 & 1,79 \\
\hline 9 & - & 1,84 & - \\
\hline 10 & 1,73 & 2,04 & - \\
\hline 11 & 1,15 & 1,75 & - \\
\hline 12 & 1,90 & 0,70 & 1,50 \\
\hline 13 & 1,79 & 1,59 & 1,85 \\
\hline 14 & 1,65 & 2,10 & 2,13 \\
\hline 15 & 2,03 & - & 2,00 \\
\hline 16 & 1,88 & 1,79 & - \\
\hline 17 & 1,74 & 1,55 & - \\
\hline 18 & 2,25 & 1,94 & - \\
\hline 19 & 1,81 & 1,82 & 1,84 \\
\hline 20 & 2,06 & 2,0 & 2,68 \\
\hline 21 & 1,80 & 2,11 & 2,15 \\
\hline 22 & 0,99 & 1,38 & - \\
\hline 23 & 1,91 & - & - \\
\hline 24 & 1,90 & 2,28 & 2,26 \\
\hline 25 & 1,48 & 1,00 & - \\
\hline 26 & 1,69 & 1,99 & 1,54 \\
\hline 27 & 1,54 & 1,76 & 1,35 \\
\hline 28 & 1,90 & 2,17 & 1,96 \\
\hline 29 & 2,24 & 1,58 & - \\
\hline 30 & 3,50 & 2,03 & - \\
\hline 31 & 1,47 & 1,50 & 1,67 \\
\hline 32 & 1,67 & 1,46 & 1,88 \\
\hline 33 & 1,93 & 1,67 & - \\
\hline 34 & 2,02 & - & - \\
\hline 35 & 2,07 & - & - \\
\hline 36 & 1,91 & - & - \\
\hline 37 & 1,92 & 1,70 & 2,05 \\
\hline 38 & 1,94 & 2,64 & - \\
\hline 39 & 1,36 & 0,91 & - \\
\hline 40 & 1,56 & 1,80 & 1,27 \\
\hline Média & 1,83 & 1,82 & 1,96 \\
\hline DP & 0,39 & 0,40 & 0,41 \\
\hline
\end{tabular}


Anexo H3 - Evolução dos níveis séricos de $\mathbf{M g T}(\mathrm{mg} / \mathrm{dl})$ na 1a semana de vida em RNT sem CIUR com asfixia perinatal (Grupo lb)

\begin{tabular}{|c|c|c|c|}
\hline CASO $\mathrm{N}$ ㅇ & $\begin{array}{l}\text { CORDÃO UMBILICAL } \\
\qquad n=20\end{array}$ & $\begin{array}{c}\text { 3으 DIA DE VIDA } \\
n=19\end{array}$ & $\begin{array}{l}\text { 70 DIA DE VIDA } \\
n=19\end{array}$ \\
\hline 1 & 1,42 & 2,87 & 1,44 \\
\hline 2 & 1,77 & 1,23 & 3,10 \\
\hline 3 & 2,66 & 1,87 & 2,21 \\
\hline 4 & 1,89 & 1,60 & 1,97 \\
\hline 5 & 1,78 & 1,50 & 1,77 \\
\hline 6 & 1,89 & 1,51 & 1,77 \\
\hline 7 & 1,48 & 1,39 & 1,10 \\
\hline 8 & 3,06 & 2,22 & 1,96 \\
\hline 9 & 1,45 & 2,90 & 1,70 \\
\hline 10 & 1,90 & 1,60 & - \\
\hline 11 & 1,30 & 1,10 & 3,80 \\
\hline 12 & 1,10 & - & 3,00 \\
\hline 13 & 2,00 & 3,50 & 2,30 \\
\hline 14 & 1,80 & 1,40 & 1,80 \\
\hline 15 & 1,80 & 1,50 & 1,30 \\
\hline 16 & 1,20 & 1,50 & 3,40 \\
\hline 17 & 2,00 & 2,90 & 2,60 \\
\hline 18 & 1,70 & 1,50 & 2,40 \\
\hline 19 & 1,40 & 2,20 & 1,80 \\
\hline 20 & 2,00 & 2,00 & 1,90 \\
\hline Média & 1,78 & 1,91 & 2,18 \\
\hline DP & 0,47 & 0,68 & 0,72 \\
\hline
\end{tabular}


Anexo H4 - Evolução dos níveis séricos de $\mathbf{M g T}(\mathrm{mg} / \mathrm{dl})$ na 1a semana de vida em RNT com CIUR e asfixia perinatal (Grupo Ilb)

\begin{tabular}{|c|c|c|c|}
\hline CASO N $~$ & $\begin{array}{c}\text { CORDÃO UMBILICAL } \\
\mathbf{n = 4}\end{array}$ & $\begin{array}{c}\text { 30 DIA DE VIDA } \\
\mathbf{n = 5}\end{array}$ & $\begin{array}{c}\text { 70 DIA DE VIDA } \\
\mathbf{n = 5}\end{array}$ \\
\hline $\mathbf{1}$ & 2,05 & 2,34 & 3,26 \\
\hline $\mathbf{2}$ & 1,66 & 1,38 & 2,44 \\
\hline $\mathbf{3}$ & 1,80 & 2,70 & 2,10 \\
\hline $\mathbf{4}$ & 1,40 & 1,50 & 1,80 \\
\hline $\mathbf{5}$ & - & 2,60 & 1,80 \\
\hline Média & $\mathbf{1 , 7 3}$ & $\mathbf{2 , 1 0}$ & $\mathbf{2 , 2 8}$ \\
\hline DP & $\mathbf{0 , 2 7}$ & $\mathbf{0 , 6 2}$ & $\mathbf{0 , 6 1}$ \\
\hline
\end{tabular}


Anexo I - Evolução dos níveis séricos de Cálcio iônico(Cai) na 1a semana de vida nos diferentes grupos de estudo

Anexo l1- Evolução dos níveis séricos de Cai ( $\mathrm{mmol} / \mathrm{L})$ na 1a semana de vida em RNT sem CIUR (Grupo la)

\begin{tabular}{|c|c|c|c|}
\hline CASO N $\mathrm{O}$ & $\begin{array}{l}\text { CORDÃO UMBILICAL } \\
\qquad n=26\end{array}$ & $\begin{array}{c}3^{\circ} \text { DIA DE VIDA } \\
n=23\end{array}$ & $\begin{array}{c}7^{\circ} \text { DIA DE VIDA } \\
n=20\end{array}$ \\
\hline 1 & 0,69 & 0,92 & - \\
\hline 2 & 1,03 & 0,99 & 0,79 \\
\hline 3 & - & 0,33 & - \\
\hline 4 & 0,89 & 0,64 & - \\
\hline 5 & 1,38 & 1,22 & 1,32 \\
\hline 6 & 1,44 & - & - \\
\hline 7 & 0,52 & 1,22 & 1,31 \\
\hline 8 & 1,32 & 1,17 & 1,22 \\
\hline 9 & 1,33 & 1,15 & - \\
\hline 10 & 1,43 & 1,23 & 1,34 \\
\hline 11 & 1,32 & 1,27 & 1,29 \\
\hline 12 & 1,30 & 1,24 & - \\
\hline 13 & 1,30 & 1,15 & 1,23 \\
\hline 14 & 1,45 & 1,14 & - \\
\hline 15 & 1,46 & 1,22 & 1,35 \\
\hline 16 & 1,33 & 1,20 & 1,32 \\
\hline 17 & 1,12 & 1,19 & 1,20 \\
\hline 18 & 1,35 & 1,16 & 1,18 \\
\hline 19 & - & 1,41 & - \\
\hline 20 & 0,80 & - & 0,90 \\
\hline 21 & 1,45 & 0,67 & 1,24 \\
\hline 22 & 1,49 & - & 1,23 \\
\hline 23 & 1,51 & - & 1,27 \\
\hline 24 & 1,38 & - & 1,32 \\
\hline 25 & 1,40 & 1,10 & 1,32 \\
\hline 26 & - & 1,18 & - \\
\hline 27 & 1,46 & - & - \\
\hline 28 & 1,13 & 1,27 & 1,27 \\
\hline 29 & 1,18 & 1,24 & 1,25 \\
\hline 30 & - & - & 1,25 \\
\hline Média & 1,25 & 1,10 & 1,23 \\
\hline DP & 0,26 & 0,25 & 0,14 \\
\hline
\end{tabular}


Anexo 12 - Evolução dos níveis séricos de Cai $(\mathrm{mmol} / \mathrm{L})$ na 1a semana de vida em RNT com CIUR (Grupo Ila)

\begin{tabular}{|c|c|c|c|}
\hline CASO $N$ & $\begin{array}{l}\text { CORDÃO UMBILICAL } \\
\qquad n=34\end{array}$ & $\begin{array}{c}\text { 3으 DIA DE VIDA } \\
n=34\end{array}$ & $\begin{array}{l}\text { 70 DIA DE VIDA } \\
\qquad n=20\end{array}$ \\
\hline 1 & - & $\begin{array}{l}0,72 \\
\end{array}$ & - \\
\hline 2 & - & 1,12 & 1,23 \\
\hline 3 & 1,33 & - & 1,23 \\
\hline 4 & - & 1,09 & 1,01 \\
\hline 5 & 0,53 & 0,88 & 0,33 \\
\hline 6 & 1,10 & 1,10 & 1,18 \\
\hline 7 & 1,22 & 0,77 & 1,02 \\
\hline 8 & 1,00 & 1,02 & 0,93 \\
\hline 9 & 0,79 & 0,83 & - \\
\hline 10 & - & 0,84 & - \\
\hline 11 & 1,04 & - & - \\
\hline 12 & 0,97 & 0,87 & 0,96 \\
\hline 13 & 1,24 & 1,08 & 1,21 \\
\hline 14 & 1,40 & 1,25 & 1,39 \\
\hline 15 & 1,40 & 1,22 & 1,29 \\
\hline 16 & 1,25 & 1,18 & - \\
\hline 17 & 1,31 & 1,16 & - \\
\hline 18 & 1,49 & 1,12 & - \\
\hline 19 & 1,30 & 1,26 & 1,54 \\
\hline 20 & 0,86 & 0,91 & 1,05 \\
\hline 21 & 0,99 & 0,78 & 0,96 \\
\hline 22 & 0,56 & 0,95 & - \\
\hline 23 & 0,85 & - & - \\
\hline 24 & 0,85 & 0,86 & 1,13 \\
\hline 25 & 0,50 & 0,92 & - \\
\hline 26 & 1,20 & 0,91 & 1,24 \\
\hline 27 & 1,13 & 0,83 & 0,91 \\
\hline 28 & - & 0,79 & 0,96 \\
\hline 29 & - & - & - \\
\hline 30 & 0,94 & 0,96 & - \\
\hline 31 & 1,34 & 1,09 & - \\
\hline 32 & 0,83 & 0,73 & 0,90 \\
\hline 33 & 1,16 & 0,43 & - \\
\hline 34 & 0,91 & - & - \\
\hline 35 & 1,04 & 1,14 & - \\
\hline 36 & 1,30 & - & - \\
\hline 37 & 0,90 & 0,89 & - \\
\hline 38 & 0,92 & 0,78 & - \\
\hline 39 & 0,56 & 0,67 & 0,72 \\
\hline 40 & 0,75 & 1,09 & - \\
\hline Média & 1,03 & 0,95 & 1,06 \\
\hline DP & 0,27 & 0,19 & 0,26 \\
\hline
\end{tabular}


Anexo I3 - Evolução dos níveis séricos de Cai(mmol/L) na 1ạ semana de vida em RNT sem CIUR com asfixia perinatal (Grupo Ib)

\begin{tabular}{|c|c|c|c|}
\hline CASO N $\cong$ & $\begin{array}{l}\text { CORDÃO UMBILICAL } \\
\qquad n=19\end{array}$ & $\begin{array}{c}\text { 30 DIA DE VIDA } \\
n=19\end{array}$ & $\begin{array}{l}\text { 70 DIA DE VIDA } \\
n=16\end{array}$ \\
\hline 1 & 0,89 & 0,92 & - \\
\hline 2 & 0,89 & 1,20 & 1,23 \\
\hline 3 & - & 1,28 & 1,19 \\
\hline 4 & 0,99 & 0,81 & 0,87 \\
\hline 5 & 0,68 & 0,81 & 0,78 \\
\hline 6 & 1,33 & 1,11 & 1,19 \\
\hline 7 & 1,07 & 1,01 & 1,23 \\
\hline 8 & 1,50 & 1,23 & 1,12 \\
\hline 9 & 1,10 & 1,07 & 1,29 \\
\hline 10 & 1,37 & 1,22 & - \\
\hline 11 & 1,14 & 1,05 & - \\
\hline 12 & 0,94 & 1,24 & - \\
\hline 13 & 1,37 & 1,22 & 1,18 \\
\hline 14 & 1,19 & 0,92 & 1,19 \\
\hline 15 & 1,12 & 1,18 & 1,17 \\
\hline 16 & 1,13 & 1,20 & 1,11 \\
\hline 17 & 1,12 & 1,12 & 1,15 \\
\hline 18 & 0,26 & 1,13 & 1,34 \\
\hline 19 & 1,01 & 1,05 & 1,10 \\
\hline 20 & 1,12 & - & 1,30 \\
\hline Média & 1,06 & 1,09 & 1,15 \\
\hline DP & 0,28 & 0,14 & 0,15 \\
\hline
\end{tabular}


Anexo 14 - Evolução dos níveis séricos de Cai(mmol/L) na 1a semana de vida em RNT com CIUR e asfixia perinatal (Grupo llb)

\begin{tabular}{|c|c|c|c|}
\hline CASO N $~$ & $\begin{array}{c}\text { CORDÃO UMBILICAL } \\
\mathbf{n = 4}\end{array}$ & $\begin{array}{c}\text { 30 DIA DE VIDA } \\
\mathbf{n = 5}\end{array}$ & $\begin{array}{c}\text { 70 DIA DE VIDA } \\
\mathbf{n = 4}\end{array}$ \\
\hline $\mathbf{1}$ & 1,02 & 0,87 & 0,90 \\
\hline $\mathbf{2}$ & 0,66 & 0,80 & 0,93 \\
\hline $\mathbf{3}$ & 1,24 & 1,07 & 1,10 \\
\hline $\mathbf{4}$ & 1,04 & 1,00 & 1,15 \\
\hline $\mathbf{5}$ & - & 1,04 & - \\
\hline Média & $\mathbf{0 , 9 9}$ & $\mathbf{0 , 9 6}$ & $\mathbf{1 , 0 2}$ \\
\hline DP & $\mathbf{0 , 2 4}$ & $\mathbf{0 , 1 2}$ & $\mathbf{0 , 1 2}$ \\
\hline
\end{tabular}


Anexo J- Evolução dos níveis séricos de Fósforo(P) na $1^{a}$ semana de vida nos diferentes grupos de estudo

Anexo J1 - Evolução dos níveis séricos de $\mathbf{P}(\mathrm{mg} / \mathrm{dl})$ na 1a semana de vida em RNT sem CIUR (Grupo la)

\begin{tabular}{|c|c|c|c|}
\hline CASO N ${ }^{\circ}$ & $\begin{array}{l}\text { CORDÃO UMBILICAL } \\
\qquad n=28\end{array}$ & $\begin{array}{l}\text { 30 DIA DE VIDA } \\
\qquad n=23\end{array}$ & $\begin{array}{c}\text { 70 DIA DE VIDA } \\
n=19\end{array}$ \\
\hline 1 & 4,9 & 6,1 & - \\
\hline 2 & 5,2 & 5,6 & 6,9 \\
\hline 3 & 6,1 & 4,6 & - \\
\hline 4 & 7,6 & 7,3 & - \\
\hline 5 & 5,4 & 5,5 & 7,7 \\
\hline 6 & 5,2 & - & 7,6 \\
\hline 7 & 4,9 & 7,7 & 8,2 \\
\hline 8 & 6,1 & 8,1 & 7,2 \\
\hline 9 & 7,7 & 6,6 & - \\
\hline 10 & 5,1 & 7,4 & 8,0 \\
\hline 11 & 7,1 & 7,6 & 8,7 \\
\hline 12 & 6,6 & 7,4 & - \\
\hline 13 & 6,5 & 6,4 & 7,7 \\
\hline 14 & 8,3 & 7,5 & - \\
\hline 15 & 7,9 & 8,8 & 7,8 \\
\hline 16 & 5,6 & 6,9 & 9,6 \\
\hline 17 & 4,3 & 5,8 & 7,4 \\
\hline 18 & 5,7 & 6,0 & 7,8 \\
\hline 19 & 7,3 & 7,2 & - \\
\hline 20 & 5,1 & - & 7,5 \\
\hline 21 & 5,8 & 5,0 & 7,5 \\
\hline 22 & 7,1 & - & 6,0 \\
\hline 23 & 6,4 & 5,3 & - \\
\hline 24 & 6,2 & - & 9,6 \\
\hline 25 & 5,3 & 7,5 & 7,7 \\
\hline 26 & - & - & - \\
\hline 27 & 6,3 & - & - \\
\hline 28 & 3,2 & 6,3 & 6,1 \\
\hline 29 & 6,0 & 6,6 & - \\
\hline 30 & - & - & 7,0 \\
\hline Média & 6,03 & 6,66 & 7,68 \\
\hline DP & 1,16 & 1,06 & 0,93 \\
\hline
\end{tabular}


Anexo J2 - Evolução dos níveis séricos de $\mathbf{P}(\mathrm{mg} / \mathrm{dl})$ na 1a semana de vida em RNT com CIUR (Grupo Ila)

\begin{tabular}{|c|c|c|c|}
\hline CASO N & $\begin{array}{l}\text { CORDÃO UMBILICAL } \\
\qquad \mathrm{n}=39\end{array}$ & $\begin{array}{l}\text { 30 DIA DE VIDA } \\
\qquad \mathrm{n}=34\end{array}$ & $\begin{array}{c}\text { 70 DIA DE VIDA } \\
n=22\end{array}$ \\
\hline 1 & 4,4 & 4,5 & - \\
\hline 2 & 8,4 & 7,4 & 7,5 \\
\hline 3 & 4,8 & 5,1 & 5,0 \\
\hline 4 & 5,2 & 5,8 & 7,2 \\
\hline 5 & 5,2 & 6,7 & 6,3 \\
\hline 6 & 5,8 & 6,3 & 7,6 \\
\hline 7 & 4,6 & 6,5 & 6,6 \\
\hline 8 & 5,5 & 5,4 & 6,3 \\
\hline 9 & - & 8,3 & - \\
\hline 10 & 5,1 & 5,8 & - \\
\hline 11 & 4,9 & 7,2 & - \\
\hline 12 & 5,3 & - & 7,9 \\
\hline 13 & 5,4 & 6,3 & 6,8 \\
\hline 14 & 6,0 & 6,7 & 6,5 \\
\hline 15 & 6,9 & - & 6,1 \\
\hline 16 & 5,4 & 5,1 & - \\
\hline 17 & 6,2 & 6,6 & - \\
\hline 18 & 6,2 & 6,3 & - \\
\hline 19 & 5,4 & 7,0 & 6,5 \\
\hline 20 & 4,6 & 5,6 & 4,6 \\
\hline 21 & 6,6 & 6,9 & 6,5 \\
\hline 22 & 4,7 & 7,1 & - \\
\hline 23 & 3,7 & - & - \\
\hline 24 & 5,6 & 6,6 & 6,5 \\
\hline 25 & 5,3 & 4,9 & - \\
\hline 26 & 5,7 & 5,8 & 6,1 \\
\hline 27 & 5,6 & 5,7 & 6,5 \\
\hline 28 & 5,0 & 5,0 & 8,3 \\
\hline 29 & 7,1 & 6,1 & - \\
\hline 30 & 6,6 & 6,6 & - \\
\hline 31 & 5,0 & 6,0 & 6,8 \\
\hline 32 & 6,0 & 6,1 & 7,2 \\
\hline 33 & 5,4 & 6,4 & - \\
\hline 34 & 4,5 & - & - \\
\hline 35 & 6,5 & - & - \\
\hline 36 & 5,3 & - & - \\
\hline 37 & 4,4 & 5,9 & 5,7 \\
\hline 38 & 4,1 & 5,7 & - \\
\hline 39 & 5,0 & 5,7 & - \\
\hline 40 & 5,2 & 5,7 & 5,6 \\
\hline Média & 5,45 & 6,17 & 6,55 \\
\hline DP & 0,90 & 0,81 & 0,88 \\
\hline
\end{tabular}


Anexo J3 - Evolução dos níveis séricos de $\mathbf{P}(\mathrm{mg} / \mathrm{dl})$ na 1a semana de vida em RNT sem CIUR com asfixia perinatal (Grupo lb)

\begin{tabular}{|c|c|c|c|}
\hline CASO $\mathrm{N}$ ㅇ & $\begin{array}{l}\text { CORDÃO UMBILICAL } \\
\qquad n=20\end{array}$ & $\begin{array}{c}\text { 3으 DIA DE VIDA } \\
n=19\end{array}$ & $\begin{array}{c}\text { 70 DIA DE VIDA } \\
n=19\end{array}$ \\
\hline 1 & 8,2 & 4,9 & 6,7 \\
\hline 2 & 4,2 & 3,8 & 5,1 \\
\hline 3 & 10,5 & 5,5 & 7,4 \\
\hline 4 & 6,7 & 5,0 & 6,0 \\
\hline 5 & 7,2 & 5,8 & 7,9 \\
\hline 6 & 8,9 & 6,5 & 10,8 \\
\hline 7 & 5,8 & 5,4 & 5,9 \\
\hline 8 & 10,6 & 6,0 & 5,6 \\
\hline 9 & 5,6 & 5,6 & 5,0 \\
\hline 10 & 7,4 & 7,2 & - \\
\hline 11 & 3,7 & 4,0 & 6,8 \\
\hline 12 & 4,6 & - & 6,8 \\
\hline 13 & 8,4 & 8,0 & 7,1 \\
\hline 14 & 8,1 & 5,4 & 4,6 \\
\hline 15 & 7,7 & 5,5 & 8,0 \\
\hline 16 & 3,0 & 6,2 & 7,6 \\
\hline 17 & 3,8 & 4,7 & 6,9 \\
\hline 18 & 8,8 & 6,7 & 6,7 \\
\hline 19 & 3,3 & 5,5 & 5,4 \\
\hline 20 & 4,4 & 5,6 & 6,1 \\
\hline Média & 6,55 & 5,65 & 6,65 \\
\hline DP & 2,38 & 1,01 & 1,41 \\
\hline
\end{tabular}


Anexo J4 - Evolução dos níveis séricos de $\mathbf{P}(\mathrm{mg} / \mathrm{dl})$ na 1a semana de vida em RNT com CIUR e asfixia perinatal (Grupo Illb)

\begin{tabular}{|c|c|c|c|}
\hline CASO N $~$ & $\begin{array}{c}\text { CORDÃO UMBILICAL } \\
\mathbf{n = 4}\end{array}$ & $\begin{array}{c}\text { 3ㅇ DIA DE VIDA } \\
\mathbf{n = 5}\end{array}$ & $\begin{array}{c}\mathbf{7} \text { DIA DE VIDA } \\
\mathbf{n = 5}\end{array}$ \\
\hline $\mathbf{1}$ & 4,2 & 2,1 & 10,5 \\
\hline $\mathbf{2}$ & 7,0 & 6,7 & 7,8 \\
\hline $\mathbf{3}$ & 6,2 & 6,7 & 6,6 \\
\hline $\mathbf{4}$ & 5,8 & 5,9 & 6,4 \\
\hline $\mathbf{5}$ & - & 5,3 & 5,7 \\
\hline Média & $\mathbf{5 , 8 0}$ & $\mathbf{5 , 3 4}$ & $\mathbf{7 , 4 0}$ \\
\hline DP & $\mathbf{1 , 1 8}$ & $\mathbf{1 , 9 1}$ & $\mathbf{1 , 8 9}$ \\
\hline
\end{tabular}


Anexo $\mathrm{L}$ - Evolução dos níveis de $\mathrm{pH}$ na $1^{\mathrm{a}}$ semana de vida nos diferentes grupos de estudo

Anexo L1 - Evolução dos níveis de pH na 1a semana de vida em RNT sem CIUR (Grupo la)

\begin{tabular}{|c|c|c|c|}
\hline CASO $N$ ㅇ & $\begin{array}{l}\text { CORDÃO UMBILICAL } \\
\qquad n=26\end{array}$ & $\begin{array}{l}\text { 30 DIA DE VIDA } \\
n=23\end{array}$ & $\begin{array}{c}\text { 70 DIA DE VIDA } \\
n=19\end{array}$ \\
\hline 1 & 7,23 & 7,36 & - \\
\hline 2 & 7,35 & 7,36 & 7,44 \\
\hline 3 & - & 7,50 & - \\
\hline 4 & 7,43 & 7,30 & 7,48 \\
\hline 5 & 7,22 & 7,45 & 7,41 \\
\hline 6 & 7,34 & - & - \\
\hline 7 & 7,24 & 7,40 & 7,41 \\
\hline 8 & 7,28 & 7,40 & 7,43 \\
\hline 9 & 7,25 & 7,43 & - \\
\hline 10 & 7,27 & 7,40 & 7,37 \\
\hline 11 & 7,35 & 7,45 & 7,36 \\
\hline 12 & 7,33 & 7,43 & - \\
\hline 13 & 7,23 & 7,51 & 7,45 \\
\hline 14 & 7,10 & 7,44 & - \\
\hline 15 & 7,24 & 7,37 & 7,41 \\
\hline 16 & 7,34 & 7,43 & 7,42 \\
\hline 17 & 7,38 & 7,38 & 7,43 \\
\hline 18 & 7,28 & 7,52 & 7,43 \\
\hline 19 & - & 7,18 & - \\
\hline 20 & 7,29 & - & - \\
\hline 21 & 7,24 & 7,49 & 7,39 \\
\hline 22 & 7,01 & - & 7,41 \\
\hline 23 & 7,32 & - & 7,44 \\
\hline 24 & 7,34 & - & 7,42 \\
\hline 25 & 7,40 & 7,43 & 7,41 \\
\hline 26 & - & 7,43 & - \\
\hline 27 & 7,22 & - & - \\
\hline 28 & 7,45 & 7,48 & 7,48 \\
\hline 29 & 7,38 & 7,36 & - \\
\hline 30 & - & - & 7,40 \\
\hline Média & 7,29 & 7,41 & 7,42 \\
\hline DP & 0,10 & 0,08 & 0,03 \\
\hline
\end{tabular}


Anexo L2 - Evolução dos níveis de pH na 1a semana de vida em RNT com CIUR (Grupo lla)

\begin{tabular}{|c|c|c|c|}
\hline 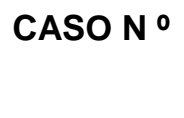 & $\begin{array}{l}\text { CORDÃO UMBILICAL } \\
\qquad n=34\end{array}$ & $\begin{array}{c}\text { 3으 DIA DE VIDA } \\
n=35\end{array}$ & $\begin{array}{c}\text { 70 DIA DE VIDA } \\
n=22\end{array}$ \\
\hline 1 & - & 7,47 & - \\
\hline 2 & - & 7,46 & 7,44 \\
\hline 3 & 7,31 & 7,46 & 7,36 \\
\hline 4 & - & 7,47 & 7,44 \\
\hline 5 & 7,43 & 7,36 & 7,40 \\
\hline 6 & 7,45 & 7,49 & 7,47 \\
\hline 7 & 7,35 & 7,45 & 7,30 \\
\hline 8 & 7,26 & 7,45 & 7,46 \\
\hline 9 & 7,37 & 7,36 & - \\
\hline 10 & - & 7,48 & - \\
\hline 11 & 7,36 & - & - \\
\hline 12 & 7,28 & 7,34 & 7,41 \\
\hline 13 & 7,35 & 7,45 & 7,38 \\
\hline 14 & 7,25 & 7,43 & 7,46 \\
\hline 15 & 7,19 & 7,43 & 7,44 \\
\hline 16 & 7,28 & 7,46 & - \\
\hline 17 & 7,33 & 7,45 & - \\
\hline 18 & 7,18 & 7,39 & 7,46 \\
\hline 19 & 7,41 & 7,43 & 7,42 \\
\hline 20 & 7,41 & 7,37 & 7,34 \\
\hline 21 & 7,32 & 7,38 & 7,37 \\
\hline 22 & 7,25 & 7,40 & - \\
\hline 23 & 7,40 & - & - \\
\hline 24 & 7,32 & 7,46 & 7,36 \\
\hline 25 & 7,42 & 7,43 & - \\
\hline 26 & 7,43 & 7,40 & 7,45 \\
\hline 27 & 7,40 & 7,44 & 7,33 \\
\hline 28 & 7,31 & 7,49 & 7,42 \\
\hline 29 & - & - & - \\
\hline 30 & 7,20 & 7,42 & - \\
\hline 31 & - & 7,45 & 7,37 \\
\hline 32 & 7,27 & 7,49 & 7,41 \\
\hline 33 & 7,40 & 7,45 & - \\
\hline 34 & 7,43 & - & - \\
\hline 35 & 7,35 & 7,44 & - \\
\hline 36 & 7,31 & - & - \\
\hline 37 & 7,37 & 7,43 & - \\
\hline 38 & 7,27 & 7,48 & - \\
\hline 39 & 7,26 & 7,37 & 7,37 \\
\hline 40 & 7,23 & 7,37 & - \\
\hline Média & 7,33 & 7,43 & 7,40 \\
\hline DP & 0,08 & 0,04 & 0,05 \\
\hline
\end{tabular}


Anexo L3 - Evolução dos níveis de pH na 1a semana de vida em RNT sem CIUR com asfixia perinatal (Grupo lb)

\begin{tabular}{|c|c|c|c|}
\hline CASO N 0 & $\begin{array}{c}\text { CORDÃO UMBILICAL } \\
\mathbf{n = 1 9}\end{array}$ & $\begin{array}{c}\text { 30 DIA DE VIDA } \\
\mathbf{n = 1 9}\end{array}$ & $\begin{array}{c}\mathbf{7 0} \text { DIA DE VIDA } \\
\mathbf{n = 1 6}\end{array}$ \\
\hline $\mathbf{1}$ & 7,52 & 7,43 & - \\
\hline $\mathbf{2}$ & 7,45 & 7,38 & 7,42 \\
\hline $\mathbf{3}$ & - & 7,42 & 7,43 \\
\hline $\mathbf{4}$ & 7,44 & 7,46 & 7,43 \\
\hline $\mathbf{5}$ & 7,29 & 7,41 & 7,44 \\
\hline $\mathbf{6}$ & 7,10 & 7,40 & 7,51 \\
\hline $\mathbf{7}$ & 7,12 & 7,41 & 7,43 \\
\hline $\mathbf{8}$ & 6,85 & 7,39 & 7,54 \\
\hline $\mathbf{9}$ & 7,34 & 7,41 & 7,41 \\
\hline $\mathbf{1 0}$ & 6,95 & 7,43 & - \\
\hline $\mathbf{1 1}$ & 7,40 & 7,43 & - \\
\hline $\mathbf{1 2}$ & 7,10 & 7,45 & 7,46 \\
\hline $\mathbf{1 3}$ & 6,93 & 7,36 & 7,41 \\
\hline $\mathbf{1 4}$ & 7,23 & 7,35 & 7,41 \\
\hline $\mathbf{1 5}$ & 7,35 & 7,44 & 7,49 \\
\hline $\mathbf{1 6}$ & 7,53 & 7,44 & 7,39 \\
\hline $\mathbf{1 7}$ & 7,45 & 7,43 & 7,42 \\
\hline $\mathbf{1 8}$ & 7,07 & 7,42 & 7,40 \\
\hline $\mathbf{1 9}$ & 7,44 & 7,40 & $\mathbf{7 , 4 4}$ \\
\hline $\mathbf{2 0}$ & 7,46 & - & $\mathbf{0 , 0 4}$ \\
\hline $\mathbf{M e ́ d i a}$ & $\mathbf{7 , 2 6}$ & $\mathbf{7 , 4 1}$ & $\mathbf{0 , 0 3}$ \\
\hline $\mathbf{D P}$ & $\mathbf{0 , 2 2}$ & & - \\
\hline
\end{tabular}


Anexo L4 - Evolução dos níveis de pH na 1a semana de vida em RNT com CIUR e asfixia perinatal (Grupo Ilb)

\begin{tabular}{|c|c|c|c|}
\hline CASO N $~$ & $\begin{array}{c}\text { CORDÃO UMBILICAL } \\
\mathbf{n = 4}\end{array}$ & $\begin{array}{c}\text { 30 DIA DE VIDA } \\
\mathbf{n = 5}\end{array}$ & $\begin{array}{c}\text { 7o DIA DE VIDA } \\
\mathbf{n = 4}\end{array}$ \\
\hline $\mathbf{1}$ & 7,39 & 7,39 & 7,38 \\
\hline $\mathbf{2}$ & 7,26 & 7,48 & 7,42 \\
\hline $\mathbf{3}$ & 7,27 & 7,44 & 7,45 \\
\hline $\mathbf{4}$ & 7,51 & 7,46 & 7,45 \\
\hline $\mathbf{5}$ & - & 7,54 & - \\
\hline Média & $\mathbf{7 , 3 6}$ & $\mathbf{7 , 4 6}$ & $\mathbf{7 , 4 3}$ \\
\hline DP & $\mathbf{0 , 1 2}$ & $\mathbf{0 , 0 6}$ & $\mathbf{0 , 0 3}$ \\
\hline
\end{tabular}


Anexo M - Evolução dos níveis séricos de Uréia(U) na 1a semana de vida nos diferentes grupos de estudo

Anexo M1 - Evolução dos níveis séricos de $\mathbf{U}(\mathrm{mg} / \mathrm{dl})$ na 1a semana de vida em RNT sem CIUR (Grupo la)

\begin{tabular}{|c|c|c|c|}
\hline CASO $\mathrm{N}$ ㅇ & $\begin{array}{l}\text { CORDÃO UMBILICAL } \\
\qquad n=15\end{array}$ & $\begin{array}{c}\text { 30 DIA DE VIDA } \\
n=15\end{array}$ & $\begin{array}{l}\text { 70 DIA DE VIDA } \\
\qquad n=10\end{array}$ \\
\hline 1 & 15 & $--^{*}$ & - \\
\hline 2 & 17 & 9 & 11 \\
\hline 3 & - & 9 & - \\
\hline 4 & $-*$ & $-^{*}$ & - \\
\hline 5 & 7 & $-^{*}$ & 10 \\
\hline 6 & 5 & - & - \\
\hline 7 & 7 & 10 & $-*$ \\
\hline 8 & 7 & $-^{*}$ & $-*$ \\
\hline 9 & 5 & 5 & - \\
\hline 10 & $-^{*}$ & $-^{*}$ & 4 \\
\hline 11 & 5 & 6 & 9 \\
\hline 12 & $-*$ & 27 & - \\
\hline 13 & 10 & 10 & - \\
\hline 14 & 10 & 8 & - \\
\hline 15 & $-^{*}$ & 8 & $-*$ \\
\hline 16 & $-*$ & $-_{-*}^{*}$ & 10 \\
\hline 17 & 18 & 9 & 6 \\
\hline 18 & $-^{*}$ & 3 & 6 \\
\hline 19 & $-*$ & $-^{*}$ & - \\
\hline 20 & $-*$ & - & - \\
\hline 21 & $-*$ & 4 & 10 \\
\hline 22 & 12 & - & 16 \\
\hline 23 & $-^{*}$ & $--^{*}$ & - \\
\hline 24 & $-*$ & - & - \\
\hline 25 & $-*$ & 9 & - \\
\hline 26 & - & 9 & - \\
\hline 27 & 6 & - & - \\
\hline 28 & 40 & - & - \\
\hline 29 & 4 & 5 & - \\
\hline 30 & - & - & 6 \\
\hline Média & 11,2 & 8,73 & 8,80 \\
\hline DP & 9,16 & 5,54 & 3,46 \\
\hline
\end{tabular}

* $<10 \mathrm{mg} / \mathrm{dl}$ 
Anexo M2 - Evolução dos níveis séricos de $\mathbf{U}(\mathrm{mg} / \mathrm{dl})$ na 1ạ semana de vida em RNT com CIUR (Grupo lla)

\begin{tabular}{|c|c|c|c|}
\hline CASO $N$ ㅇ & $\begin{array}{l}\text { CORDÃO UMBILICAL } \\
\qquad n=25\end{array}$ & $\begin{array}{c}\text { 3으 DIA DE VIDA } \\
n=28\end{array}$ & $\begin{array}{c}\text { 70 DIA DE VIDA } \\
n=17\end{array}$ \\
\hline 1 & - & 16 & - \\
\hline 2 & - & 7 & 10 \\
\hline 3 & 13 & 24 & 8 \\
\hline 4 & - & 10 & 10 \\
\hline 5 & 13 & 12 & 15 \\
\hline 6 & $-^{*}$ & 5 & 4 \\
\hline 7 & 17 & 19 & $--^{*}$ \\
\hline 8 & $-^{*}$ & $-^{*}$ & 7 \\
\hline 9 & 26 & 38 & - \\
\hline 10 & - & 6 & - \\
\hline 11 & 13 & - & - \\
\hline 12 & 16 & 8 & 7 \\
\hline 13 & 7 & 3 & 4 \\
\hline 14 & 5 & 5 & 6 \\
\hline 15 & 22 & 4 & 6 \\
\hline 16 & - & - & - \\
\hline 17 & 10 & 12 & - \\
\hline 18 & - & 16 & - \\
\hline 19 & $-^{*}$ & 4 & 5 \\
\hline 20 & 10 & 23 & 42 \\
\hline 21 & - & 26 & 15 \\
\hline 22 & $-^{*}$ & 11 & - \\
\hline 23 & 13 & - & - \\
\hline 24 & 19 & 24 & 11 \\
\hline 25 & 9 & $-^{*}$ & - \\
\hline 26 & 12 & 6 & 5 \\
\hline 27 & 27 & 11 & 13 \\
\hline 28 & - & 12 & $-^{*}$ \\
\hline 29 & - & - & - \\
\hline 30 & 22 & $-^{*}$ & - \\
\hline 31 & 5 & 10 & - \\
\hline 32 & 25 & 13 & 10 \\
\hline 33 & 11 & 7 & - \\
\hline 34 & 12 & - & - \\
\hline 35 & $-^{*}$ & $-^{*}$ & - \\
\hline 36 & $-^{*}$ & - & - \\
\hline 37 & 7 & 7 & - \\
\hline 38 & 14 & $-^{*}$ & - \\
\hline 39 & 13 & 20 & $--^{*}$ \\
\hline 40 & 5 & $-^{*}$ & - \\
\hline Média & 13,84 & 12,82 & 10,47 \\
\hline DP & 6,52 & 8,36 & 8,86 \\
\hline
\end{tabular}

${ }^{*}<10 \mathrm{mg} / \mathrm{dl}$ 
Anexo M3 - Evolução dos níveis séricos de $\mathbf{U}(\mathrm{mg} / \mathrm{dl})$ na 1a semana de vida em RNT sem CIUR com asfixia perinatal (Grupo lb)

\begin{tabular}{|c|c|c|c|}
\hline CASO N $\cong$ & $\begin{array}{l}\text { CORDÃO UMBILICAL } \\
\qquad n=14\end{array}$ & $\begin{array}{c}\text { 3으 DIA DE VIDA } \\
n=12\end{array}$ & $\begin{array}{l}\text { 70 DIA DE VIDA } \\
n=10\end{array}$ \\
\hline 1 & 15 & $-*$ & - \\
\hline 2 & 12 & 12 & 29 \\
\hline 3 & - & 5 & $-*$ \\
\hline 4 & 10 & $-^{*}$ & 10 \\
\hline 5 & 13 & 12 & 15 \\
\hline 6 & 9 & 9 & $-*$ \\
\hline 7 & $-*$ & $-^{*}$ & 6 \\
\hline 8 & 6 & 10 & 6 \\
\hline 9 & $-*$ & 6 & $-*$ \\
\hline 10 & 8 & 4 & - \\
\hline 11 & 10 & 4 & - \\
\hline 12 & 14 & 13 & - \\
\hline 13 & - & 11 & 8 \\
\hline 14 & 9 & 13 & 7 \\
\hline 15 & 12 & 6 & 7 \\
\hline 16 & $-*$ & $-*$ & 13 \\
\hline 17 & 18 & $-*$ & 10 \\
\hline 18 & $-*$ & $-*$ & $-*$ \\
\hline 19 & 18 & $-^{*}$ & $-*$ \\
\hline 20 & 9 & - & $-^{*}$ \\
\hline Média & 11,64 & 8,75 & 11,10 \\
\hline DP & 3,63 & 3,55 & 7,00 \\
\hline
\end{tabular}

${ }^{*}<10 \mathrm{mg} / \mathrm{dl}$ 
Anexo M4 - Evolução dos níveis séricos de $\mathbf{U}(\mathrm{mg} / \mathrm{dl})$ na 1ạ semana de vida em RNT com CIUR e asfixia perinatal (Grupo Illb)

\begin{tabular}{|c|c|c|c|}
\hline CASO N $~$ & $\begin{array}{c}\text { CORDÃO UMBILICAL } \\
\mathbf{n = 3}\end{array}$ & $\begin{array}{c}\text { 3ㅇ DIA DE VIDA } \\
\mathbf{n}=\mathbf{4}\end{array}$ & $\begin{array}{c}\mathbf{7} \text { DIA DE VIDA } \\
\mathbf{n}=\mathbf{3}\end{array}$ \\
\hline $\mathbf{1}$ & 9 & 13 & 12 \\
\hline $\mathbf{2}$ & 10 & 13 & 10 \\
\hline $\mathbf{3}$ & 14 & 10 & 10 \\
\hline $\mathbf{4}$ & - & $-^{*}$ & $-^{*}$ \\
\hline $\mathbf{5}$ & - & 16 & - \\
\hline Média & $\mathbf{1 1 , 0}$ & $\mathbf{1 3 , 0}$ & $\mathbf{1 0 , 7}$ \\
\hline DP & $\mathbf{2 , 6 5}$ & $\mathbf{2 , 4 5}$ & $\mathbf{1 , 1 6}$ \\
\hline
\end{tabular}


Anexo N-Evolução dos níveis séricos de Creatinina(Cr) na 1ạ semana de vida nos diferentes grupos de estudo

Anexo N1 - Evolução dos níveis séricos de $\mathbf{C r}(\mathrm{mg} / \mathrm{dl})$ na 1a semana de vida em RNT sem CIUR (Grupo la)

\begin{tabular}{|c|c|c|c|}
\hline 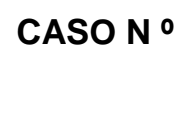 & $\begin{array}{l}\text { CORDÃO UMBILICAL } \\
\qquad n=28\end{array}$ & $\begin{array}{c}\text { 30 DIA DE VIDA } \\
n=22\end{array}$ & $\begin{array}{c}\text { 70 DIA DE VIDA } \\
n=16\end{array}$ \\
\hline 1 & 0,48 & 0,45 & - \\
\hline 2 & 0,61 & 0,16 & 0,18 \\
\hline 3 & 0,54 & 0,42 & - \\
\hline 4 & 0,60 & 0,50 & 0,44 \\
\hline 5 & 0,62 & 0,28 & 0,40 \\
\hline 6 & 0,52 & - & - \\
\hline 7 & 0,56 & 0,64 & 0,28 \\
\hline 8 & 0,50 & 0,37 & 0,15 \\
\hline 9 & 0,88 & 0,51 & - \\
\hline 10 & 0,53 & 0,27 & 0,3 \\
\hline 11 & 0,41 & 0,30 & 0,15 \\
\hline 12 & 0,63 & 0,64 & - \\
\hline 13 & 0,65 & 0,42 & 0,20 \\
\hline 14 & 0,62 & 0,43 & - \\
\hline 15 & 0,63 & 0,28 & 0,28 \\
\hline 16 & 0,52 & 0,43 & 0,30 \\
\hline 17 & 1,16 & 0,10 & 0,40 \\
\hline 18 & 0,53 & 0,49 & 0,30 \\
\hline 19 & 0,58 & 0,40 & - \\
\hline 20 & 0,58 & - & - \\
\hline 21 & 0,65 & 0,14 & - \\
\hline 22 & 0,64 & - & 0,69 \\
\hline 23 & 0,46 & 0,16 & - \\
\hline 24 & 0,53 & - & - \\
\hline 25 & 0,60 & 0,61 & 0,30 \\
\hline 26 & - & - & 0,40 \\
\hline 27 & 0,53 & - & - \\
\hline 28 & 1,98 & 0,40 & - \\
\hline 29 & 0,40 & - & - \\
\hline 30 & - & - & 0,29 \\
\hline Média & 0,64 & 0,38 & 0,32 \\
\hline DP & 0,30 & 0,16 & 0,13 \\
\hline
\end{tabular}


Anexo N2 - Evolução dos níveis séricos de $\mathbf{C r}(\mathrm{mg} / \mathrm{dl})$ na 1a semana de vida em RNT com CIUR (Grupo Ila)

\begin{tabular}{|c|c|c|c|}
\hline CASO $\mathrm{N}$ & $\begin{array}{l}\text { CORDÃO UMBILICAL } \\
\qquad n=39\end{array}$ & $\begin{array}{c}\text { 3으 DIA DE VIDA } \\
n=34\end{array}$ & $\begin{array}{c}\text { 70 DIA DE VIDA } \\
n=\mathbf{2 1}\end{array}$ \\
\hline 1 & 0,60 & 0,19 & - \\
\hline 2 & 0,78 & 0,45 & 0,40 \\
\hline 3 & 0,90 & 0,48 & 0,44 \\
\hline 4 & 1,13 & 0,30 & 0,29 \\
\hline 5 & 1,00 & 0,69 & 0,53 \\
\hline 6 & 0,75 & 0,50 & 0,68 \\
\hline 7 & 0,70 & 0,65 & 0,10 \\
\hline 8 & 0,54 & 0,28 & 0,25 \\
\hline 9 & - & 0,70 & - \\
\hline 10 & 0,59 & 0,37 & - \\
\hline 11 & 0,58 & 0,41 & - \\
\hline 12 & 0,98 & 0,55 & 0,19 \\
\hline 13 & 1,07 & 0,36 & 0,43 \\
\hline 14 & 0,66 & 0,40 & 0,11 \\
\hline 15 & 1,11 & - & 0,46 \\
\hline 16 & 0,69 & 0,61 & - \\
\hline 17 & 0,65 & 0,35 & - \\
\hline 18 & 0,77 & 0,43 & - \\
\hline 19 & 0,77 & 0,48 & 0,45 \\
\hline 20 & 0,58 & 0,50 & 0,16 \\
\hline 21 & 0,63 & 0,43 & 0,13 \\
\hline 22 & 0,58 & 0,96 & - \\
\hline 23 & 1,22 & - & - \\
\hline 24 & 0,79 & 0,63 & 0,12 \\
\hline 25 & 0,69 & 0,59 & - \\
\hline 26 & 0,77 & 0,42 & 0,32 \\
\hline 27 & 0,54 & 0,26 & 0,24 \\
\hline 28 & 0,58 & 0,53 & 0,17 \\
\hline 29 & 0,57 & 0,43 & - \\
\hline 30 & 0,67 & 0,52 & - \\
\hline 31 & 0,46 & 0,58 & 0,31 \\
\hline 32 & 0,97 & - & - \\
\hline 33 & 0,48 & 0,21 & - \\
\hline 34 & 0,58 & - & - \\
\hline 35 & 0,67 & - & - \\
\hline 36 & 0,73 & - & - \\
\hline 37 & 0,48 & 0,29 & 0,24 \\
\hline 38 & 0,70 & 0,65 & - \\
\hline 39 & 0,43 & 0,46 & - \\
\hline 40 & 0,59 & 0,30 & 0,34 \\
\hline Média & 0,72 & 0,47 & 0,30 \\
\hline DP & 0,20 & 0,16 & 0,16 \\
\hline
\end{tabular}


Anexo N3 - Evolução dos níveis séricos de $\mathbf{C r}(\mathrm{mg} / \mathrm{dl})$ na 1a semana de vida em RNT sem CIUR com asfixia perinatal (Grupo lb)

\begin{tabular}{|c|c|c|c|}
\hline 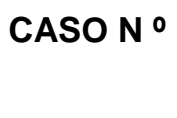 & $\begin{array}{l}\text { CORDÃO UMBILICAL } \\
\qquad n=19\end{array}$ & $\begin{array}{c}\text { 3ㅇ DIA DE VIDA } \\
n=18\end{array}$ & $\begin{array}{c}\text { 7o DIA DE VIDA } \\
n=19\end{array}$ \\
\hline 1 & 3,10 & 5,80 & 0,50 \\
\hline 2 & 1,50 & 0,97 & 0,79 \\
\hline 3 & 1,10 & 0,30 & 0,36 \\
\hline 4 & 0,49 & 0,17 & 0,27 \\
\hline 5 & 0,62 & 0,10 & 0,40 \\
\hline 6 & 0,68 & 0,68 & 0,16 \\
\hline 7 & 0,90 & 0,33 & 0,27 \\
\hline 8 & 0,65 & 0,40 & 0,40 \\
\hline 9 & 0,63 & 0,26 & 0,18 \\
\hline 10 & 0,44 & 0,20 & - \\
\hline 11 & 0,69 & 0,32 & 0,30 \\
\hline 12 & 0,71 & - & 0,30 \\
\hline 13 & 0,49 & 0,15 & 0,26 \\
\hline 14 & 0,59 & 0,75 & 0,47 \\
\hline 15 & 0,48 & - & 0,19 \\
\hline 16 & - & 0,24 & 0,32 \\
\hline 17 & 2,22 & 0,20 & 0,43 \\
\hline 18 & 0,63 & 0,17 & 0,06 \\
\hline 19 & 1,16 & 0,59 & 0,41 \\
\hline 20 & 0,57 & 0,20 & 0,19 \\
\hline Média & 0,93 & 0,66 & 0,33 \\
\hline DP & 0,68 & 1,31 & 0,16 \\
\hline
\end{tabular}


Anexo N4 - Evolução dos níveis séricos de $\operatorname{Cr}(\mathrm{mg} / \mathrm{dl})$ na 1a semana de vida em RNT com CIUR e asfixia perinatal (Grupo Ilb)

\begin{tabular}{|c|c|c|c|}
\hline CASO N $~$ & $\begin{array}{c}\text { CORDÃO UMBILICAL } \\
\mathbf{n = 4}\end{array}$ & $\begin{array}{c}\text { 3 DIA DE VIDA } \\
\mathbf{n = 4}\end{array}$ & $\begin{array}{c}\text { 70 DIA DE VIDA } \\
\mathbf{n}=\mathbf{5}\end{array}$ \\
\hline $\mathbf{1}$ & 1,00 & 0,31 & 0,46 \\
\hline $\mathbf{2}$ & 0,88 & 0,84 & 0,54 \\
\hline $\mathbf{3}$ & 0,74 & - & 0,14 \\
\hline $\mathbf{4}$ & 0,82 & 0,45 & 0,46 \\
\hline $\mathbf{5}$ & - & 0,73 & 0,54 \\
\hline Média & $\mathbf{0 , 8 6}$ & $\mathbf{0 , 5 8}$ & $\mathbf{0 , 4 3}$ \\
\hline DP & $\mathbf{0 , 1 1}$ & $\mathbf{0 , 2 5}$ & $\mathbf{0 , 1 7}$ \\
\hline
\end{tabular}




\section{8 - REFERÊNCIAS}


American Academy of Pediatrics. Use and abuse of the apgar score. Pediatrics 1996;98:1-4.

Altman DG, Hytten FE. Intrauterine growth retardation: let's be clear about it. Br J Obstet Gynecol 1989;96:1127-32.

Altura BM. Introduction: importance of $\mathrm{Mg}$ in physiology and medicine and the need for ion selective electrodes. Scand J Clin Lab Invest 1994;54 suppl 217:5-9.

Altura BM, Altura BT. Magnesium in cardiovascular biology. Sci Med 1995;28-37.

Anast CS, Mohs JM, Kaplan SL, Burns TW. Evidence for parathyroid failure in magnesium deficiency. Science 1972;177:606-8.

Anastasiadis P, Atassi S, Rimpler M. The concentration of the elements $\mathrm{Zn}$, $\mathrm{Cu}, \mathrm{Mg}, \mathrm{Fe}, \mathrm{Na}$ and $\mathrm{K}$ in human amniotic fluid during birth. $J$ Perinat Med 1981;9:228-34.

Anslow P. Birth asphyxia. Eur J Radiol 1998;26:148-53.

Bajpai CP, Sugden D, Ramos A, Stern L. Serum magnesium levels in the newborn and older child. Arch Dis Child 1966;41:424-7.

Battaglia FC, Lubchenco LO . A practical classification of newborn infants by weight and gestational age. J Pediatr 1967;71:159-61.

Beattie RB, Johnson P. Practical assessment of neonatal nutrition status beyond birthweight : na imperative for the 1990s. Br J Obstet Gynecol 1994;101:842-6.

Behar J. Magnesium absorption by the rat ileum and colon. Am J Physiol 1974;227:334-40.

Bei L, Wood RJ, Rosenberg IH. Glucose polymer increases jejunal calcium, magnesium and zinc absorption in humans. Am J Clin Nutr 1986;44: 244-7. 
Berger R, Garnier Y. Pathophysiology of perinatal brain damage. Brain Res Rev 2000;30:107-34.

Bittar R, Ramos JLA, Leone CR. Crescimento fetal. In: Marcondes E, Vaz FAC, Ramos JLA, Okay Y. Pediatria Básica. 9a ed. São paulo: Sarvier; 2002. p.255-65.

Capurro $\mathrm{H}$. A simplified mehod for diagnosis of gestational age in the newborn infant. J Pediatr 1978;93:120-2.

Casey BM, McIntire DD, Levene KJ. The continuing value of the apgar score for the assessment of newborn infants. N Engl J Med 2001;344:467-71.

Cashman KD, Flynn A. Optimal nutrition: calcium, magnesium and phosphorus. Proc Nutr Soc 1999;58:477-87.

Cetin I, Marconi AM, Bozzetti P, Sereni LP, Corbetta C, Pardi G. Umbilical amino acid concentrations in appropriate and small for gestational age infants : a biochemical difference present in utero. Am J Obstet Gynecol 1988;158:120-6.

Cetin I, Ronzoni S, Marconi A, Perugino G, Corbetta C, Battaglia F. Maternal concentrations and fetal-maternal concentration differences of plasma amino acids in normal and intrauterine growth-restricted pregnancies. Am J Obstet Gynecol 1996;174:1575-83.

Chiswick M. Intrauterine growth retardation. Br Med J 1985;291:845-8.

Cianfarani S, Geremia C, Germani D. Growth IGF system and cortisol in children with intrauterine growth retardation: is catch-up growth affected by reprogramming of the hypothalamic-pituitary-adrenal axis? Pediatr Res 2002;51:94-9.

Classen $H$, Marquardt $P$, Späth $M$, Schumacher K. Hypermagnesemia following exposure to acute stress. Pharmacology 1971;5:287-94.

Cook LA, Mimouni FB. Whole blood ionized magnesium in the healthy neonate. J Am Coll Nutr 1997;16:181-3.

Cruikshank DP, Pitkin RM, Reynolds WA, Williams GA, Hargis GK. Effects of magnesium sulfate treatment on perinatal calcium metabolism. Am J Obstet Gynecol 1979;134:243-9. 
Dacey MJ. Hypomagnesemic disorders. Crit Care Clin 2001;17:155-73.

David L, Anast CS. The interrelationship of parathyroid function and calcium, magnesium, and phosphorus metabolism in normal, "sick", and hypocalcemic newborns. J Clin Invest 1974;54:287-96.

David L, Salle BL, Putet G, Grafmeyer DC. Serum immunoreactive calcitonin in low birth weight infants. Description of early changes; effect of intravenous calcium infusion; relationships with early changes in serum calcium, phosphorus, magnesium, parathyroid hormone, and gastrin levels. Pediatr Res 1981;15:803-8.

Dollberg S, Bauer R, Lubetzky R, Mimouni FB. A reappraisal of neonatal blood chemistry reference ranges using the Nova $\mathrm{M}$ electrodes. $\mathrm{Am} \mathrm{J}$ Perinatol 2001;18:433-40.

Donovan EF, Tsang RC, Steichen JJ, Strub RJ, Chen M. Neonatal hypermagnesemia. Effect on parathyroid hormone and calcium homeostasis. J Pediatr 1980;96:305-10.

Dorea JG. Magnesium in human milk. J Am Coll Nutr 2000;19:210-19.

Dória Filho U. Introdução à Bioestatística. São Paulo: Negócio Editora; 1999.

Du Plessis A, Johston MV. Hypoxic-ischemic brain injury in the newborn. Cellular mechanisms and potential strategies for neuroprotection. Clin Perinatol 2002;24:627-55.

Duran N, Justo GZ, Haun M, Souza-Brito ARM.O Magnésio e o sistema biológico. Rev Cienc Farmac 1998;19:9-36.

Elin RJ. Assessment of magnesium status. Clin Chem 1987;33:1965-70.

Engel RR, Elin RJ. Hypermagnesemia from birth asphyxia. $J$ Pediatr 1970;77:631-7.

Engidawork E, Loidl F, Chen Y, Kohlhauser C, Stoeckler S, Dell'anna E, Lubec B, Lubec G, Goiny M, Gross J, Andersson K, Herrera-Marschitz M. Comparison between hypothermia and glutamate antagonism on the immediate outcome of perinatal asphyxia. Exp Brain Res 2001;375-83.

Farrell EC. Fósforo. In: Pesce AJ, Kaplan LA. Química Clínica - Métodos. Buenos Aires : ed.med.panam; 1990a. p.1047-51. 
Farrell EC. Magnesio. In: Pesce AJ, Kaplan LA. Química Clínica - Métodos. Buenos Aires:ed.med.panam; 1990b. p.1031-6.

Fawcett WJ, Haxby EJ, Male DA. Magnesium: physiology and pharmacology. Brit J Anaesth 1999;83:302-20.

Fiser RT, Torres A, Butch AW, Valentine J . lonized magnesium concentrations in critically ill children. Crit Care Med 1998;26:2048-52.

Fletcher R, Fletcher SW, Wagner EH. Epidemiologia clínica: elementos essenciais. $3^{a}$ ed. Porto Alegre: Artes Médicas; 1996.

Foley C, Zaritsky A .Should we measure ionized magnesium? Crit Care Med 1998;26:1949-50.

Forfar, J.O. Normal and abnormal calcium, phosphorus and magnesium metabolism in the perinatal period . Clin Endocrinol Metab 1976;5:123-48.

Georgieff, MK. Intrauterine growth retardation and subsequent somatic growth and neurodevelopment. J Pediatr 1998;133:3-5.

Geven WB, Monnens LAH, Willems JM. Magnesium metabolism in childhood. Miner Electrolyte Metab 1993;19:308-13.

Gluckman PD, Cutfield W, Harding JE, Milner D, Jensen E, Woodhall S, Gallaher B, Bauer M, Breier BH. Metabolic consequences of intrauterine growth retardation. Acta Paediatr Scand 1996;417:3-6.

Gluckman PD, Harding JE. The physiology and pathophysiology of intrauterine growth retardation. Horm Res 1997;48:11-16.

Goldenberg RL, Cliver SP. Small for gestational age and intrauterine growth restriction : definitions and standards. Clin Obstet Gynecol 1997;40:704-14.

Handwerker SM, Altura BT, Jones KY, Altura BM. lonized serum magnesium and potassium levels in pregnant women with preeclampsia and eclampsia. $J$ Reprod Med 1995;40:201-8.

Harris I, Wilkinson AW. Magnesium depletion in children. Lancet 1971;2:735-6. 
Harrison V, Peat G. Red blood cell magnesium and hypoxic-ischaemic encephalopaty. Early Hum Dev 1997;47:287-96.

Hawdon JM, Platt MP. Metabolic adptation in small for gestational age infants. Arch Dis Child 1993;68:262-8.

Henriksen T, Clausen T. The fetal origin hypothesis :placental insufficiency and inheritance versus maternal malnutrition in well-nourished populations. Acta Obstet Gynecol Scand 2002;81:112-4.

Hillman LS, Rojanasathit S, Slatopolsky E, Haddad JG. Serial measurements of serum calcium, magnesium, parathyroid hormone, calcitonin, and 25hydroxy-vitamin $D$ in premature and term infants during the first week of life. Pediatr Res 1977;11:739-44.

Hristova EN, Rehak NN, Cecco S, Ruddel M, Heron D, Eckardt M, Linnoila $M$, Elin RJ. Serum ionized magnesium in chronic alcoholism : is it really decreased ? Clin Chem 1999;43:394-9.

Husain SM, Sibley CP. Measurement of ionized calcium concentration in neonates. Arch Dis Child 1993;69:296-307.

Ilves $\mathrm{P}$, Kiisk M, Soopõld T, Talvik T. Serum total magnesium and ionized calcium concentrations in asphyxiated term newborn infants with hypoxicischaemic encephalopathy. Acta Paediatr 2000;89:680-5.

Jaffé M. Über den Niederschlag Welchen Pkrinsaüre in normalen harn erzeugt und über eine neue Reaktion des kreatinins. $Z$ Physio Chem 1886;10:391-400.

James D. Diagnosis and management of fetal growth retardation. Arch Dis Child 1990;65:390-4.

James MFM. Magnesium: quo vadis? Brit J Anaesth 1999;83:202-3.

Kliegman RM. Intrauterine growth retardation. In: Fanaroff AA, Martin RJ, ed. Neonatal-perinatal medicine: diseases of the fetus and infant. $6^{\text {th }}$ ed. New York: Mosby; 1997. p.203-40.

Kobayashi A, Igarashi Y. Serum magnesium level in salt-losing type of congenital adrenal hyperplasia. Arch Dis Child 1968;43:223-8. 
Krachler M, Rossipal E, Micetic-Turk D. Trace element transfer from the mother to the newborn - investigations on triplets of colostrum, maternal and umbilical cord sera. Eur J Clin Nutr 1999;53:486-94.

Kramer MS, Mclean FH, Olivier M, Willis D, Usher R. Body proportionality and head and length "sparing" in growth retarded neonates:a critical reappraisal. Pediatrics 1989;84:717-23.

Kramer MS, Platt R, Yang HM, Mcnamara H, Usher R. Are all growthrestricted newborns created equal(ly)? Pediatrics 1999;103:599-602.

Larsen T. Intrauterine growth restriction. Dan Med Bull 2001;4:256-74.

Levene M, Blennow M, Whitelaw A, Hanko E, Fellman V, Hartley R. Acute effects of two different doses of magnesium sulphate in infants with birth asphyxia. Arch Dis Child 1995;73:174-7.

Loughead JL, Mimouni F, Tsang RC, Khoury JC. A role for magnesium in neonatal parathyroid gland function? J Am Coll Nutr 1991;10:123-6.

Lyon ME, Bremner D, Laha T, Malik S, Henderson PJ, Kenny MA. Specific heparin preparations interfere with the simultaneous measurement of ionized magnesium and ionized calcium. Clin Biochem 1995;28:79-84.

Marcus JC, Valencia GB, Altura BT, Cracco RQ, Jean-Baptiste D, Sinha K, Altura B. Serum ionized magnesium in premature and term infants. Pediatr Neurol 1997;18:311-4.

Martin-Ancel A, Garcia-Alix A, Gaya F, Cabanas F, Burgueros M, Quero J. Multiple organ involvement in perinatal asphyxia. J Pediatr 1995;127:786- 93.

Massry SG, Seelig MS. Hypomagnesemia and hypermagnesemia. Clin Nephrol 1977;7:147-53.

Mclean R. Magnesium and its therapeutic uses: a review. Am J Med 1994;96:63-76.

Mimouni F, Tsang RC, Hertzberg VS, Miodovnik M. Polycythemia, hypomagnesemia, and hypocalcemia in infant of diabetic mothers. Am J Dis Child 1986;140:798-800. 
Mimouni F, Loughead JL, Tsang RC, Khoury J. Postnatal surge in serum calcitonin concentrations: no contribution to neonatal hypocalcemia in infants of diabetic mothers. Pediatr Res 1990;28:493-5.

Mimouni F, Tsang RC. Neonatal hypocalcemia : to treat or not to treat? J Am Coll Nutr 1994;13:408-15.

Mimouni FB. The ion-selective magnesium electrode : a new tool for clinicians and investigators. J Am Coll Nutr 1996;15:4-5.

Munoz R, Laussen P, Palacio G, Zienko L, Piercey G, Wessel DL. Whole blood ionized magnesium : age-related differences in normal values and clinical implications of ionized hypomagnesemia in patients undergoing surgery for congenital cardiac disease. J Thorac Cardiovasc Surg 2000;119:891-8.

Murphy E. Mysteries of magnesium homeostasis. Circ Res 2000;86:245-8.

Murray RL. Creatinina. In: Pesce AJ, Kaplan LA. Química Clínica - Métodos. Buenos Aires: Ed.med.panam; 1990. p.29-35.

Namgung R, Tsang RC, Specker BL, Sierra RI, Ho ML. Reduced serum osteocalcin and 1,25-dihydroxyvitamin D concentrations and low bone mineral content in small for gestational age infants : evidence of decreased bone formation rates. J Pediatr 1993;122:269-75.

Namgung R, Tsang RC. Neonatal calcium, phosphorus and magnesium homeostasis. In: Polin, RA, Fox, WW. Fetal and neonatal physiology. $2^{\text {nd }} \mathrm{ed}$. Philadelphia: Saunders;1998. p.2308-35.

Nandakumaran N, Dashti HM, Al-Zaid NS. Maternal-fetal transport kinetics of copper, selenium, magnesium and iron in perfused human placental lobule : in vitro study. Mol Cel Biochem 2002;231:9-14.

Nelson N, Finnstrom O, Larsson L. Neonatal reference values for ionized calcium, phosphate and magnesium. Selection of reference population by optimality criteria. Scand J Clin Lab Invest 1987;47:111-7.

Nieto-Diaz A, Villar J, Weinig RM, Ruiz PV. Intrauterine growth retardation at term: association between anthropometric and endocrine parameters. Acta Obstet Gynecol Scand 1996;75:127-31. 
Nordstrom L, Arulkumaran S. Intrapartum fetal hipoxia and biochemical markers : a review. Obstet Gynecol Surv 1998;53:645-57.

Nova Biomedical, Stat Profile M Reference Manual, Whaltham, MA: Nova Biomedicals; 1998.

Olofsson K, Matthiesen G, Rudnicki M. Whole blood ionized magnesium in neonatal acidosis and preterm infants : a prospective consecutive study. Acta Paediatr 2001;90:1398-401.

Organização Mundial De Saúde-OMS. Public health aspects of low birth weigth. Techn Rep Series no.217. Geneve;1961.

Ott W. Diagnosis of intrauterine growth restriction : comparison of ultrasound parameters. Am J Perinatol 2002;19:133-7.

Patterson RM, Pouliot MR. Neonatal morphometrics and perinatal outcome : who is growth retarded? Am J Obstet Gynecol 1987;157:691-3.

Paunier L. Effect of magnesium on phosphorus and calcium metabolism. Monatsschr Kinderheilkd 1992;140:17-20.

Perveen S, Altaf W, Vohra N, Bautista ML, Harper RG, Wapnir RA. Effect of gestational age on cord blood plasma copper, zinc, magnesium and albumin. Early Hum Dev 2002;69:15-23.

Pitkin RM. Calcium metabolism in pregnancy and the perinatal period : A review. Am J Obstet Gynecol 1985;151:99-109.

Pollack RN, Divon MY. Intrauterine growth retardation : definition, classification, and etiology. Clin Obstet Gynecol 1992;35:99 -107.

Quamme GA .Renal magnesium handling: new insights in understanding old problems. Kidney Int 1997;52:1180-95.

Ramos JLA. Avaliação do crescimento intra-uterino por medidas antropométricas do recém-nascido. [tese] São Paulo: Faculdade de Medicina da Universidade de São Paulo;1983. 
Reinhart RA . Magnesium metabolism. Arch Intern Med 1988;148:2415-20.

Rivkin MJ. Hypoxic-ischemic brain injury in the term newborn. Clin Perinatol 1997;24:607-24.

Roche Diagnostic Systems. Magnesio, p.21/07-24/07,2000.

Rondó PHC. Weight, lenght, ponderal index, and intrauterine growth retardation in Brazil. J Trop Pediatr 1998;44:355-7.

Rude RK. Magnesium metabolism. In: Becker KL, editor. Principles and Practice of Endocrinology and Metabolism. $3^{\text {rd }}$ ed. Philadelphia: Lippincott; 2001.

Saris NL, Mervaala E, Karppanen H, Khawaja JÁ, Lewenstam A. Magnesium. An update on physiological, clinical and analytical aspects. Clin Chim Acta 2000;294:1-26.

Sasaki S, Oshima T, Matsuura H, Ozono R, Higashi Y, Sasaki N, Matsumoto T, Nakano Y, Ueda A, Yoshimizu A, Kurisu S, Kambe M, Kajiyama G. Abnormal magnesium status in patients with cardiovascular diseases. Clin Sci 2000;98:175-81.

Schuck P, Gammelin G, Resch KL. Magnesium and phosphorus. Lancet 1998;352:1474-5.

Shaul PW, Mimouni F, Tsang RC, Specker BL. The role of magnesium in neonatal calcium homeostasis : effects of magnesium infusion on calciotropic hormones and calcium. Pediatr Res 1987; 22:319-23.

Shaw AJ, Mughal MZ, Mohammed T, Maresh MJA, Sibley CP. Evidence for active maternofetal transfer of magnesium across the in situ perfused rat placenta. Pediatr Res 1990;27:622-5.

Sigma Plot ${ }^{\circledR}$ Scientific Graphing Software for Windows ${ }^{\top \mathrm{M}}$, User's Manual. San Rafael, Jandel Corporation,1994.

Sigma Stat $\AA$ Statistical Software User's Manual. Version 2.0 For Windows 95®, NT\& 3.1.SPSS®. Chicago,Science,1997.

Soothhill PW, Nicolaides KH, Campbell S. Prenatal asphyxia, hyperlacticaemia, hypoglycaemia, and erythroblastosis in growth retarded fetuses. Br Med J 1987;294:1051-3. 
Takeda Y, Iwashita M. Assessment of intrauterine growth retardation. Acta Obstet Gynecol Scand 1997;76 suppl167:4.

Tsang RC, Kleimnman LI, Sutherland JM, Light IJ. Hypocalcemia in infants of diabetic mothers. J Pediatr 1972a;80:384-95.

Tsang RC. Neonatal magnesium disturbances. Am J Dis Child 1972b; 124:282-93.

Tsang RC, Light LI, Sutherland JM, Kleimnman LI. Possible pathogenetic factors in neonatal hypocalcemia of prematury . J Pediatr 1973a;82:423-9.

Tsang RC, I-Wen C, Friedman A, Chen I. Neonatal parathyroid function : role of gestational age and postnatal age. J Pediatr 1973b;83:728-38.

Tsang RC, Chen I, Hayes W, Atkinson W, Atherton H, Edwards N. Neonatal hypocalcemia in infants with birth asphyxia. $J$ Pediatr 1974;84:428-33.

Venkataraman PS, Tsang RC. Calcium, magnesium and phosphorus in the nutrition of the newborn. J Am Coll Nutr 1995;14:439-47.

Verive MJ, Irazuzta J, Steinhart CM, Orlowski JP, Jaimovich DG. Evaluating the frequency rate of hypomagnesemia in critically ill pediatric patients by using multiple regression analysis and a computer-based neural network. Crit Care Med 2000;28:3534-9.

Vetter T, Lohse MJ. Magnesium and the parathyroid. Curr Opin Nephrol Hypertens 2002;11:403-10.

Wacker WEC, Parisi AF. Magnesium metabolism. $N$ Engl $J$ Med 1968;278:658-61.

Weisinger J, Bellorin-Font E. Magnesium and phosphorus. Lancet 1998;352:391-6.

Wicks TC. AANA Journal course: update for nurse anesthetists - magnesium homeostasis and deficiency. AANA J 1999;67:171-9.

Wieland P, Fischer JA, Trechsel U, Roth H-R, Vetter K, Schneider H, Huch A. Perinatal parathyroid hormone, vitamin $\mathrm{D}$ metabolites, and calcitonin in man. Am J Physiol 1980;239:385-90. 
Williams GD, Smith MB. Application of the accurate assessment of intracelular magnesium and $\mathrm{pH}$ from the ${ }^{31} \mathrm{P}$ shifts of ATP to cerebral hypoxia-ischemia in neonatal rat. Magn Reson Med 1995;33:853-7.

Wong V, Goodenough DA . Paracellular channels. Science 1999;285:62-4.

Yau K-IT, Chang M-H. Weight to lenght ratio - a good parameter for determining nutritional status in preterm and full-term newborns. Acta Paediatr 1992;82:427-9.

Yu ASL. Evolving concepts in epithelial magnesium transport. Curr Opin Nephrol Hypertens 2001;10:649-53.

Referências de acordo com:

"Uniform requirements for manuscripts submitted to medical journals" ( $N$ Engl $J$ Med 1997;336:309-15). Este corresponde ao documento oficial criado a partir do Grupo de Vancouver em 1978 e elaborado pelo "International Committee of Medical Journal Editors". 